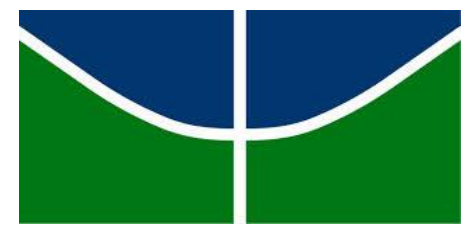

Universidade de Brasília - UnB

Instituto de Química - IQ

Programa de Pós-Graduação em Química - PPGQ

Análise estequiométrica da dinâmica não-linear de redes de reações químicas

Elder Taciano Romão da Silva

Brasília (DF), fevereiro de 2016 
Elder Taciano Romão da Silva

\title{
Análise estequiométrica da dinâmica não-linear de redes de reações químicas
}

\begin{abstract}
Dissertação apresentada ao Instituto de Química da Universidade de Brasília, UnB, para obtenção de título de Mestre em Química, pelo Programa de Pós-Graduação em Química, PPGQ.
\end{abstract}

Orientador: Fernando de Magalhães Coutinho Vieira 
Aos meus pais, que sempre me apoiaram em todas minhas decisões de vida. 
Gostaria de agradecer primeiramente ao professor e orientador, Dr. Fernando de Magalhães Coutinho Vieira, pelos momentos de sabedoria que a mim foram compartilhados, pelo constante amparo e preocupação ao longo dessa jornada e sobretudo, por me permitir fazer parte desse projeto, que tanto me agradou, mesmo que no início eu não demonstrasse afinidade alguma com o tema proposto.

Agradeço também aos professores que participaram da minha formação acadêmica durante o período em que fui aluno de mestrado na Universidade de Brasília, principalmente aos professores, Dr. Kleber Carlos Mundim e Msc. Francisco Alexandre de Melo Castro, a quem tenho muita estima e admiração.

Aos meus pais, bases da minha vida, pois a eles devo tudo e aos meus amigos, pelos momentos que vivemos juntos, e pelos que ainda virão. E por fim, ao auxílio financeiro que me foi prestado pelo Conselho Nacional de Desenvolvimento Científico e Tecnológico, CNPq. 
Ser ou não ser, eis a questão.

William Shakespeare 


\section{RESUMO}

O estado vivente de um organismo é caracterizado principalmente pela presença de um constante fluxo de reações química, e por isso, seres vivos são formados por inúmeras reações, ligadas umas as outras, em uma espécie de rede. A teoria das redes bioquímicas fornece uma estrutura matemática e computacional usada para analisar e simular tais redes de reações. É um modelo de construção, diagnóstico e análise de redes baseados em equações diferenciais ordinárias. Algumas redes de reações químicas são estudadas, principalmente, pelos comportamentos dinâmicos complexos. Longe do equilíbrio, tais sistemas dinâmicos não-lineares exibem fenômenos, como, múltiplos estados estacionários e oscilações. Foram analisadas algumas redes químicas de interesse bioquímico, como as redes de cálcio nos cílios dos neurônios receptores olfativos, da via glicolítica, da oxidase-peroxidase e a rede que concede uma dinâmica multiestável na embriogênese da mosca de fruta, Drosophila melanogaster, assim como redes teóricas. Para estuda-las, o método, Stoichiometric Network Analysis, ou SNA, forneceu uma abordagem sistemática para a dinâmica de mecanismos químicos ou de quaisquer outros sistemas que contém estequiometria. Primeiro foi necessário compreender a bioquímica de sistemas que apresentam dinâmicas complexas e a importância das tais na manutenção de processos metabólicos e de comunicação celular em seres viventes para, então, avaliar a eficácia da técnica de análise estequiométrica de redes no inquérito de fenômenos não lineares. A variante gráfica do método SNA foi usada na criação de sub-redes que exibem comportamentos incomuns, e o consequente emprego da mesma na modelagem de redes elementares de fácil apreensão. Por fim, os métodos mostraram-se eficazes na análise de dinâmicas complexas, ademais, podese verificar a análise de bifurcação para algumas redes. Além das condições necessárias e suficientes para a observação de dinâmicas complexas, a técnica por SNA pôde, inclusive, expor outra propriedade biológica dos modelos.

\section{Palavras chave: Stoichiometric Network Analysis, Bifurcação de Hopf, Sela-nó, Oscilações, Multiestabilidade.}




\section{ABSTRACT}

The state of a living body is mainly characterized by the presence of a constant flow of chemical reactions, and therefore living beings are formed by several reactions, linked to each other in a kind of network. The theory of biochemical networks provides a mathematical and computational framework used to analyze and simulate reactions such networks. It is a building model, diagnosis and network analysis based on ordinary differential equations. Some chemical reactions networks are studied mainly for the complex dynamic behavior. Far from equilibrium, such nonlinear dynamical systems exhibit phenomena such as, multiple steady states and oscillations. Some chemical networks of biochemical interest were analyzed, such as calcium networks in the cilia of olfactory receptor neurons, the glycolytic pathway, oxidase-peroxidase and network granting a multistable dynamics in the fruit fly embryogenesis, Drosophila melanogaster, as well as networks theoretical. To study them, the method Stoichiometric Network Analysis, or SNA, provided a systematic approach to the dynamics of chemical mechanisms or other systems containing stoichiometry. First it was necessary to understand the biochemical systems that exhibit complex dynamics and the importance of such in maintaining metabolic and cellular communication in living creatures to then assess the effectiveness of the stoichiometric analysis of technical networks in the investigation of nonlinear phenomena. The graphical variant of the SNA method was used to create subnets that exhibit unusual behaviors and the consequent use of the same in modeling elementary easy to grasp networks. Finally, the methods have been shown effective in analyzing complex dynamic, moreover, it can verify the bifurcation analysis for some networks. In addition to the necessary and sufficient conditions for observing complex dynamics, the SNA by technique could even expose another biological properties of the models.

Keywords: Stoichiometric Network Analysis, Bifurcation Hopf, Saddle-node, Oscillation, multistability. 


\section{LISTA DE FIGURAS}

Figura 1. Padrão ondulatório do movimento celular durante a agregação da Dictyostelium discoideum em ágar.

Figura 2. Molécula 3',5'-monofosfato cíclica.

Figura 3. Ácido etilenodiamino tetraacético, EDTA e ácido etilenoglicol tetraacético, EGTA.

Figura 4. Diagrama de fitas simbolizando as estruturas hélice-volta-hélice da parvalbumina. Sítio EF e sua semelhança com um mão. Sete ligantes do domínio mão-EF. Esquema estrutural da proteína calmodulina.

Figura 5. Resposta de um neurônio receptor olfativo ao estímulo provocado pelo eucaliptol.

Figura 6. Nicotinamida adenina dinucleotídeo e nicotinamida adenina dinucleótido fosfato.

Figura 7. Medida simultânea da concentração do oxigênio e a absorção da luz em $418 \mu \mathrm{m}$.

Figura 8. Biestabilidade $\mathrm{O}+\mathrm{S}$ na reação de oxidase-peroxidase.

Figura 9. Consecutivas clivagens que ocorrem na célula-mãe.

Figura 10. Representação gráfica de uma mórula e uma blástula.

Figura 11. Marcação fluorescente das proteínas bicoid e hunchback ao longo do embrião.

Figura 12. Ajuste do modelo auto-regulatório da hunchback ao perfil de distribuição.

Figura 13. Representação esquemática do efeito visual de uma reação Belousov-Zhabotinsky em uma placa de Petri.

Figura 14. Solução numérica para o modelo de Lotka-Volterra.

Figura 15. Comportamento da equação cúbica para $\mu$ constante $>0$.

Figura 16. Comportamento de histerese pode ser observado na transição 
entre os regimes biestáveis.

Figura 17. Multiestabilidade na região plana, $(\mu, \lambda)$, onde existem três raízes reais para $x$.

Figura 18. Representação gráfica do cone das correntes extremas.

Figura 19. Retrato de fase de equação. $\quad 64$

Figura 20. Diagramas de fase de uma bifurcação de Hopf. 66

Figura 21. Diagramas de fase para $d x / d t=r-x^{2} .68$

Figura 22. Representação gráfica das correntes extremas para o menor modelo teórico oscilante.

Figura 23. Comportamento oscilatório na concentração da espécie $X$ em função do tempo.

Figura 24. Extinção da dinâmica oscilatória e dependência da frequência às constantes cinéticas.

Figura 25. Fragmento crítico, $S_{2}=\left(\begin{array}{l}X \\ 1\end{array}\right)$, para o menor modelo teórico oscilante.

Figura 26. Fragmento crítico, $S_{2}=\left(\begin{array}{l}X \\ 2\end{array}, \frac{Y}{2}\right)$, para o menor modelo teórico oscilante.

Figura 27. Comportamento oscilatório na concentração da espécie $X$ em função do tempo.

Figura 28. Comportamento oscilatório na concentração das espécies $X \mathrm{e} Z$ em função do tempo.

Figura 29. Fragmento crítico, $S_{2}=\left(\begin{array}{c}A \\ 5\end{array}\right)$, para o menor modelo teórico oscilante.

Figura 30. Matriz E das correntes extremas para o menor modelo cíclico oscilante.

Figura 31. Comportamento oscilatório na concentração da espécie $A$ em função do tempo 
Figura 32. Diagrama de bifurcação, com duas constantes, para o menor modelo cíclico teórico oscilante.

Figura 33. Diagrama de bifurcação, com três constantes, para o menor modelo cíclico teórico oscilante.

Figura 34. Análise de bifurcação em razão da constante cinética $\mathrm{k}_{4} \mathrm{e}$ a concentração de $A$.

Figura 35. Análise de bifurcação para oscilações de cálcio no cílio olfativo.

Figura 36. Oscilações na concentração de $B$, íons de $\mathrm{Ca}^{2+}$, em função do tempo.

Figura 37. Grafo bipartido para oscilações na via glicolítica.

Figura 38. Fragmento crítico, $S_{3}=\left(\begin{array}{c}B \\ 2\end{array}, \frac{C}{4}, \begin{array}{l}D \\ 6\end{array}\right)$, para oscilações na via glicolítica.

Figura 39. Representação gráfica das correntes extremas.

Figura 40. Oscilações em função do tempo na concentração da enzima fosfofrutoquinase.

Figura 41. Grafo bipartido para o modelo de múltiplos estados estacionários na reação de peroxidase-oxidase.

Figura 42. Fragmento crítico, $S_{3}=\left({ }_{3}^{A}, \frac{B}{4}, \frac{C}{5}\right)$, para o modelo de múltiplos estados estacionários na reação de peroxidase-oxidase.

Figura 43. Análise de bifurcação para múltiplos estados estacionários no substrato $\mathrm{H}_{2} \mathrm{O}_{2}$, na enzima peroxidase e no complexo enzima-substrato.

Figura 44. Matriz estequiométrica para 0 modelo biestável para a embriogênese da Drosophila melanogaster.

Figura 45. Fragmento crítico, $S_{5}=\left(\begin{array}{c}b_{2} \\ 4\end{array}, \frac{H}{1}, \frac{h_{1}}{1}, \frac{h_{2}}{2}, \frac{h_{3}}{3}\right)$, para 0 modelo biestável para a embriogênese da Drosophila melanogaster.

Figura 46. Análise de bifurcação da proteína hunchback no modelo biestável para a embriogênese da Drosophila melanogaster. 
Figura 47. Diagrama de análise de bifurcação para o modelo biestável para a embriogênese da Drosophila melanogaster.

Figura 48. Dependência do formato e região biestável, para a concentração da espécie $D$, proteína hunchback, com a variação da constante $\mathrm{k}_{1}$.

Figura 49. Concentração no estado estacionário da proteína hunchback, pela variação da constante cinética de formação da proteína bicoid. 


\section{LISTA DE TABELAS}

Tabela 1. Principais sistemas biológicos oscilatórios, classificados de acordo com o período.

Tabela 2. Formulação da reação de Belousov

Tabela 3. Múltiplos estados para o menor modelo multiestável.

Tabela 4. Múltiplos estados para reação de peroxidase-oxidase.

Tabela 5. Múltiplos estados para a rede diminuta da embriogêniese da mosca Drosophila melanogaster. 


\section{LISTA DE ABREVIATURAS E SIGLAS}

AMP cícliclo ou cAMP - Adenosina 3',5'-monofosfato cíclica.

ATP - Adenosina trifosfato.

SNA - Stoichiometric Network Analysis (análise da rede estequiométrica).

$\mathrm{IP}_{3} \mathrm{R}$ - Inositol trifosfato.

RyR - Receptor de rianodina.

CICR - Calcium-induced calcium release (liberação de cálcio induzido por cálcio).

EDTA - Ethylenediamine tetraacetic acid (ácido etilenodiamino tetraacético).

EGTA - Ethyleneglycol tetraacetic acid (etilenoglicol tetraacético).

CNG - Cyclic nucleotide-gated ion channels (canais iônicos regulados por nucleotídeos cíclicos).

CaM - Calmodulina.

CaM4 - Complexo formado pela calmodulina e quatro íons $\mathrm{Ca}^{2+}$.

PFK - Phosphofructokinase (fosfofrutoquinase).

ADP - Adenosina difosfato.

$\mathrm{NADH}$ - Nicotinamide adenine dinucleotide (nicotinamida adenina dinucleotídeo reduzida).

NADPH - Nicotinamide adenine dinucleotide phosphate (nicotinamida adenina dinucleótido fosfato reduzida).

O+S - Oscillations plus steady state (oscilação mais estado estacionário).

mRNA - RNA mensageiro.

ODE - Equações diferenciais ordinárias. 


\section{LISTA DE SÍMBOLOS}

$\mathrm{N}$ - Matriz estequiométrica.

$\alpha_{i j}$ - Quantidade de espécies $X_{i}$ na reação $R_{j}$ nas etapas de produção.

$\beta_{i j}$ - Quantidade de espécies $X_{i}$ na reação $R_{j}$ nas etapas de consumo.

$V_{\mathrm{ee}}$ - Vetor das taxas de reação no estado estacionário.

E - Matriz das correntes extremas.

j - Vetor das taxas das correntes extremas.

$\mathrm{C}_{\mathrm{v}}$ - espaço como um cone poliedral convexo onde estão os vetores $\mathrm{V}_{\mathrm{ee}}$

M - Matriz de linearização.

$\mathrm{h}$ - Matriz de elementos $h_{\mathrm{i}}$, das concentrações das $i$ espécies no estado estacionário.

G - Grafo bipartido.

$V_{1}$ - Vértice das $n$ substâncias químicas.

$V_{2}$ - Vértice das $n$ reações químicas.

C - Ciclo de G.

g - Subgrafo composto por ciclos e arestas de G, mutuamente disjuntos.

$\mathrm{S}$ - Fragmento de $\mathrm{G}$, formado por um conjunto de subgrafos $\mathrm{g}$.

$r$ - Posto da matriz estequiométrica. 


\section{SUMÁRIO}

1. INTRODUÇÃO

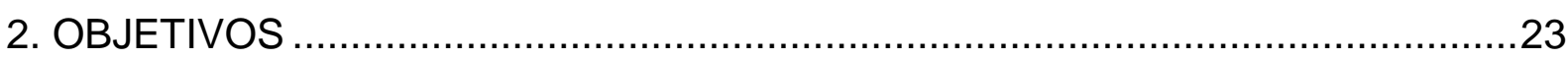

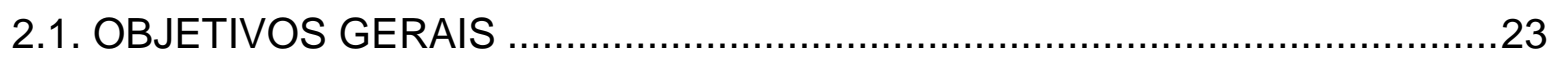

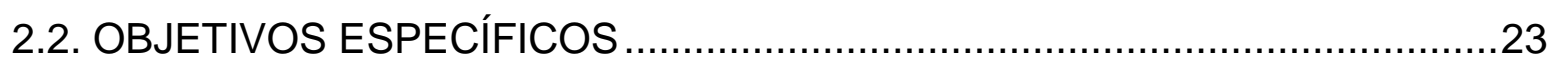

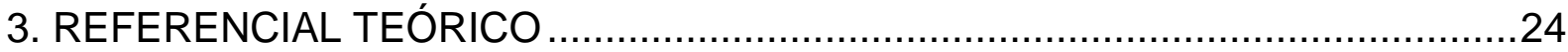

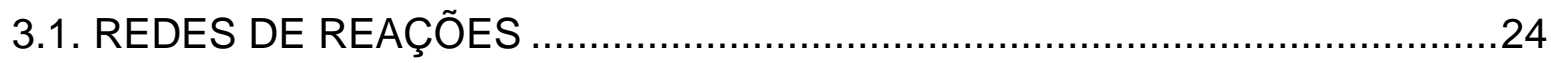

3.1.1. MODELO PARA OSCILAÇÕES DE CÁLCIO NO CÍLIO OLFATIVO .........24

3.1.2. MODELO PARA OSCILAÇÕES NA VIA GLICOLÍTICA ..........................30

3.1.3. MODELO DE ESTADOS MÚLTIPLOS NA REAÇÃO DE

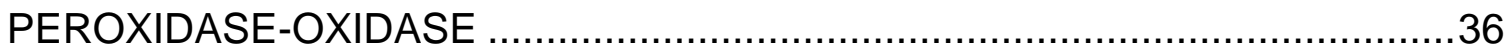

3.1.4. MODELO DE ESTADOS MÚLTIPLOS NA EMBRIOGÊNESE DA

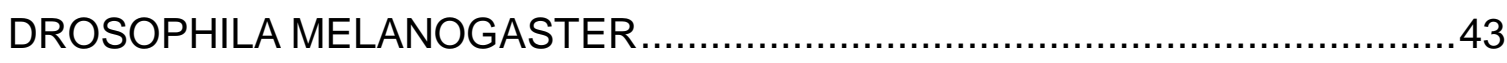

3.1.5. DINÂMICAS COMPLEXAS EM MODELOS TEÓRICOS ...........................48

3.1.5.1. MENOR MODELO OSCILATÓRIO ................................................49

3.1.5.2. MENOR MODELO CÍCLICO OSCILATÓRIO ...................................49

3.1.5.3. MENOR MODELO MULTIESTÁVEL ............................................50

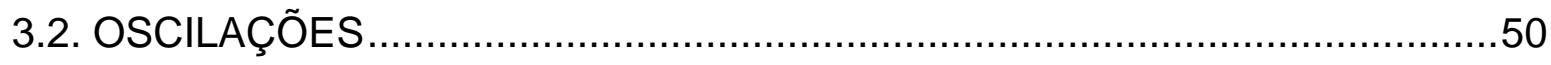

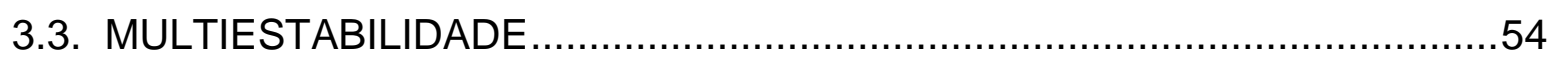

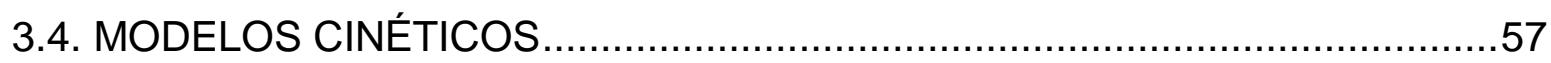

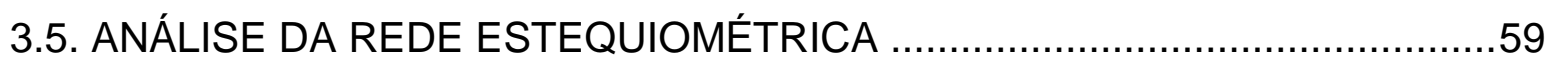

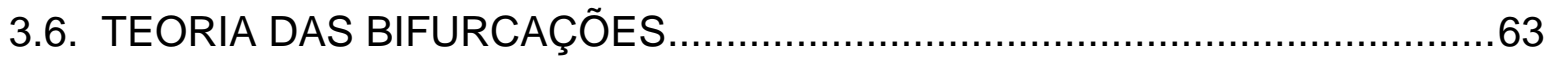

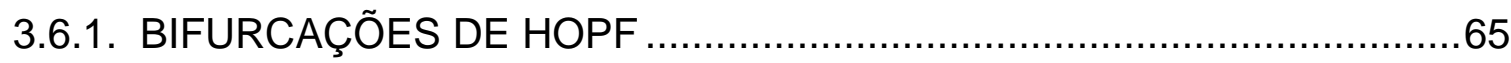

3.6.2. BIFURCAÇÕES DO TIPO SELA-NÓ.....................................................67

3.7. ANÁLISE GRÁFICA DA REDE ESTEQUIOMÉTRICA.................................69

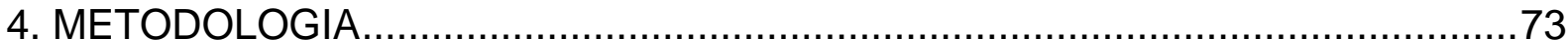

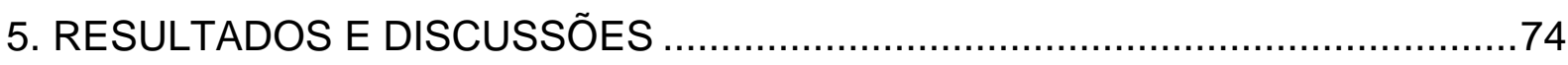

5.1. OSCILAÇÕES NO MENOR MODELO TEÓRICO: UM CASO CLÁSSICO.....74

5.2. OSCILAÇÕES NO MENOR MODELO TEÓRICO: UM CASO

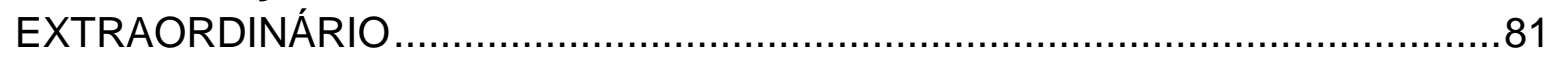

5.3. OSCILAÇÕES NO MENOR MODELO CÍCLICO TEÓRICO ….........................83

5.4. MULTIESTABILIDADE NO MENOR MODELO TEÓRICO ….........................91

5.5. OSCILAÇÕES DE CÁLCIO NO CÍLIO OLFATIVO …...................................95 


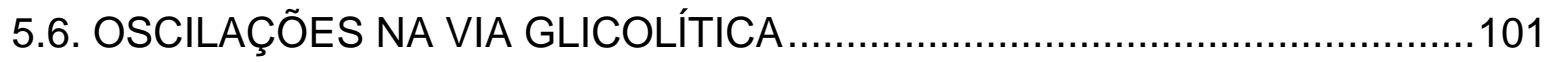

5.7. ESTADOS MÚLTIPLOS E NA REAÇÃO DE PEROXIDASE-OXIDASE .......107 5.8. ESTADOS MÚLTIPLOS NA EMBRIOGÊNESE DA DROSOPHILA

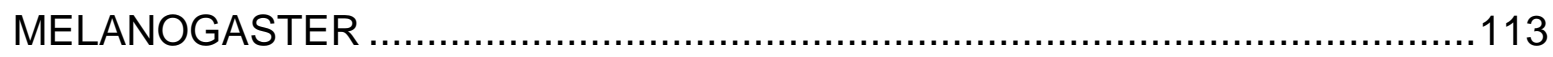

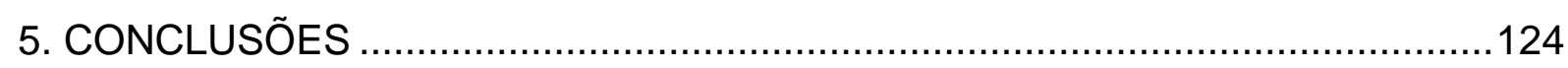

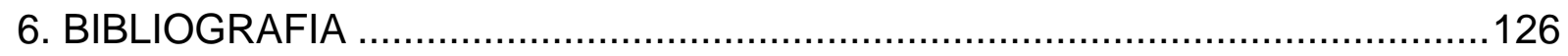




\section{INTRODUÇÃO}

O estado vivente de um organismo é caracterizado principalmente pela presença de um constante fluxo de reações químicas. Por exemplo, seres autotróficos utilizam minerais simples e energia solar para a manutenção da vida, enquanto os heterotróficos metabolizam moléculas complexas pelo mesmo objetivo, e, apesar das diferenças entre esses grupos, há em comum uma rede de reações químicas que lhes conferem a condição de organismos vivos. Assim, seres vivos são formados por inúmeras reações, ligadas umas as outras, em uma espécie de rede. ${ }^{1}$

Como indicativo da complexidade dos sistemas bioquímicos, estima-se que se conhece de um sexto a um terço das reações presentes na bactéria Escherichia coli, e, por isso, existem de três a seis mil moléculas diferentes no microorganismo. ${ }^{1}$ A enorme complexidade das interações moleculares e celulares necessita de ferramentas para modelar e interpretar corretamente os experimentos biológicos. ${ }^{2}$

Para isso, teoria das redes bioquímicas fornece uma estrutura matemática e computacional usada para analisar e simular sistemas. É um modelo de construção, diagnóstico e análise de redes baseados em equações diferenciais ordinárias e parciais. Foi proposta por Michael Savageau em 1969, e, mesmo sendo originalmente desenvolvida para vias bioquímicas, tornou-se amplamente aplicada aos mais diversos conjuntos. ${ }^{3}$

Simulações e modelagem matemática de redes ajudam a entender a dinâmica de processos químicos e bioquímicos ${ }^{4}$, e quando devidamente formulados, são ferramentas eficazes na compreensão do sistema ${ }^{3}$, fornecendo dados, inclusive, sobre os efeitos de interações do objeto estudado com o meio ambiente. ${ }^{4}$ Equações químicas formam a linguagem da modelagem biológica. É a notação usada para expressar processos químicos, seja qualitativamente ou quantitativamente. Nesse sentido, representar processos por equações químicas é o método mais básico para executar cálculos e fazer previsões sobre o sistema. ${ }^{3}$

Algumas redes de reações químicas são estudadas, principalmente, pelos comportamentos dinâmicos complexos. ${ }^{5}$ Longe do equilíbrio, tais sistemas dinâmicos não-lineares exibem fenômenos como, múltiplos estados estacionários, oscilações senoidais, oscilações com picos de amplitude variante, ritmos biológicos, quasiperiodicidade e caos. $^{6}$ Duas dinâmicas incomuns são de grande interesse 
bioquímico: os fenômenos oscilatórios e de multiestabilidade, sendo esse, uma situação onde um sistema apresenta dois ou mais equilíbrios estáveis. ${ }^{5}$

Oscilação é uma das propriedades mais evidentes nos sistemas vivos. Ocorrem em todos os níveis de organização biológica, desde o unicelular ao organismo multicelular, com períodos variando de frações de segundo a anos. Em humanos, os processos oscilatórios cardíacos e respiratórios, assim como o ritmo circadiano de sono e vigília, são fundamentais para manutenção da vida. ${ }^{7}$ Alguns sistemas oscilatórios estão listados na Tabela 1.

Tabela 1. Principais sistemas biológicos oscilatórios, classificados de acordo com o período.

\begin{tabular}{ll}
\hline Sistema & Período \\
\hline Neural & De 0.01 a 10 segundos \\
Cardíaco & 1 segundo \\
Oscilações de cálcio & De 1 segundo a minutos \\
Oscilações bioquímicas & De 1 a 20 minutos \\
Ciclo mitótico & De 10 minutos a 24 horas \\
Ciclo menstrual & 28 dias \\
Oscilações ecológicas e epidemiológicas & Anos \\
\hline
\end{tabular}

Fonte: $\overline{\text { GOLDBETER, } 1997.7}$

Um número considerável de sistemas demonstram a importância das oscilações no fenômeno de comunicação intracelular, assim como acontece no protozoário do gênero amoeba Dictyostelium discoideum, que possui a capacidade de alternar entre um estado unicelular para um estado multicelular durante seu ciclo de vida. O mecanismo de comunicação intracelular que governa a transição entre as fases possui natureza oscilatória. O ciclo de vida do protozoário se inicia com um esporo germinado, a célula resultante desse processo passa por um período de divisão celular até que o ambiente não forneça mais alimento. Nas etapas posteriores as células formam um bolor limoso e em seguida um esporocarpo encimando uma haste, e após dispensar os esporos, o ciclo volta à etapa inicial. ${ }^{7}$ 
A fase de agregação da Dictyostelium discoideum forma um padrão periódico. Enquanto as células estão se agregando, os indivíduos que estão no centro, periodicamente, emitem um sinal químico para atrair as células presentes no ambiente, formando um padrão de gradiente. A esse processo é dado o nome de quimiotaxia. $O$ agente quimiotáxico responsável pela agregação das células é a molécula adenosina 3',5'-monofosfato cíclica, AMP cícliclo ou cAMP, um derivado da adenosina trifosfato (ATP). A análise da cAMP extra celular demonstra um comportamento oscilatório, responsável pelo padrão de agregação do protozoário, como representado no seguinte esquema. ${ }^{7}$

Figura 1. Padrão ondulatório do movimento celular durante a agregação da Dictyostelium discoideum em ágar. As faixas brancas representam os protozoários em movimento respondendo ao agente quimiotáxico, as bandas escuras são as células agregadas imóveis. ${ }^{7}$

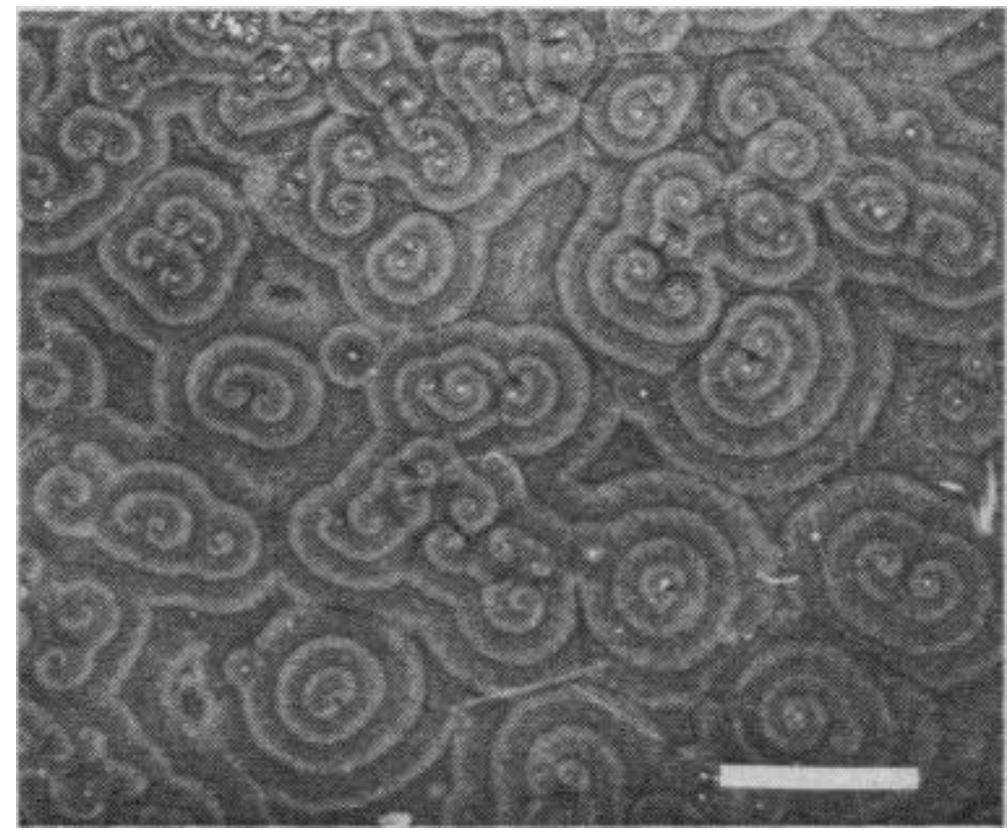

Fonte: TOMCHIK; DEVREOTES, $1981{ }^{8}$

A molécula cAMP possui um papel importante em organismos eucariotas, onde o estímulo por hormônios ou neurotransmissores provocam a síntese desse segundo mensageiro, molécula responsável pelo controle de como as células irão reagir a estímulos externos. ${ }^{7,9}$ Outro importante mecanismo de sinalização celular 
provém das respostas do organismo à concentração de íons $\mathrm{Ca}^{2+}$ citoplasmático. $\mathrm{A}$ elevação do $\mathrm{Ca}^{2+}$ plasmático intermedeia uma série de eventos rápidos, como a contração muscular e a neurossecreção, ou eventos mais lentos e sutis, tal e qual a divisão celular, diferenciação celular ou apoptose. ${ }^{10}$

Figura 2. 3',5'-monofosfato cíclica. Molécula responsável pela comunicação intracelular no Dictyostelium discoideum. ${ }^{7}$

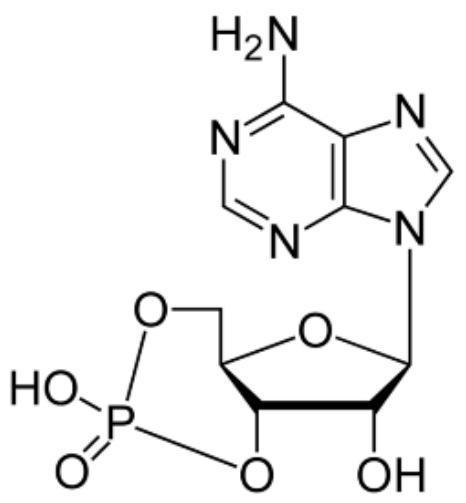

Ao contrário dos sistemas monoestáveis, os multiestáveis alternam entre dois ou mais estados estacionários. Sabe-se que, no geral, as redes de sinalização celular apresentam uma dinâmica multiestável e, por isso, um dos desafios da biologia e da matemática é compreender como a multiestabilidade de proteínas sinalizadoras afeta o comportamento das células vivas. Esse fenômeno está presente, por exemplo, no interruptor que alterna as etapas de lise e lisogenia do fago lambda, um vírus de bactérias. ${ }^{11}$

O bacteriófago lambda possui dois ciclos vitais independentes, o ciclo lítico, um ciclo virulento que provoca a morte da célula hospedeira, e um alternativo, chamado lisogênico, no qual o fago estabelece uma relação de inquilinismo com a célula infectada. $\mathrm{Na}$ fase de lise, o bacteriófago domina o metabolismo da célula fazendo com que essa produza partículas virais necessárias para a montagem de novos indivíduos. O processo termina com o rompimento da célula, sua lise, e a liberação de bacteriófagos no ambiente. Opcionalmente, pode entrar em fase de lisogenia, onde o genoma do fago, também chamado de prófago, é replicado com o genoma do hospedeiro, e durante a divisão celular, o prófago é passado para as gerações seguintes. $O$ ciclo termina com a reversão ao caminho lítico. ${ }^{12}$ 
Um processo multiestável governa a troca entre os ciclos. ${ }^{11}$ Duas proteínas repressoras são os elementos chave para mudança de fase, as proteínas Cro e ci. A concentração das macromoléculas no estado estacionário determina qual ciclo o fago lambda irá seguir. Quando a concentração de Cro domina, a fase de lise é ativada, do contrário, se a concentração de ci for maior, o fago entrará em fase lisogênica. ${ }^{12}$ A multiestabilidade também está presente nos ciclos celulares do organismo celular Saccharomyces cerevisiae e das rãs do gênero Xenopus. ${ }^{11}$

Com os exemplos citados acima, é fácil perceber o quão importante são as dinâmicas multiestáveis e oscilatórias nos organismos com vida. Para estuda-las, o método Stoichiometric Network Analysis (Análise da rede estequiométrica) ou SNA, proposto por Bruce L. Clarke em 1980, fornece uma abordagem sistemática para a dinâmica de mecanismos químicos ou de quaisquer outros sistemas que contém estequiometria. A principal vantagem desse método é a não necessidade do conhecimento explícito dos valores das constantes de velocidade para determinar os aspectos qualitativos da dinâmica. ${ }^{13}$

A utilização desse método para analisar e demonstrar comportamentos dinâmicos complexos nas redes bioquímicas é a principal motivação desta dissertação, que tem como principal objetivo avaliar a eficácia da SNA em determinar fenômenos dinâmicos de interesse bioquímico. A análise tem início com a determinação de um conjunto de vetores de velocidades das reações nos estados estacionários. Tal conjunto forma uma matriz chamada de "correntes extremas" e, fisicamente tem o valor de uma sub-rede. Quaisquer vetores da rede original são combinações lineares dos vetores extremos, que representam os caminhos mais simples que as reações tomam. Inquirir instabilidades nas correntes extremas equivale a observar as mesmas na rede maior. ${ }^{12}$

De maneira complementar será utilizada a análise pela teoria dos grafos bipartidos ou grafos. No método dos grafos bipartidos, as equações químicas são representadas em um grafo, onde cada conjunto de vértice corresponde às espécies químicas ou aos caminhos de reação. A técnica é uma interpretação gráfica da SNA e foi explorada principalmente por Ermakov (2001). Baseia-se no fato que um subgrafo pode ser equivalente a uma sub-rede de reações responsável pela instabilidade do sistema. ${ }^{14}$ 
Apoiando-se no fato de que as dinâmicas complexas são fundamentais para o melhor entendimento dos organismos vivos, algumas redes de reações químicas que apresentam comportamento não linear foram destacadas como objetos de estudo para essa dissertação. As escolhas apoiaram-se em duas principais características: a relevância bioquímica dos sistemas e uma grande base de estudos precedentes que garantem modelos ideais para averiguar a efetividade das técnicas.

As redes oscilatórias estudadas são, as de oscilações de cálcio nos cílios olfatórios e o oscilador glicolítico. A primeira diz respeito às oscilações de íons $\mathrm{Ca}^{2+}$ nos neurônios olfativos e sua função na adaptação sensorial aos estímulos odorantes externos. O oscilador glicolítico mostra a relação de como a enzima fosfofrutoquinase controla o caminho metabólico da glicólise, o ajustando em resposta as condições intra e extracelular. ${ }^{15,16,17}$ Os modelos representantes da multiestabilidade são as redes de peroxidase-oxidase ${ }^{18}$, e a rede da dinâmica multiestável na embriogênese da mosca de fruta, Drosophila melanogaster. ${ }^{19}$

Interações bioquímicas são complexas demais para ser imaginadas em todos os detalhes, em vista disso, a solução é encontrar modelos matemáticos simples que auxiliam no entendimento de suas dinâmicas. O grande desafio na biologia de sistemas é modelar problemas em que a simplicidade seja justificada pela acurácia. $\mathrm{Na}$ teoria de redes, pode-se concentrar em sub-redes que possuam uma dinâmica capaz de ser transladada para modelo original. Por isso, o estudo de sistemas puramente teóricos e mínimos é importante. ${ }^{20}$ Assim, além das redes com significado biológico, também serão estudadas redes exclusivamente teóricas contendo oscilação ou multiestabilidade..$^{21,22,23}$ 


\section{OBJETIVOS}

\subsection{OBJETIVOS GERAIS}

- Compreender a bioquímica de sistemas que apresentam dinâmicas complexas e sua importância na manutenção de processos metabólicos e de comunicação celular em seres viventes;

- Avaliar a eficácia da técnica de análise estequiométrica de redes, Stoichiometric Network Analysis, no inquérito de fenômenos não lineares, como oscilações e multiestabilidade, em redes de interesse biológico;

- Investigar o uso da variante gráfica do método SNA na criação de sub-redes que exibem comportamentos incomuns, e o consequente emprego das mesmas na modelagem de redes elementares de fácil apreensão.

\subsection{OBJETIVOS ESPECÍFICOS}

- Analisar as redes de reações, bioquímicas e teóricas, utilizando as técnicas estequiométricas gráficas e numéricas;

- Estudar os aspectos biológicos e bioquímicos das dinâmicas oscilatórias e multiestáveis nas redes de reações químicas, envolvendo:

I. Íons de cálcio em cílios olfativos;

II. Metabolismo na via glicolítica;

III. Catalise de oxidação de substratos orgânicos pela enzima peroxidase de raíz-forte e;

IV. Embriogênese da mosca de fruta, Drosophila melanogaster.

- Ilustrar, contando com recursos gráficos, a evolução temporal das espécies nos sistemas oscilatórios e os múltiplos estados estacionários em redes multiestáveis. 


\section{REFERENCIAL TEÓRICO}

\subsection{REDES DE REAÇÕES}

\subsubsection{MODELO PARA OSCILAÇÕES DE CÁLCIO NO CÍLIO OLFATIVO}

Oscilações de íons de cálcio, $\mathrm{Ca}^{2+}$, estão entre as descobertas mais importantes na área de sinalização intracelular, principalmente devido à ocorrência em uma grande quantidade de tipos de células, sendo o fenômeno oscilatório mais comum de que se tem registo. Podem ocorrer de forma espontânea ou em resposta a estímulos externos, como por exemplo, de hormônios e neurotransmissores. Também representam um dos mais estudados eventos de organização espaçotemporal a nível celular, conforme visto nas ondas de $\mathrm{Ca}^{2+}$ em citosol. ${ }^{7}$

A versatilidade do cálcio em termos de velocidade, amplitude e padronização espaço-temporal vem de uma variedade de caminhos de sinalização que utilizam $\mathrm{Ca}^{2+}$, assim, a célula dispõe de numerosas combinações de mecanismos de ação que garantem uma alta variabilidade em métodos de comunicação. De modo geral as células dispõem de quatro dispositivos de ação que envolve os íons de cálcio. São eles: os sinais de cálcio derivado de estímulos, a abertura de canais que promove a alimentação do íon no citoplasma, a atuação do cálcio como segundo mensageiro e os canais de remoção de cálcio, levando a célula ao seu estado inicial. $^{24}$

As células geram seus sinais usando fontes externas e internas de $\mathrm{Ca}^{2+}$. As reservas internas são mantidas no sistema de membranas de organelas como o retículo endoplasmático, ou seus equivalentes, tal qual o retículo sarcoplasmático, nas células musculares, por exemplo. A liberação de cálcio dessas reservas é feita por canais, como o receptor de inositol trifosfato $\left(\mathrm{IP}_{3} \mathrm{R}\right)$, ou o receptor de rianodina (RyR). Usualmente os canais são ativados pelo próprio $\mathrm{Ca}^{2+}$, e o processo de liberação de cálcio induzido por cálcio, em inglês, calcium-induced calcium release, ou ainda, CICR, é o método primário de geração celular de sinais de cálcio. ${ }^{24}$

Normalmente, a sequência de procedimentos de sinalização celular começa com um estímulo atua gerando sinais de $\mathrm{Ca}^{2+}$, esses abrem os canais pelo CICR, liberando íons e elevando sua concentração intracelular. Dentro da célula, o cálcio 
aciona uma série de eventos sensíveis ao cálcio, atuando como segundo mensageiro. Para finalizar, o íon é retirado da célula e os canais são fechados. Essa sequência configura oscilações na concentração de cálcio $\mathrm{Ca}^{2+}$ dentro da célula ${ }^{24}$, e possui frequências que variam de segundos a dezenas de minutos. ${ }^{7}$

A célula conta com uma série de estratégias para se defender da ação do cálcio livre no citosol, podendo bombeá-lo para fora da célula ou o permutar com outro íon extracelular, como por exemplo, $\mathrm{Na}^{2+}$. Não menos importante, pode, também, formar um quelato com a espécie. As células, de um modo geral, evoluíram suas proteínas, adaptando-as à função de ligar-se ao $\mathrm{Ca}^{2+}$. Hipoteticamente, a principal função de tais proteínas seria a de diminuir a concentração do íon no citosol, mas a formação de quelatos com o metal, permitiu usar essa energia de ligação para ativar processos celulares. ${ }^{25}$

O íon cálcio pode acomodar entre quatro a uma dúzia de átomos oxigênio na sua esfera de coordenação primária, sendo mais comum encontrá-lo com seis ou oito. Os compostos quelantes, ácido etilenodiamino tetraacético, ou, ethylenediamine tetraacetic acid (EDTA), e também o ácido etilenoglicol tetraacético, do inglês, ethyleneglycol tetraacetic acid (EGTA), coordenam-se ao cálcio pelo seu par de aminas e os quatro grupos carboxilatos (Figura 3). Em comparação, as proteínas especializadas em ligação com o metal, utilizam os oxigênios de suas carboxilas e carbonilas, e não raramente, da água, para a coordenação. Normalmente, as proteínas arranjam-se em volta do cálcio por sete ligações, a uma distância de aproximadamente $2,5 \AA$, com geometria bipiramidal pentagonal. ${ }^{25}$

Existem inúmeras proteínas capazes de se ligar ao cálcio, entretanto, há pouca variabilidade na quantidade de sítios ligantes com tal habilidade, sendo mais comum o mão-EF, um motivo estrutural do tipo hélice-volta-hélice. A designação, mão-EF, é devida a uma famosa representação gráfica da proteína parvalbumina (Figura $4 \mathrm{a}-\mathrm{b}){ }^{26}$ Esse sítio pode ser específico para $\mathrm{Ca}^{2+}$, ou realizar ligações também com o $\mathrm{Mg}^{2+}$, dependendo da proteína em que se encontra. De acordo com sua afinidade, especificidade, cooperatividade e cinética, suas proteínas desempenham as mais diversas funções, como, ativação de uma proteína sinalizadora, tamponamento de $\mathrm{Ca}^{2+}$, atividade regulatória, entre outras. Da família das proteínas que contém o sítio mão-EF, a calmodulina é uma das proteínas mais comuns, pois está presente em todas as células eucariontes. ${ }^{27}$ 
Figura 3. a) Ácido etilenodiamino tetraacético, EDTA. b) Ácido etilenoglicol tetraacético, EGTA. c) O EDTA coordena-se ao cálcio iônico, realizando seis ligações, em uma geometria octaédrica. Estão envolvidos o par de nitrogênios das aminas e os quatro oxigênios das carboxilas, preenchendo a esfera de coordenação primária de $\mathrm{Ca}^{2+}$ com seis ligantes diretos. ${ }^{25}$

a)

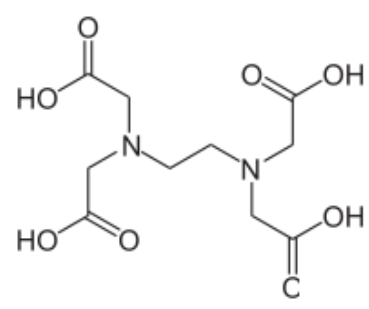

b)<smiles>O=C(O)CN(CCOCCOCCN(CC(=O)O)CC(=O)O)CC(=O)O</smiles>

c)

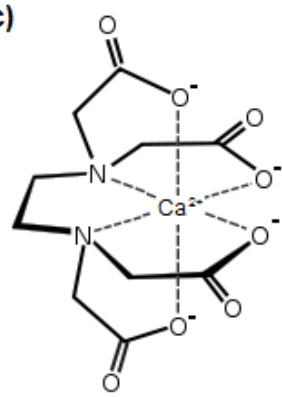

Como visto, as oscilações de cálcio intracelulares são fundamentais para a regulação celular, e também, em processos onde sinais ou estímulos são convertidos em informações para outros receptores distintos, chamados de transduções celulares. Um exemplo da participação da dinâmica oscilante de cálcio em funções biológicas está presente nos sensores neurais olfativos. Neles, as oscilações de cálcio tem papel importante na adaptação a odorantes. ${ }^{28}$

Adaptação sensorial é definida como uma mudança na zona de resposta a uma incitação, devido a um condicionamento ou sinais de fundo, e, com isso, a célula pode trabalhar com uma ampla gama de intensidades de estímulos. ${ }^{29}$ Essa característica é especialmente importante para as células olfativas, pois, sem a adaptação, os receptores não terão a capacidade de prevenir a saturação do transdutor celular, nem de manter uma alta sensibilidade durante uma condição de estímulo contínuo. ${ }^{30}$ 
Figura 4. a) Diagrama de fitas simbolizando as estruturas hélice-volta-hélice da parvalbumina. Seis hélices estão representadas de $A$ a $F$, formando três domínios, um para cada par, $A B, C D$ e EF. As esferas amarelas descrevem, cada, um íon $\mathrm{Ca}^{2+} \cdot{ }^{31}$ b) Sítio $E F$ e sua semelhança com um mão. A hélice $E$ está representado em vermelho e corresponde ao dedo indicador, o polegar, em verde, é análogo à hélice F, em azul, a volta se assemelha a um dedo médio dobrando-se em torno do íon. ${ }^{27}$ c) Em contraste com os compostos quelantes, EDTA e EGTA, que formam com o cálcio uma geometria octaédrica (Figura 3), os sete ligantes do domínio mão-EF, conferem uma geometria bipiramidal pentagonal. d) Esquema estrutural da proteína calmodulina. Os quatro motivos mão-EF possuem afinidade distinta com o cálcio. ${ }^{25}$

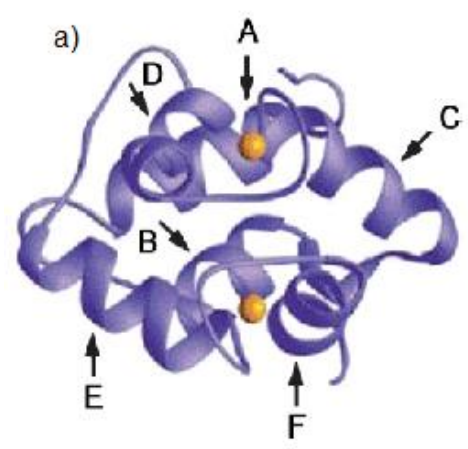

b)

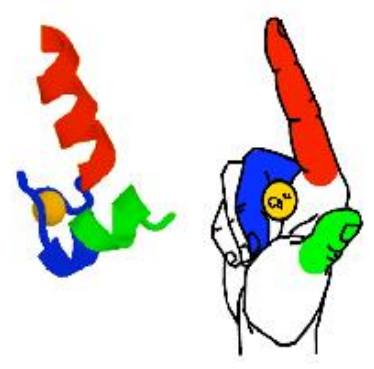

c)

d)
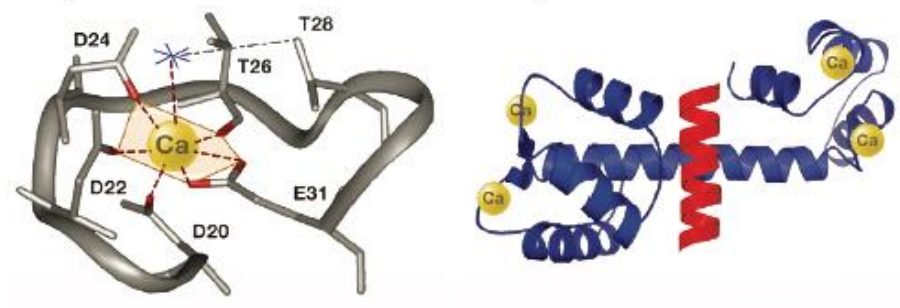

Fontes: ARIF, 2009. ${ }^{31}$; ALMEIDA, 2000. ${ }^{27}$; CLAPHAM, $2007 .{ }^{25}$

A adaptação sensorial é observada experimentalmente nos neurônios receptores olfativo da espécie de salamandra, Ambystoma tigrinum. ${ }^{32}$ Os neurônios intactos são dissociados do anfíbio e estimulados por pulsos de eucaliptol. Quando dois pulsos idênticos são gerados, separados por um curto período de tempo, medese na célula nervosa, uma baixa resposta neural ao segundo pulso. À medida que o intervalo entre os pulsos aumenta, percebe-se uma maior resposta ao segundo odorante, até que as duas se igualam quando o período entre os estímulos é maior que dez segundos, como pode ser visto no seguinte esquema. ${ }^{30}$ 
Figura 5. Resposta de um neurônio receptor olfativo ao estímulo provocado pelo eucaliptol. No primeiro quadro, o segundo estímulo foi dosado com dois segundos de diferença do primeiro. Nota-se que houve um forte declínio no pico de reação, comprovando a adaptação sensorial. No quadro de número dois, o segundo pulso foi aplicado após seis segundos, e apresenta um pico que caracteriza uma recuperação parcial da resposta ao odorante. No último esquema, com dez segundos de diferença entre os estímulos, as duas reações apresentam a mesma intensidade, evidenciando uma recuperação total ao odorante. Pelo reestabelecimento relativamente rápido observado na salamandra, tal fenômeno foi classificado como adaptação sensorial de curto prazo. ${ }^{30}$
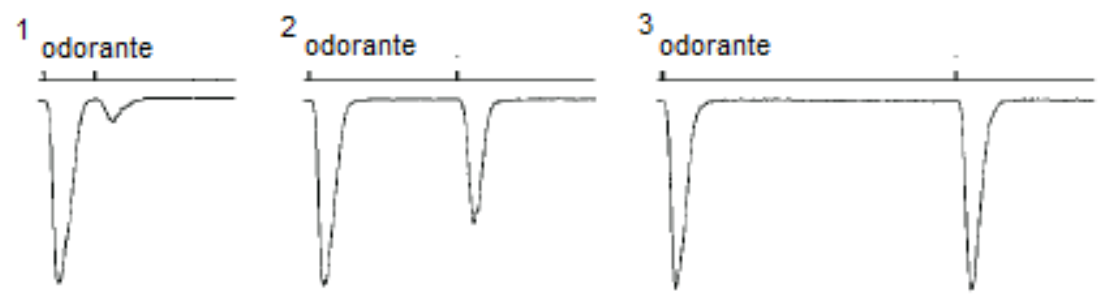

Fonte: ZUFALL, $2000 .^{30}$

É comprovado empiricamente que a presença de cálcio na célula não só ativa o processo de adaptação sensorial, como também determina a taxa de recuperação do processo. Usando microscopia confocal de alta resolução, é possível gerar imagens que comprovam o aumento da concentração de cálcio nos cílios olfativos em resposta a um odorante. Observa-se também que a concentração de cálcio e a recuperação da adaptação sensorial pela célula são proporcionais. Assim, o decréscimo da concentração acarreta na redução da adaptação ao odorante e, por fim, a supressão do cálcio por um composto quelante reflete na quase completa perda da capacidade de habituação ao estímulo. Tais eventos indicam que o cálcio tem profunda relação com a ativação da adaptação sensorial de curto prazo e a duração do caso. ${ }^{30}$

A transdução de sinais nos neurônios receptores olfativos dá-se nos epitélios olfatório dos vertebrados ou em estruturas de antenas em invertebrados. Principiase com a molécula odorante se ligando a proteína receptora localizada no cílio olfativo, resultando em um encadeamento de processos que tem como finalidade 
avolumar a concentração de cAMP nos cílios. Tal molécula atua abrindo os canais iônicos regulados por nucleotídeos cíclicos, ou em inglês, cyclic nucleotide-gated ion channels (CNG), que por sua vez, permitem a entrada de cátions, a exemplo do cálcio, na célula. Após a sinalização, em resposta ao acréscimo de íons $\mathrm{Ca}^{2+}$, a célula inicia o extermínio dos cátions, utilizando, dentre outros artifícios, as interações $\mathrm{Ca}^{2+}$-calmodulina. ${ }^{33}$

Por conjectura, o complexo formado pelo cálcio coordenado a proteína calmodulina causa a inibição dos canais iônicos regulados por nucleotídeos cíclicos. Esses, porém, estão intimamente ligados ao processo de percepção olfativa. Ao inibi-los, tem-se o fenômeno de adaptação sensorial, ou seja, o decréscimo da resposta elétrica celular ao odorante. ${ }^{34}$

Com isso, percebe-se que as oscilações de cálcio são fundamentais nos mecanismos de adaptação sensorial curta, e, em consequência, foi proposto um modelo dessa dinâmica especial. ${ }^{28}$

$$
\begin{gathered}
C N G^{f} \rightleftharpoons C N G^{a} \\
C a M+4 C a^{2+} \rightleftharpoons C a M 4 \\
C N G^{a}+C a M 4 \rightarrow C N G^{i} \\
C N G^{f}+C a M 4 \rightleftharpoons C N G^{i}
\end{gathered}
$$

Onde as espécies CNG são os canais iônicos regulados por nucleotídeos cíclicos, e os índices "a", "f" e "i”, representam aberto, fechado e inativo, respectivamente. A proteína calmodulina é representada por CaM e forma um complexo com quatro íons $\mathrm{Ca}^{2+}$, denominado CaM4. De cima para baixo, na ordem, as reações de (1) representam: a) a ativação dos canais iônicos, cuja constante de velocidade depende da concentração do odorante; b) a formação do complexo calmodulina-cálcio, CaM4; c) a inativação dos canais iônicos pelo complexo CaM e por último, d) o fechamento dos canais. ${ }^{28}$

Omitindo as variações de atividade e inatividade dos canais iônicos, é possível fazer com que o modelo seja reduzido. Nessa fração, as espécies, $C N G^{a}$, $C N G^{f}$ e $C N G^{i}$, são representadas por $A$, o cátion de cálcio por $B$ e o complexo CaM4 por $C .^{28}$ Assim, o modelo pode ser resumido nas equações seguintes: ${ }^{35}$ 


$$
\begin{gathered}
\stackrel{0^{k_{1}}}{\rightarrow} A \\
A \stackrel{k_{2}}{\rightarrow} A+B \\
4 B \stackrel{k_{3}}{\rightarrow} C \\
C \stackrel{k_{4}}{\rightarrow} \text { } 4 B \\
A+C \stackrel{k_{5}}{\rightarrow} C \\
B \stackrel{k_{6}}{\rightarrow} 0
\end{gathered}
$$

O conjunto de equações diferenciais, das derivadas das concentrações das espécies com o tempo (t), para o sistema (2) é: ${ }^{35}$

$$
\begin{gathered}
\frac{d[A]}{d t}=k_{1}-k_{5}[A][C] \\
\frac{d[B]}{d t}=k_{2}[A]-4 k_{3}[B]^{2}+4 k_{4}[C]-k_{6}[B]^{\varepsilon} \\
\frac{d[C]}{d t}=k_{3}[B]^{2}-k_{4}[C]
\end{gathered}
$$

Para evidenciar a dinâmica oscilatória nesse sistema, algumas considerações devem ser feitas. Mesmo que sejam necessários quatro íons de $\mathrm{Ca}^{2+}$, a cinética é considerada de segunda ordem e o termo que rege o escoamento de $B$ deve ter ordem igual a $\varepsilon<0,05 .^{28}$

\subsubsection{MODELO PARA OSCILAÇÕES NA VIA GLICOLÍTICA}

A glicólise é o principal modelo de oscilações em uma via metabólica e evidencia o processo bioenergético mais antigo e poderoso que ocorre em seres viventes. Compreender a dinâmica oscilatória da via glicolítica é uma etapa importante para desvendar a organização desse processo. O oscilador glicolítico, primariamente estudado em células de leveduras, é um indicativo que propriedades periódicas podem ser propiciadas pela ação de uma única enzima em um caminho metabólico. ${ }^{15}$

Oscilações glicolíticas representam o caso clássico, tanto teórico, quanto experimental, no estudo da dinâmica de redes de reações. Dentre os modelos calculados para prever o comportamento da atividade na glicólise, o proposto por 
Sel'kov, em 1967, que diz respeito a reação da enzima fosfofrutoquinase, é um exemplo rico para o estudo do fenômeno oscilatório. ${ }^{16}$ De grande significado biológico, a glicólise pode ser resumida em uma sequência de reações que metaboliza uma molécula de glicose em duas moléculas de piruvato e outras duas de adenosina trifosfato, ATP ou do inglês, adenosine triphosphate. ${ }^{17}$

É uma via quase universal do catabolismo da glicose, e dá-se em microorganismos anaeróbicos, células e tecidos de mamíferos, em alguns tecidos vegetais modificados para o armazenamento de amido, como o tubérculo da batata, e por fim, em vegetais adaptados para crescer em áreas inundadas, tal e qual o agrião. A quebra anaeróbica da glicose é, provavelmente, um mecanismo de obtenção de energia remanescente dos princípios da vida terrestre, visto que os organismos vivos ocorreram, primitivamente, em uma atmosfera desprovida de oxigênio. Ao longo da evolução, tal fluxo de reações manteve-se inalterado. As enzimas da glicólise em vertebrados assemelham-se as suas análogas em leveduras e espinafre, e a regulação da via difere-se, entre espécies, apenas em detalhes. ${ }^{37}$

A glicólise é dividida em duas etapas, as chamadas, fase preparatória e fase de pagamento. Na primeira, a glicose é inicialmente fosforilada no grupo hidroxila do seu sexto carbono, ou seja, ocorre uma reação, por intermédio de uma enzima, com o gasto energético de uma molécula de ATP, no intuito de formar uma molécula de glicose-6-fosfato: ${ }^{37}$

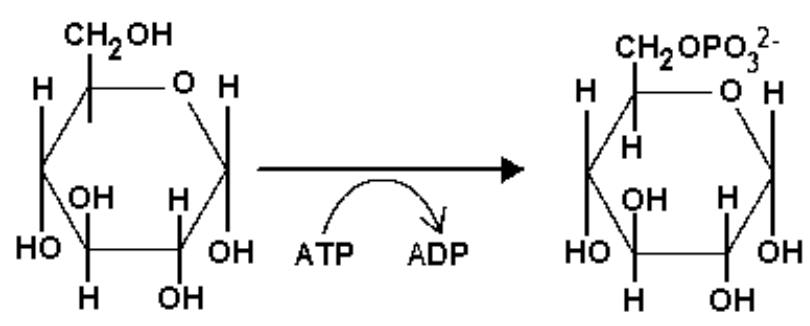

A recém-formada, glicose-6-fosfato, é convertida em frutose-6-fosfato e então novamente fosforilada, agora, porém, no primeiro carbono, formando uma molécula de frutose-1-6-bifosfato: ${ }^{37}$ 


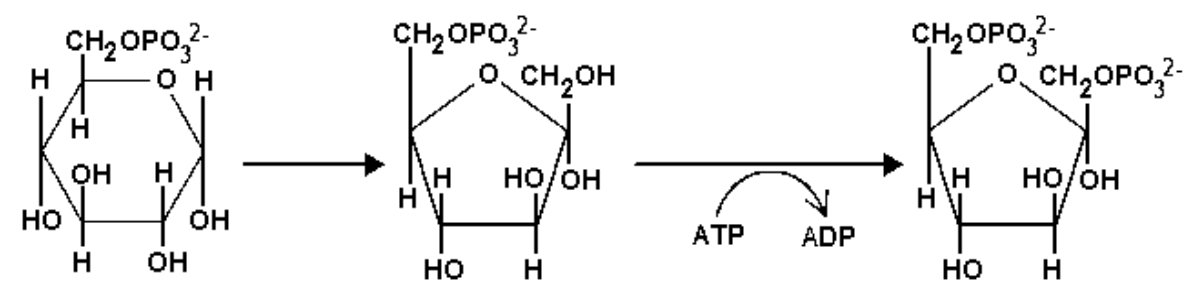

Esta primeira etapa finaliza-se com a reação de quebra da frutose-1-6bifosfato em duas moléculas de três carbonos cada, a diidroxiacetona fosfato e a gliceraldeído-3-fosfato, seguida da reação de isomerização da diidroxiacetona fosfato em outra molécula de gliceraldeído-3-fosfato: ${ }^{37}$

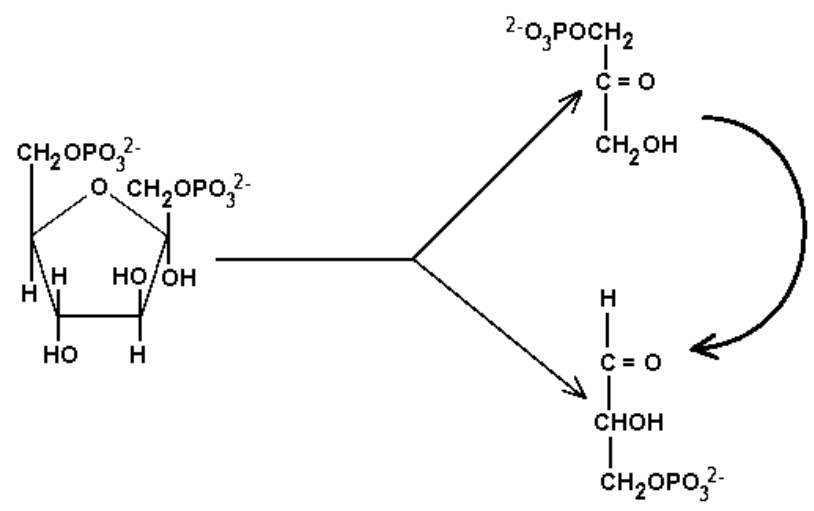

$\mathrm{Na}$ segundo etapa, a do pagamento, ocorre o ganho energético. Cada molécula de gliceraldeído-3-fosfato é fosforilada por fosfato inorgânico, formando 1,3-bifosfoglicerato: ${ }^{37}$

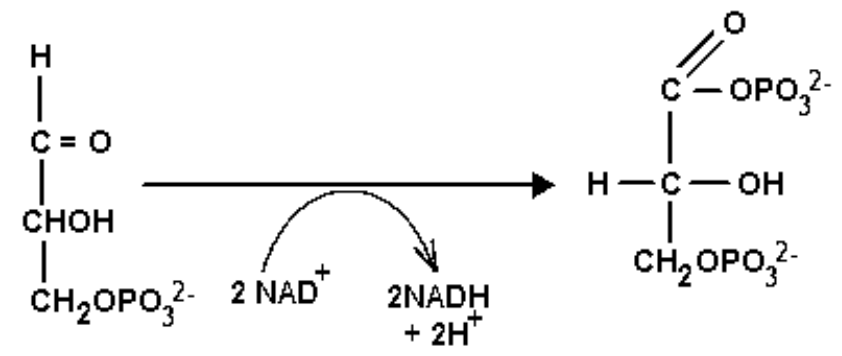

As seguintes reações são responsáveis pelo lucro de energia alcançado pela via glicolítica. Com a série de etapas que transformam as duas moléculas de 1,3bifosfoglicerato em outras duas de piruvato, tem-se a produção de quatro ATP, isso 
é, existe um ganho líquido de duas adenosinas trifosfato, visto que a fase preparatória consome duas moléculas de ATP. ${ }^{37}$

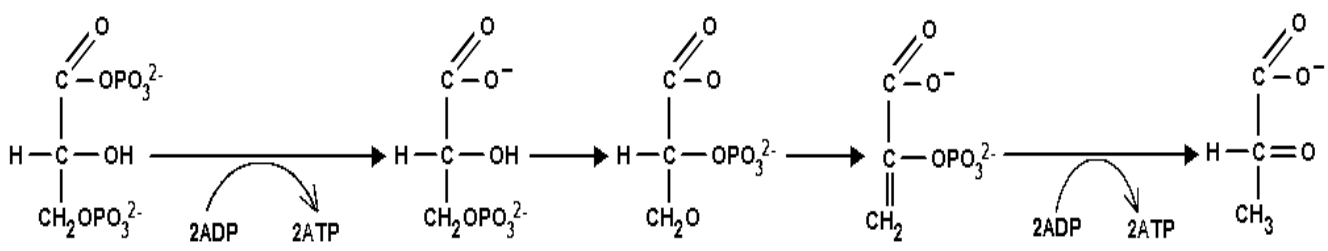

$\mathrm{Na}$ etapa preparatória, uma enzima opera como um dos mecanismos de regulação da glicólise. A fosfofrutoquinase, ou, em inglês, phosphofructokinase (PFK), terceira enzima da via glicolítica, funciona convertendo a frutose-6-fosfato em frutose-1-6-bifosfato, assim como na equação (5). ${ }^{38}$ Por encontrar-se no início do caminho glicolítico, essa enzima é um dos principais meios de controle do processo de glicólise. Em mamíferos, o controle do caminho metabólico permite o armazenamento do carboidrato, que poderá ser utilizado em outro momento, em células que necessitam de maior quantidade de energia. As hemácias, ou eritrócitos, são células desprovidas de organelas, com a mitocôndria e núcleo, de modo que a glicólise é o único processo energético na célula, espera-se então que a energia armazenada supra a demanda dessas. Fato também observado nas células do tecido cerebral, já que, apesar de possuírem mitocôndrias, a constante atividade requer um abastecimento energético extraordinário. ${ }^{39}$

Sob concentrações fisiológicas, de 0,5 a $3 \mathrm{mM}$, o ATP fortemente inibe a atividade da PFK. Esse acontecimento é esperado, pois a principal função da glicólise é a produção de ATP, sendo assim, quando esse substrato encontra-se em abundância, a glicólise é inibida, e o metabolismo é controlado. A inibição da fosfofrutoquinase continuará a menos que a concentração de adenosina trifosfato decresça a níveis irrisórios, ou que um ativador alostérico esteja presente, a exemplo da adenosina difosfato, ADP. ${ }^{38,39}$

O controle alostérico que a ADP exerce sobre a fosfofrutoquinase representa a chave para o fenômeno oscilatório na via glicolítica. A equação (5) mostra que um dos produtos da reação de fosforilação oxidação é justamente uma molécula de adenosina difosfato. Sendo assim, a mesma molécula, ADP, é um reagente, por ativar a enzima PKF, e também um produto da reação. Essa propriedade incomum 
em uma via metabólica representa uma retroalimentação positiva, também chamada de reação de autocatálise. ${ }^{7}$

Sabe-se, empiricamente, que a dinâmica da fosfofrutoquinase afeta a estabilidade da glicólise, isto posto, o comportamento oscilatório depende de um balanço delicado entre o processo de produção e transformação dos substratos da enzima. Citando os íons amônio e citrato, ativador e inibidor da PFK, respectivamente, ambos aniquilam a dinâmica oscilatória. ${ }^{7}$ Nas células de levedura Saccharomyces cerevisiae, as moléculas de adenosina trifosfato e difosfato, juntamente com a PFK, são necessárias para a existência do fenômeno oscilatório, e atuam como parâmetros de controle da frequência e amplitude das ondas. Tais fatos ratificam a PFK como centro de oscilações na via glicolítica. ${ }^{40}$

Assim, Sel'kov (1968) propôs um modelo simples baseado na auto-regulação. No geral, o modelo apoia-se no substrato ATP sendo suprido por alguma fonte, convertido em ADP, e então, removido por um escoadouro. A enzima PFK, sozinha, é inativa, porém torna-se ativa quando forma um complexo, PFK|ADP, ao ligar-se com duas (ou mais) moléculas de ADP. A conversão entre as adenosinas acontece quando o ATP coordena-se a enzima ativa e forma um complexo, ATP|PFK|ADP, para então, doar um fosfato em (5) e liberar um ADP como produto. ${ }^{16}$

$$
\begin{gathered}
0 \stackrel{k_{1}}{\rightarrow} A T P \\
A T P+P F K\left|A D P \stackrel{k_{2}}{\rightarrow} A T P\right| P F K \mid A D P \\
A T P|P F K| A D P \stackrel{k_{3}}{\rightarrow} A T P+P F K \mid A D P \\
A T P|P F K| A D P \stackrel{k_{4}}{\rightarrow} P F K \mid A D P+A D P \\
A D P \stackrel{k_{5}}{\rightarrow} 0 \\
2 A D P+P F K_{\rightarrow}^{k_{6}} P F K \mid A D P \\
P F K \mid A D P \stackrel{k_{6}}{\rightarrow} 2 A D P+P F K
\end{gathered}
$$

No modelo sugerido, é importante constatar que a dinâmica oscilatória só é percebida quando a estequiometria de ADP em $\mathrm{k}_{6}$ for maior que uma unidade. Tal característica não é apenas uma norma estequiométrica, mas carrega um significado físico de coibir a inibição da enzima pelo ATP. ${ }^{41}$ 
É possível representar as equações em (9) de maneira genérica, substituindo as espécies na ordem que se segue: $:^{14}$

$$
\begin{aligned}
& 0 \stackrel{k_{1}}{\rightarrow} A \\
& A+B \stackrel{k_{2}}{\rightarrow} C \\
& C_{\rightarrow}^{k_{3}} A+B \\
& C_{\rightarrow}^{k_{4}} B+D \\
& D_{\rightarrow}^{k_{5}} 0 \\
& 2 D+E_{\rightarrow}^{k_{6}} B \\
& B \stackrel{k_{7}}{\rightarrow} 2 D+E
\end{aligned}
$$

Logo, a equação (10) apresenta o sistema de equações diferenciais: ${ }^{14}$

$$
\begin{gathered}
\frac{d[A]}{d t}=k_{1}-k_{2}[A][B]+k_{3}[C] \\
\frac{d[B]}{d t}=-k_{2}[A][B]+k_{3}[C]+k_{4}[C]+k_{6}[D]^{2}[E]-k_{7}[B] \\
\frac{d[C]}{d t}=k_{2}[A][B]-k_{3}[C]-k_{4}[C] \\
\frac{d[D]}{d t}=k_{4}[C]-k_{5}[D]-2 k_{6}[D]^{2}[E]+2 k_{7}[B] \\
\frac{d[D]}{d t}=-k_{6}[D]^{2}[E]+k_{7}[B]
\end{gathered}
$$

A função principal das oscilações nem sempre está bem definida. Mesmo que a dinâmica oscilatória da via glicolítica seja bem compreendida, pouco se sabe sobre sua parte na manutenção da via. Como o metabolismo anaeróbico da glicose esteve presente desde os seres primordiais, acredita-se que suas oscilações apresentam protagonismo maior do que o atual compreendido. Argumenta-se que numa etapa inicial a glicólise teve um papel importante na regulamentação do tempo circadiano, pois, alterando os parâmetros de bifurcação, é possível constatar frequências oscilatórias no período de aproximadamente vinte e quatro horas. ${ }^{42}$ 


\subsubsection{MODELO DE ESTADOS MÚLTIPLOS NA REAÇÃO DE PEROXIDASE-OXIDASE}

O grupo de enzimas peroxidase, no geral, possui como primeira serventia catalisar a oxidação de substratos orgânicos pelo peróxido de hidrogênio. Algumas peroxidases também conseguem catalisar a oxidação de alguns doadores de hidrogênio pelo oxigênio. A nicotinamida adenina dinucleotídeo reduzida, ou NADH (sigla para nicotinamide adenine dinucleotide) e a nicotinamida adenina dinucleótido fosfato reduzida, NADPH (sigla para nicotinamide adenine dinucleotide phosphate) são alguns exemplos de doadores de hidrogênio catalisados pelas enzimas peroxidase. $^{43}$

Esses nucleotídeos derivados da piridina estão entre as inúmeras moléculas envolvidas no metabolismo, biossíntese redutora e processos antioxidativos. Estruturalmente, as NADH e NADPH são praticamente idênticas, exceto pela adição de um grupamento fosfato no segundo carbono da ribose em NADPH. Embora essa diferença pareça trivial, a disparidade constitucional é o fator determinante que rege a maneira de atuação das moléculas. Enquanto a nicotinamida adenina dinucleotídeo está principalmente envolvida com processos catalíticos, seu análogo fosforilado age em reações anabólicas. ${ }^{44}$

Figura 6. Da direita para a esquerda, as estruturas da nicotinamida adenina dinucleotídeo, e da sua forma fosforilada, a nicotinamida adenina dinucleótido fosfato. $^{44}$
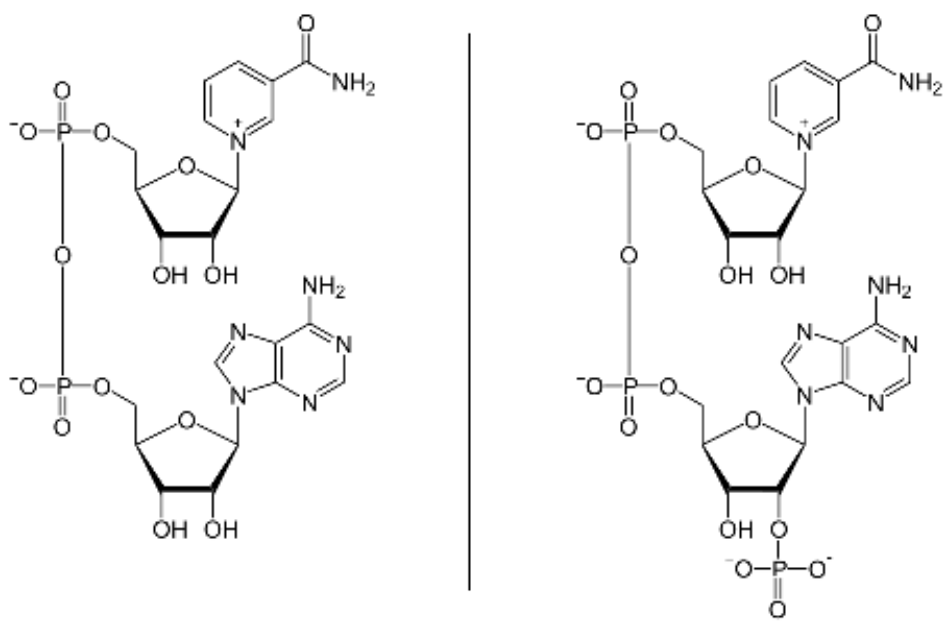
As duas formas da nicotinamida adenina dinucleotídeo desempenham papeis significativos em quase todas vias metabólicas conhecidas, participando como um dos mediadores na glicólise, a exemplo da equação (7), e em outras reações metabólicas no citosol, tal e qual na interconversão, catalizada pela enzima lactato desidrogenase, entre as moléculas de piruvato e lactato. Ademais, os processos de apoptose, homeostase do cálcio, expressão gênica, carcinogênese, funções imunológicas e até o envelhecimento, contam com a participação dessas moléculas. $^{44}$

Os meados do século XIX marcaram a descoberta das peroxidases. A exploração das enzimas foi impulsionada pelos cientistas que, na época, investigavam tecidos animais e vegetais com compostos orgânicos que variam sua cor de acordo com o estado de oxidação. A primeira evidência deu-se em 1855, quando foi relatado que o guaiacol oxidava-se quando em contato com tecidos vegetais ou animais. Em 1941 ocorreu a purificação de uma proteína enzimaticamente ativa derivada de leucócitos humanos. De cor verde, a substância foi nomeada como "verdoperoxidase", porém, o nome foi abandonado quanto se constatou que as enzimas peroxidase formavam cristais esverdeados. Desde então, a peroxidase derivada de leucócitos humanos passou a ser conhecida como mieloperoxidase e seu isolamento tornou-se, na época, o método padrão para purificação de enzimas. ${ }^{45}$

Os espécimes da Armoracia rusticana, também conhecidos como raízesfortes, representam uma rica fonte de peroxidases. Suas enzimas destacam-se por possuir grupos hemo, ou seja, possuem um átomo de ferro contido no centro de uma porfirina. Possuem uso comercial como componentes de conjuntos de análise clínicas, e, por isso, são produzidas em larga escala. A principal reação catalítica da peroxidase de raiz-forte pode ser expressada pela seguinte equação: ${ }^{46}$

$$
\mathrm{H}_{2} \mathrm{O}_{2}+2 \mathrm{AH}_{2} \rightarrow 2 \mathrm{H}_{2} \mathrm{O}+2 \mathrm{AH}
$$

Onde, $\mathrm{AH}_{2}$ e $\mathrm{AH}$ - representam, respectivamente, um substrato reduzido e seu radical. Tipicamente, os substratos dessa enzima são fenóis aromáticos, ácidos fenólicos, indóis, aminas e composto sulfonatados. ${ }^{46}$ A reação da oxidação aeróbica 
do $\mathrm{NADH}$, quando catalisada pela peroxidase, é comumente conhecida como a reação de peroxidase-oxidase. A estequiometria da sua equação global é: ${ }^{43}$

$$
2 \mathrm{NADH}+\mathrm{O}_{2}+\mathrm{H}^{+} \rightarrow 2 \mathrm{NAD}^{+}+\mathrm{H}_{2} \mathrm{O}
$$

Caso essa reação ocorra com excesso de NADH e oxigênio, uma variedade de dinâmicas não lineares pode ser observada, como por exemplo, oscilações e multiestabilidade. ${ }^{43}$ A biestabilidade é um fenômeno recorrente nas reações peroxidase-oxidase, isso significa que, não raramente, duas dinâmicas coexistem simultaneamente e levam a estados estacionários estáveis e distintos. ${ }^{47}$

Dois estados estacionários são constatados empiricamente quando a reação de oxidação da NADH, pela enzima peroxidase de raiz-forte, é inibida. Sabendo que, em altas concentrações de oxigênio, a enzima é convertida na sua forma inativa, denominada composto (ou complexo) III, e a reação não se completa, o experimento consiste em uma cubeta analisada por um espectrofotômetro de UV-Vis, com o aparelho calibrado para o máximo de absorção do composto III. ${ }^{48}$

A cubeta é suprida com uma alta concentração de NADH no intuito de manter sua quantidade virtualmente inalterada. A enzima peroxidase também está presente no meio reacional, de forma que ocorra sua reação com o substrato, de acordo com a equação (13). A reação se completa quando uma mistura de gases, oxigênio e nitrogênio, é bombeada na solução. A partir desse ponto, existem duas possibilidades que levam a estados estacionários diferentes. No primeiro caso, o oxigênio é bombeado violentamente, e como consequência, a forma inativa da enzima peroxidase é formada. Desse modo, a concentração de oxigênio cresce rapidamente até um estado metaestável, e continua a avançar, mais devagar, até que o oxigênio deixe de ser fornecido, e sua concentração despenca ao nível inicial. ${ }^{48}$

Paralelamente, a concentração do complexo III segue quase a mesma dinâmica do oxigênio, alcançando um estado estacionário rapidamente após o pulso inicial de oxigênio, e decaindo com a retirada de oxigênio do meio. Tais comportamentos são esperados. A concentração elevada de oxigênio favorece a formação do composto III, inibindo a reação de peroxidase-oxidase. ${ }^{48}$ 
Uma segunda dinâmica é observada quando o oxigênio é introduzido no sistema sem um pulso inicial. Observa-se que rapidamente $\circ \mathrm{O}_{2}$ na solução alcança um estado estacionário e mantêm-se nele até que é desligada a fonte de oxigênio. Correlativamente, a concentração do complexo III preserva-se baixa. Dessa vez, como não houve a formação demasiada da forma inativa da peroxidase, a reação de oxidação do NADH pode ocorrer, fazendo com que as espécies atinjam velozmente seus estados estacionários. ${ }^{48}$

Como a concentração nos estados estacionários são distantes entre si, caracteriza um fenômeno de biestabilidade. Dependendo do caminho que a reação tomar, com ou sem um acréscimo rápido na concentração de $\mathrm{O}_{2}$, o sistema irá se encaminhar para estados diferentes. $O$ experimento também é consistente com as hipóteses de que a substância formada é, de fato, a enzima em sua forma inativa. Uma representação demonstrativa, com os resultados do experimento discutido está exposta na figura que se segue: ${ }^{48}$

Figura 7. Medida simultânea da concentração do oxigênio (cima) e a absorção da luz em $418 \mu \mathrm{m}$ (baixo). O meio reacional é composto por $0,4 \mu \mathrm{M}$ da enzima peroxidase da Armoracia rusticana e 1,4 mM de NADH, em 0,07 M de um tampão de fosfato para $\mathrm{pH} 5,5 .{ }^{48}$

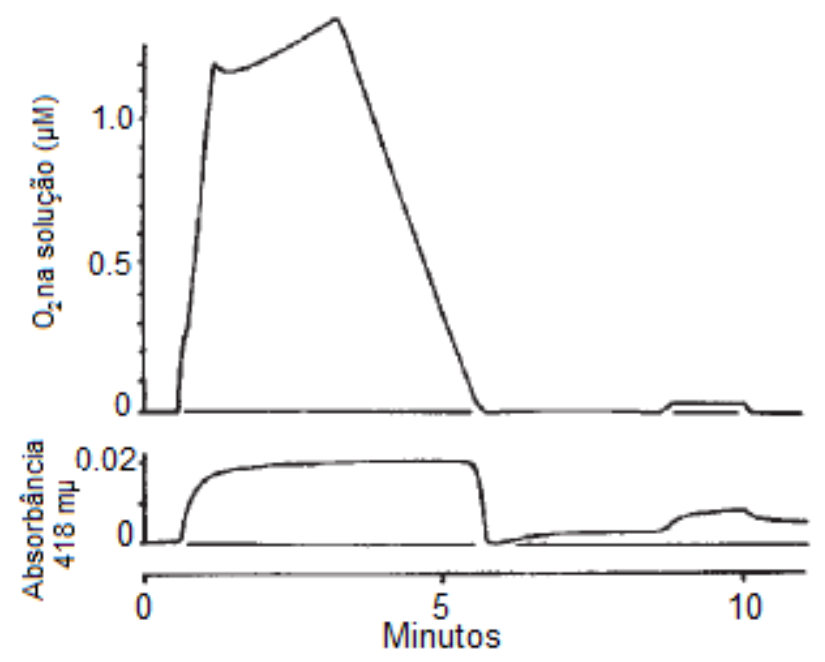

Fonte: DEGN, $1968{ }^{48}$

$\mathrm{Na}$ ausência de um substrato redutor e participando de um ambiente com excesso de peróxido de hidrogênio, a enzima peroxidase forma um intermediário 
chamado composto I. Daí, dois caminhos são possíveis, podendo acontecer uma reação onde $\circ \mathrm{H}_{2} \mathrm{O}_{2}$ atua como redutor em vez de oxidante, ou a formação reversível do composto III, por intermédio do composto II:49, 50

$$
\begin{gathered}
\text { peroxidase }+\mathrm{H}_{2} \mathrm{O}_{2} \rightarrow \text { composto I } \\
\text { composto } \mathrm{I}+e^{-} \rightarrow \text { composto II } \\
\text { composto } \mathrm{II}+\mathrm{H}_{2} \mathrm{O}_{2} \rightleftharpoons \text { composto III }
\end{gathered}
$$

A auto-oxidação da NADH atua como fonte alternativa de peróxido de hidrogênio, cujo consumo dá origem ao composto $1 \mathrm{II}:{ }^{51}$,

$$
\mathrm{NADH}+\mathrm{O}_{2}+\mathrm{H}^{+} \rightarrow \mathrm{NAD}^{+}+\mathrm{H}_{2} \mathrm{O}_{2}
$$

Com tudo, um modelo para biestabilidade, baseado na inibição da enzima, é proposto: ${ }^{18,48}$

$$
\begin{gathered}
S+E \stackrel{k_{1}}{\rightarrow} E S \\
E S \stackrel{k_{2}}{\rightarrow} E+P \\
S+E S \stackrel{k_{3}}{\rightarrow} E S_{2} \\
E S_{2} \stackrel{k_{4}}{\rightarrow} S+E S
\end{gathered}
$$

Onde $S$ é o substrato $\mathrm{H}_{2} \mathrm{O}_{2}$, a espécie $E$ equivale á enzima peroxidase e os complexos $E S$ e $E S_{2}$ são, respectivamente, formados por uma enzima com uma e duas unidades do substrato. $O$ complexo $E S_{2}$ é a forma inativa da enzima. A dinâmica dos produtos, $P$, é irrelevante, e pode ser descartado no modelo genérico: ${ }^{48,14}$ 


$$
\begin{gathered}
S_{\rightarrow}^{k_{1}} 0 \\
0 \stackrel{k_{2}}{\rightarrow} S \\
S+E_{\stackrel{k_{3}}{\rightarrow}}^{k^{2}} E S \\
E S_{\rightarrow}^{k_{4}} E \\
S+E S_{\rightarrow}^{k_{5}} E S_{2} \\
E S_{2} \stackrel{k_{6}}{\rightarrow} S+E S
\end{gathered}
$$

Na sequência, as reações indicam o escoadouro e uma fonte para a enzima peroxidase, sua ligação irreversível com o substrato peróxido de hidrogênio, a reação de catálise com a formação de produtos e, por fim, as reações reversíveis para produção do complexo III. ${ }^{14}$

As derivadas das concentrações das espécies com o tempo (t), para o sistema (16) são: ${ }^{14}$

$$
\begin{gathered}
\frac{d[S]}{d t}=-k_{1}[S]+k_{2}-k_{3}[S][E]-k_{5}[S][E S]+k_{6}\left[E S_{2}\right] \\
\frac{d[E]}{d t}=-k_{3}[S][E]+k_{4}[E S] \\
\frac{d[E S]}{d t}=k_{3}[S][E]-k_{4}[E S]-k_{5}[S][E S]+k_{6}\left[E S_{2}\right] \\
\frac{d\left[E S_{2}\right]}{d t}=k_{5}[S][E S]-k_{6}\left[E S_{2}\right]
\end{gathered}
$$

Uma segunda dinâmica biestável é observada quando peróxido de hidrogênio, ou um composto que intermedeie sua formação, como o azul de metileno, é um dos reagentes iniciais de um meio reacional semelhante ao da figura 7. ${ }^{52,53}$ Diferente da dinâmica biestável entre dois estados estacionários, esses outros múltiplos estados permutam entre uma dinâmica oscilatória e um estado estacionário, sendo assim conhecidos como biestabilidade $\mathrm{O}+\mathrm{S}$, uma sigla oriunda do inglês, oscillations plus steady state. ${ }^{54}$

Prevista teoricamente, a dinâmica biestável foi corroborada experimentalmente pela reação em solução aquosa entre a enzima peroxidase de raiz-forte, a nicotinamida adenina dinucleotídeo reduzida, azul de metileno e oxigênio molecular dissolvido. Assim como antecipado pelo modelo teórico, 
intercambialidade entre os estados é observada, na prática, quando a fonte de oxigênio é suprida, por alguns instantes, do sistema. Nesse caso, quando o sistema está no estado estacionário e acontece um breve corte no abastecimento de $\mathrm{O}_{2}$, 0 sistema entrará em um estado oscilatório. A transição reversa, da dinâmica oscilatória para um estado estacionário, é notada ao adicionar peróxido de hidrogênio na solução. Esse fenômeno prova a reversibilidade nas dinâmicas de um sistema $\mathrm{O}+\mathrm{S}^{54}$

Figura 8. Biestabilidade $\mathrm{O}+\mathrm{S}$ na reação de oxidase-peroxidase. No primeiro quadro é possível observar a mudança entre um estado estacionário para uma dinâmica oscilatória enquanto que o segundo quadro apresenta o fenômeno inverso. 0 terceiro quatro comprova a reversibilidade da reação. As setas $a$ e $b$ indicam quando ocorre o corte de oxigênio e sua posterior reativação. $\mathrm{O}$ índice $\mathrm{H}_{2} \mathrm{O}_{2}$ sobre a seta aponta o momento quando foi adicionado peróxido de hidrogênio na solução. ${ }^{54}$

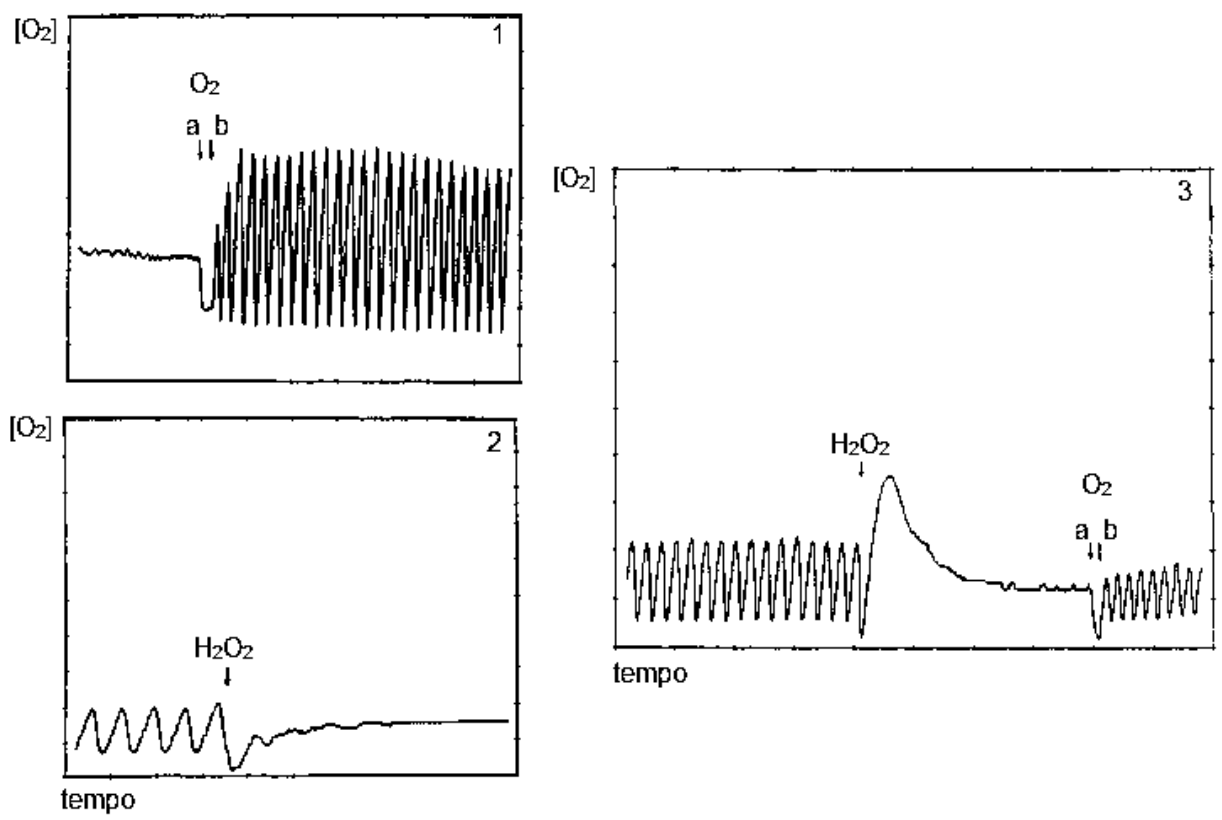

Fonte: AGUDA; FRISCH; OLSEN, $1990 .^{54}$

Acredita-se que a biestabilidade $\mathrm{O}+\mathrm{S}$ aconteça in vivo por possuir um mecanismo capaz de proteger a enzima da inativação. Durante a dinâmica oscilatória, a concentração de oxigênio reativo é menor se comparado à dinâmica de estado estacionário. Uma vez que o oxigênio reativo, produzido durante o metabolismo celular ou sinalização celular, é danoso para algumas enzimas, manter 
sua concentração baixa é essencial para manutenção da peroxidase. Os estados múltiplos proporcionam a capacidade de permutar entre um estado de oscilação, protegendo a enzima, e outro estado, de dinâmica linear, onde a peroxidase tem uma atuação mais eficiente. ${ }^{47}$

\subsubsection{MODELO DE ESTADOS MÚLTIPLOS NA EMBRIOGÊNESE DA DROSOPHILA MELANOGASTER}

A embriogênese de um indivíduo consiste em uma série de processos de estruturação e diferenciação de um organismo partindo da sua fecundação e os mecanismos responsáveis pelas mudanças. Consiste no procedimento mais óbvio de formação dos órgãos e organismos. Trata-se de um fenômeno complexo, pois requer a coordenação de inúmeras ações em grande quantidade de células. Sua complexidade é agravada por ocorrer geralmente em embriões opacos, dificultando a observação direta dos eventos. ${ }^{55}$

Após a anfimixia, ou seja, a fusão de gametas, a divisão celular inicia-se pela clivagem da célula-ovo em duas células-filhas, ou blastômeros. Após a clivagem em alguns blastômeros, sem que seu volume aumente aparentemente, o grupamento de células-filhas terá a aparência de uma amora, e por isso, esse estágio é denominado de mórula. ${ }^{56}$

Figura 9. Da direita para esquerda, as consecutivas clivagens que ocorrem na célula-mãe. Mais a esquerda está ilustrada uma mórula a etapa final da segmentação. ${ }^{56}$

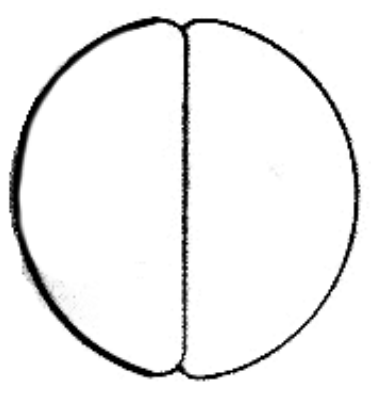

$1^{\text {a }}$ segmentação

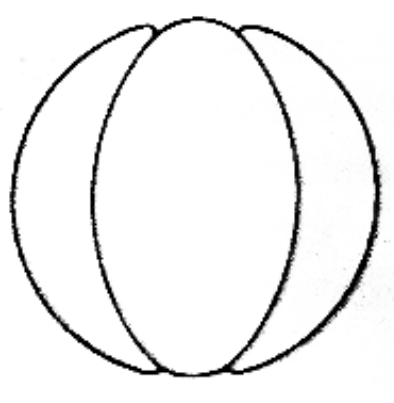

$2^{\mathrm{a}}$ segmentação

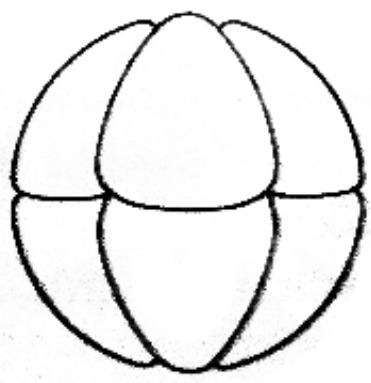

$3^{\mathrm{a}}$ segmentação

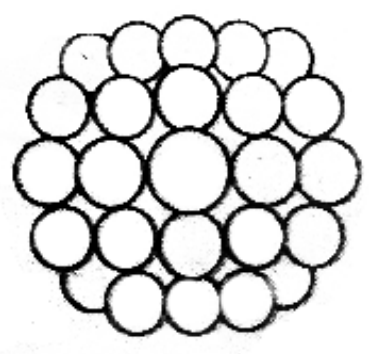

Mórula

Fonte: HOUILLON, $1972 .^{56}$ 
Os blastômeros, então, tendem a ordenar-se ao redor de uma cavidade central, formando uma cavidade de segmentação ou blastocela. Nesse estado, o germe é denominado como blástula. ${ }^{56}$

Figura 10. O resultado de uma segmentação total é uma mórula. A seguir, os blastômeros se organizam em uma cela chamada blástula. Um corte seccional na blástula revela um interior cavado, tal cavidade recebe o nome de blastocela. ${ }^{56}$

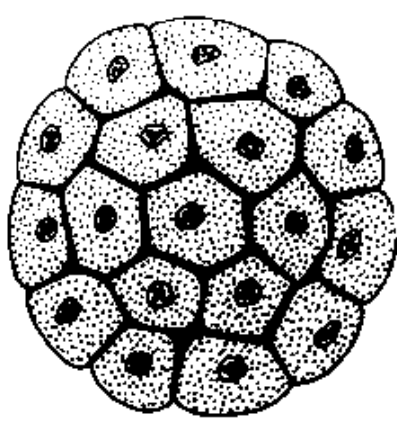

Mórula

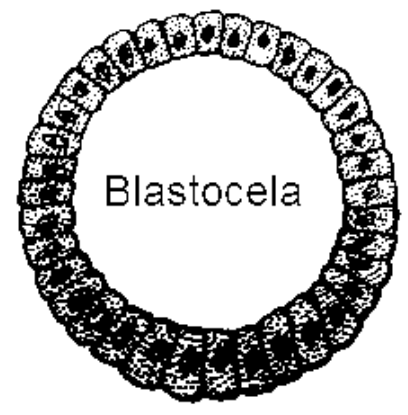

Blástula

Fonte: HOUILLON, $1972 .{ }^{56}$

A gastrulação é o estágio que procede a formação da blástula. É o primeiro conjunto de processos morfogenéticos e ordena os blastômeros em camadas. $\mathrm{O}$ folheto mais externo, ou ectoblasto, recobre um mais profundo, nomeado endoblasto, e, interpondo-se entre os dois, pode existir um terceiro folheto denominado mesoblasto. ${ }^{56}$ Assim, as células que têm potencial para formar os órgãos endodérmicos e mesodérmicos são conduzidos para o interior do embrião, ao passo que as células que podem formar a pele e o sistema nervoso são distribuídas na superfície exterior. É nessa etapa que surgem as cavidades que darão origem à boca ou ao ânus do indivíduo. ${ }^{57}$

Os movimentos morfogenéticos continuam após a gastrulação, durante a etapa da morfocoresis, onde um esboço da forma embrionária é formada. As camadas que ainda não apresentavam diferenciação biológica adquirem uma caracterização e cada blastômero é ordenado de acordo com sua futura função. Uma vez ordenados, esses territórios organoformadores diferenciam-se histologicamente. Com o fim da morfocoresis o embrião começa a ganhar volume e os tecidos se aglomeram para formar órgãos. A eclosão ocorre quando a larva é 
capaz de sustentar uma vida independente. Em geral a forma larval difere-se demasiadamente do animal adulto e processos de metamorfose são necessários para que esse alcance o amadurecimento, entretanto, do ponto de vista biológico, sua embriogênese acaba com o início da fase larval. ${ }^{56}$

De modo geral, as características a nível molecular são comuns à grande maioria de seres vivos, a exemplo da via glicolítica, no entanto, características estruturais são profundamente distintas entre os grupamentos de espécies. Por sorte, as variações não são tão acentuadas dentre as espécies que compõe o mesmo grupo e assim os fenômenos básicos da genética não necessitam ser estudados à exaustão, um estudo para cada espécie. Assim, uma espécie que apresenta similaridades genéticas com todos ou muitos indevidos de um grupo são escolhidos como organismos modelo. ${ }^{58}$

A mosca de fruta Drosophila melanogaster é um conhecido organismo modelo. Por possuir apenas quatro pares de cromossomos, são facilmente observadas alterações genéticas oriundas de mutações e suas implicações na morfologia e bioquímica do indivíduo. Outro fato que a classifica com um bom organismo modelo é que durante sua embriogênese, são gerados segmentos de corpo que são comuns a seres invertebrados e vertebrados. ${ }^{58}$

No início da década de noventa, a maior parte dos genes envolvidos na formação larval da Drosophila melanogaster foram identificados. Há evidências da existência de três conjuntos de determinantes morfogênicos nessas moscas, 0 primeiro conjunto controla a polaridade dorso-ventral, causando a distinção entre o dorso e o ventre na larva da mosca. Um segundo grupo é responsável pela polaridade antero-posterior, o que leva a formação da cabeça e da cauda. Um terceiro grupo gera as células germinativas, capazes de produzir gametas. ${ }^{57}$

O responsável pela especificação da parte anterior na Drosophila melanogaster é a proteína bicoid. Durante a ovogênese o mRNA que codifica esta proteína está localizado na dianteira do ovócito e quando traduzido na proteína, distribui-se ao longo do embrião em forma de um gradiente decrescente, do volume anterior ao posterior. Fêmeas que não possuem o gene bicoid dão origem a embriões sem estruturas de cabeça, com tórax formado por tecidos abdominais e caudas nas duas extremidades. Tal fato é um indicativo que a bicoid é responsável pela formação da cabeça e é corroborado experimentalmente ao injetar a proteína 
purificada durante a etapa de clivagem. Caso a proteína seja injetada na parte anterior os embriões serão estruturalmente normais. Do contrário, quando é injetada na porção posterior, duas cabeças são formadas, uma em cada extremidade. $\mathrm{Na}$ última das hipóteses, e injetada na parcela central, a região mediana originará uma cabeça e as extremidades formarão estruturas torácicas. ${ }^{57}$

Juntamente com o bicoid, um segundo gene é responsável pela morfogênese do segmento anterior na mosca, o chamado hunchback. Na ausência da atividade do hunchback, a bicoid é incapaz de conferir a polaridade antero-posterior ao embrião. ${ }^{59}$ Embriões que carecem do gene hunchback apresentam um abdômen em plano de reflexão ligados por uma estrutura rudimentar de cabeça. No embrião, é distribuído fortemente na parte anterior e apresenta uma lacuna chegando ao meio da estrutura. ${ }^{19}$

Figura 11. Marcação fluorescente das proteínas bicoid $(A)$ e hunchback (B) ao longo do embrião. A intensidade da luminosidade fluorescente é proporcional à concentração das proteínas. O polo a esquerda representa o anterior, ao passo que a direita está o polo posterior. O gráfico (C) confronta o perfil fluorescente contra a posição no embrião, o padrão verde reproduz a proteína bicoid e o azul, a hunchback. $^{19}$
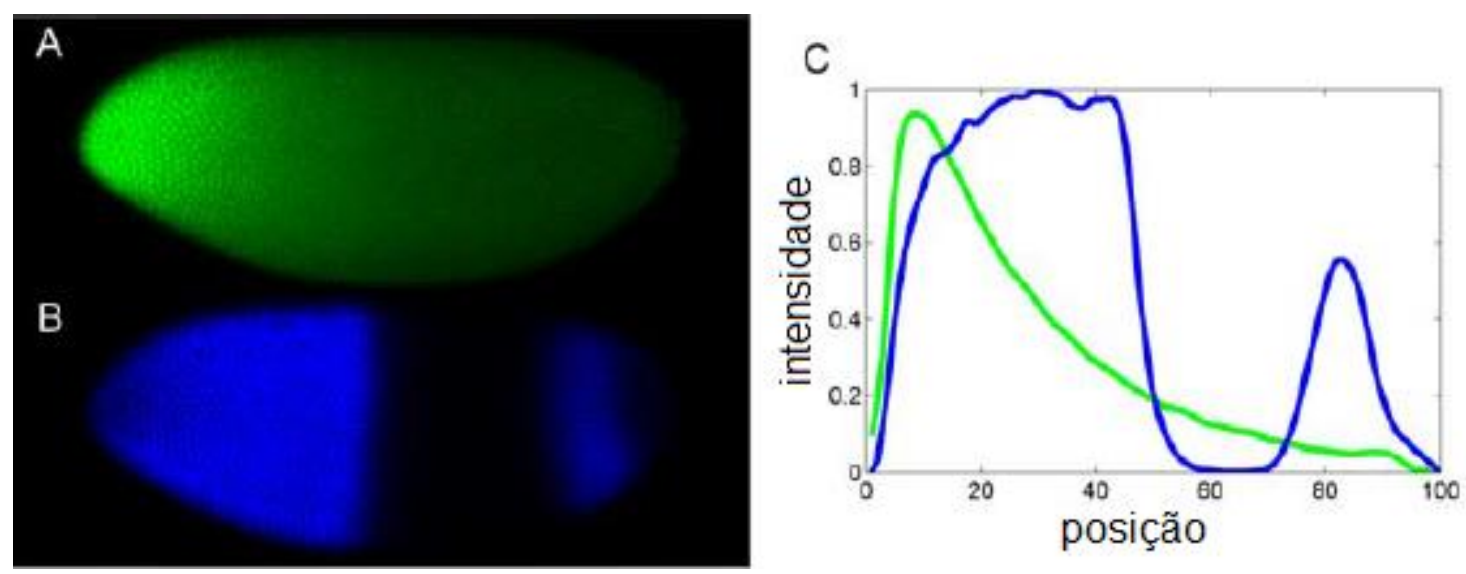

Fonte: LOPES et al., $2008 .^{19}$

Acredita-se que a lacuna observada na distribuição da proteína hunchback se dá por um processo de biestabilidade espacial na dinâmica da proteína. Um modelo biestável, chamado modelo auto-regulatório da hunchback, se ajusta ao padrão de 
distribuição das proteínas responsáveis pela formação da estrutura anterior na Drosophila melanogaster. ${ }^{19}$

Figura 12. Ajuste do modelo auto-regulatório da hunchback ao perfil de distribuição como na figura $11(\mathrm{C})$, as linhas pretas e vermelhas representam os dados experimentais, para a hunchback e bicoid, respectivamente. Os ajustes das mesmas proteínas, hunchback e bicoid, na ordem, estão em verde e azul. ${ }^{19}$

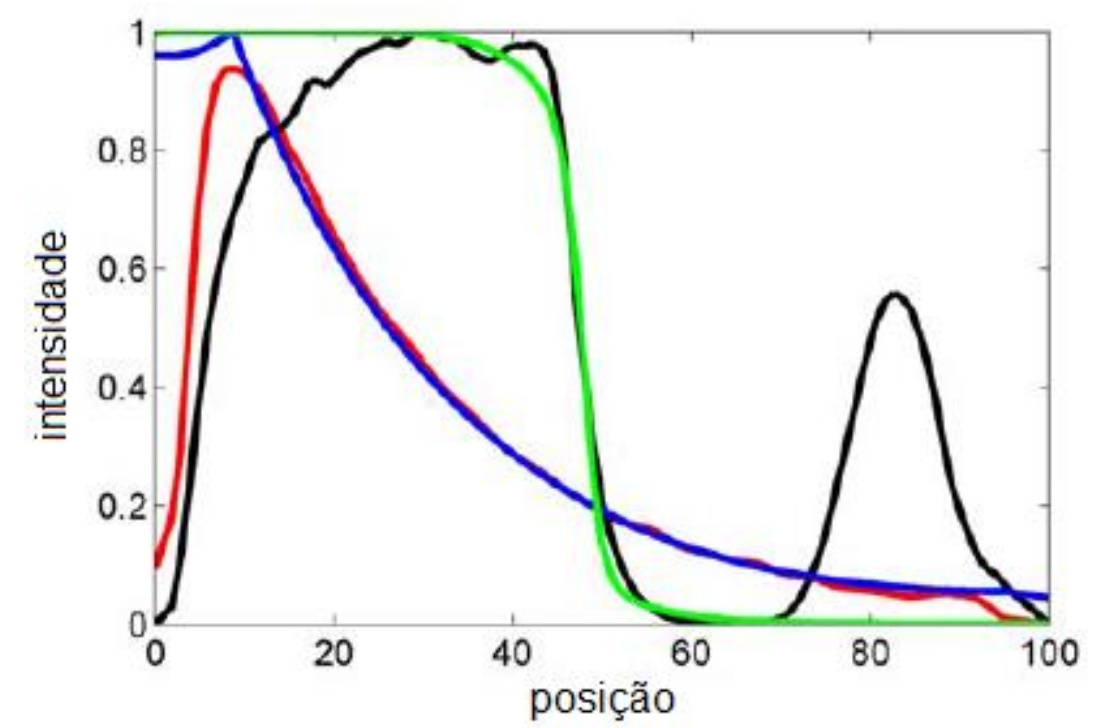

Fonte: LOPES et al., 2008. ${ }^{19}$

Pelo ótimo ajuste, tanto no degrau observado na distribuição da hunchback, quanto na concentração da bicoid ao longo do embrião, conclui-se que o fenômeno de biestabilidade espacial pode estar relacionado com os padrões de disseminação das proteínas nas fases inicias da Drosophila melanogaster. Essa dinâmica é consequência das reações autocatalíticas no modelo auto-regulatório da hunchback: ${ }^{19}$ 


$$
\begin{aligned}
& 0 \rightarrow^{K 1} \mathrm{~B} \\
& \mathrm{~B}+\mathrm{b}_{0} \rightarrow \rightarrow^{K 2} \mathrm{~b}_{1} \quad \mathrm{~B}+\mathrm{b}_{3} \rightarrow^{K 11} \mathrm{~b}_{4} \quad \mathrm{H}+\mathrm{h}_{0} \rightarrow^{K 20} \mathrm{~h}_{1} \\
& \mathrm{~b}_{1} \rightarrow^{K 3} \mathrm{~B}+\mathrm{b}_{0} \quad \mathrm{~b}_{4} \rightarrow^{K 12} \mathrm{~B}+\mathrm{b}_{3} \quad \mathrm{~h}_{1} \rightarrow^{K 21} \mathrm{H}+\mathrm{h}_{0} \\
& \mathrm{~b}_{1} \rightarrow^{K 4} \mathrm{~b}_{1}+\mathrm{H} \quad \mathrm{b}_{4} \rightarrow{ }^{K 13} \mathrm{~b}_{4}+\mathrm{H} \quad \mathrm{h}_{1} \rightarrow{ }^{K 22} \mathrm{~h}_{1}+\mathrm{H} \\
& \mathrm{B}+\mathrm{b}_{1} \rightarrow^{K 5} \mathrm{~b}_{2} \quad \mathrm{~B}+\mathrm{b}_{4} \rightarrow^{K 14} \mathrm{~b}_{5} \quad \mathrm{H}+\mathrm{h}_{1} \rightarrow^{K 23} \mathrm{~h}_{2} \\
& \mathrm{~b}_{2} \rightarrow^{K 6} \mathrm{~B}+\mathrm{b}_{1} \quad \mathrm{~b}_{5} \rightarrow{ }^{K 15} \mathrm{~B}+\mathrm{b}_{4} \quad \mathrm{~h}_{2} \rightarrow \rightarrow^{K 24} \mathrm{H}+\mathrm{h}_{1} \\
& \mathrm{~b}_{2} \rightarrow{ }^{K 7} \mathrm{~b}_{2}+\mathrm{H} \quad \mathrm{b}_{5} \rightarrow{ }^{K 16} \mathrm{~b}_{5}+\mathrm{H} \quad \mathrm{h}_{2} \rightarrow{ }^{K 25} \mathrm{~h}_{2}+\mathrm{H} \\
& \mathrm{B}+\mathrm{b}_{2} \rightarrow^{K 8} \mathrm{~b}_{3} \quad \mathrm{~B}+\mathrm{b}_{5} \rightarrow^{K 17} \mathrm{~b}_{6} \quad \mathrm{H} \rightarrow^{K 26} 0 \\
& \mathrm{~b}_{3} \rightarrow{ }^{K 9} \mathrm{~B}+\mathrm{b}_{2} \quad \mathrm{~b}_{6} \rightarrow{ }^{K 18} \mathrm{~B}+\mathrm{b}_{5} \\
& \mathrm{~b}_{3} \rightarrow{ }^{K 10} \mathrm{~b}_{3}+\mathrm{H} \quad \mathrm{b}_{6} \rightarrow^{K 19} \mathrm{~b}_{6}+\mathrm{H} \quad \mathrm{B} \rightarrow{ }^{K 27} 0
\end{aligned}
$$

O modelo consiste em uma série de equações reversíveis e irreversíveis entre o gene promotor da hunchback e seus ativadores. O promotor apresenta seis sítios de ligação com o bicoid e outros dois, auto-regulatórios, que se ligam a proteína hunchback. A primeira equação (K1) representa a formação da proteína bicoid (B) por uma fonte qualquer. As três equações seguintes (K2-K4) dizem respeito à síntese da proteína hunchback $(\mathrm{H})$, resultado da transcrição que ocorre quando o sítio para a bicoid $\left(b_{n}\right)$ é ativado. O subíndice $n$ aponta quantas proteínas bicoid (ou hunchback) estão ligadas àquele sítio. As próximas quinze equações (K5-K19) são semelhantes e também indicam a produção de H. Nas seis seguintes (K20-K25) ocorre a auto-regulação da hunchback, quando essa se liga ao sítio auto-regulatório $\left(h_{n}\right)$. Por fim, as últimas equações (K26 e K27) mostram um escoadouro para as proteínas envolvida. $^{19}$

Divergindo dos outros modelos estudados, aqui a modalidade gráfica da análise estequiométrica de redes será utilizada para investigar um possível modelo reduzido e biestável.

\subsubsection{DINÂMICAS COMPLEXAS EM MODELOS TEÓRICOS}

A análise da rede estequiométrica, $S N A$, tem como base a decomposição de redes estequiométricas complexas em frações mais simples, denominadas correntes extremas. Se a corrente extrema contiver alguma estabilidade, o sistema maior pode apresentar o mesmo comportamento dinâmico. Teorizar e resolver a dinâmica de 
modelos simples, ou mínimos, é uma ferramenta crucial para compreender a dinâmica de sistemas maiores, uma vez que os modelos mínimos podem constituir correntes extremas de modelos ascendentes. ${ }^{22}$

Assim, motivado pela facilidade de entendimento, pouca necessidade de discussões adicionais, a possibilidade de fundamentar outros sistemas maiores, e a melhor elucidação da análise por SNA, as seguintes serão investigadas.

\subsubsection{MENOR MODELO OSCILATÓRIO}

Uma rede de reações foi classificada como o menor modelo que possui dinâmica oscilatória por apresentar o número mínimo de reagentes, termos quadráticos possíveis e reações bimoleculares: ${ }^{21}$

$$
\begin{aligned}
X+A & \stackrel{k_{1}}{\rightarrow} 2 X \\
X+Y & \stackrel{k_{2}}{\rightarrow} A+Y \\
X & \stackrel{k_{3}}{\rightarrow} Z \\
Z & \stackrel{k_{4}}{\rightarrow} Y \\
Y & \stackrel{k_{5}}{\rightarrow} A
\end{aligned}
$$

\subsubsection{MENOR MODELO CÍCLICO OSCILATÓRIO}

Contendo cinco espécies químicas, o seguinte modelo compõe-se do número mínimo de reações químicas capazes de gerar um comportamento oscilante quando interligadas em um padrão cíclico: ${ }^{22}$

$$
\begin{gathered}
A \stackrel{k_{1}}{\rightarrow} B \\
B \stackrel{k_{2}}{\rightarrow} C \\
C \stackrel{k_{3}}{\rightarrow} D \\
D \stackrel{k_{4}}{\rightarrow} E \\
E+A \stackrel{k_{5}}{\rightarrow} 2 A
\end{gathered}
$$




\subsubsection{MENOR MODELO MULTIESTÁVEL}

O modelo quadrático é a menor rede de reações químicas multiestável considerando os parâmetros: menor número de complexos, menor número de componentes conectados e o menor número de espécies. ${ }^{23}$

$$
\begin{aligned}
& 3 A \stackrel{k_{1}}{\rightarrow} A+2 B \\
& A+2 B \stackrel{k_{2}}{\rightarrow} 3 B \\
& 3 B \stackrel{k_{3}}{\rightarrow} 2 A+B \\
& 2 A+B \stackrel{k_{4}}{\rightarrow} 3 A
\end{aligned}
$$

\subsection{OSCILAÇÕES}

Oscilações químicas são mudanças rítmicas, temporais ou espaciais, nas concentrações das espécies de uma reação. Em sistemas fechados à pressão e temperatura constantes, podem ser formadas espécies intermediárias que possuem uma quantidade máxima e mínima de concentração. Normalmente, reações paralelas e opostas geram uma condição de consumo e produção que mantém os intermediários em um estado quase estacionário, em uma concentração média. Quando tais intermediários possuem vida curta, a espécie pode passar da concentração máxima para a mínima, ou o contrário, com velocidade elevada, produzindo um sistema oscilante. ${ }^{60}$

As oscilações que ocorrem em sistemas bioquímicos são eventos importantes para a manutenção da vida humana. Devido sua relevância, o comportamento oscilatório a nível metabólico, envolvendo o sistema glicolítico, foi amplamente investigado e compreendido, assim como as oscilações de NADH em ambiente celular. Outros exemplos conhecidos são as oscilações em mitocôndrias, membranas naturais, músculos e até em células tumorais. ${ }^{60}$

Apesar de serem comumente associados com a fisiologia, fenômenos oscilatórios não são restritos a sistemas vivos. Desde a descoberta da reação química oscilatória de Belousov-Zhabotinsky (BZ), tornou-se evidente que numerosas reações químicas que não participam de algum sistema bioquímico, também, demonstram comportamento de periodicidade em função do tempo. ${ }^{7}$ 
Belousov, em 1951, ao investigar um análogo inorgânico para o ciclo de Krebs, preparou uma solução de ácido cítrico, íons bromato e de cério $\left(\mathrm{Ce}^{4+}\right)$. Esperava a mudança da solução de cor amarelada, devido aos íons $\mathrm{Ce}^{4+}$, em uma solução incolor, de íons $\mathrm{Ce}^{3+}$. No entanto, a solução tornou-se incolor e, logo após, voltou a ficar amarela. ${ }^{61}$

Em seguida, ao estudar a reação em diversas condições de temperatura e concentrações iniciais, Belousov submeteu um manuscrito para publicação, que foi rejeitado por falta de evidências. Seis anos depois, um trabalho revisado foi enviado a outro jornal, porém o editor propôs que o artigo fosse resumido a uma carta. Belousov desistiu da publicação, porém seu manuscrito seguiu circulando no cenário acadêmico. Em 1961, Zhabotinsky, um biofísico, teve acesso a formulação original da reação de Belousov: ${ }^{61}$

Tabela 2. Formulação da reação de Belousov

\begin{tabular}{ll}
\hline \hline Reagente & Quantidade \\
\hline $\mathrm{KBrO}_{3}$ & $0,2 \mathrm{~g}$ \\
$\mathrm{Ce}\left(\mathrm{SO}_{4}\right)_{2}$ & $0,16 \mathrm{~g}$ \\
Ácido cítrico & $2 \mathrm{~g}$ \\
$\mathrm{H}_{2} \mathrm{SO}_{4}$ & $2 \mathrm{~mL}$ \\
Água & Suficiente para preparar $10 \mathrm{~mL}$ de solução
\end{tabular}

Fonte: EPSTEIN, $1998 .^{6}$

Zhabotinsky aprimorou a reação, substituindo o ácido cítrico por ácido malônico, que não produz precipitado. Os dois cientistas avançaram na compreensão da reação e chegaram a conclusão de que a ferroína é um melhor indicador para a reação. De melhor visibilidade, o composto é capaz de mudar da sua coloração avermelhada, na sua forma reduzida, para um azul, quando oxidado. ${ }^{61} \mathrm{O}$ efeito visual obtido é um padrão de ondas circulares, na superfície do líquido, que não se refletem ao encontrarem com o limite do recipiente..$^{60}$ 
Figura 13. Representação esquemática do efeito visual de uma reação BelousovZhabotinsky em uma placa de Petri. É um padrão semelhante à agregação da Dictyostelium discoideum em ágar (Figura 1). ${ }^{60}$

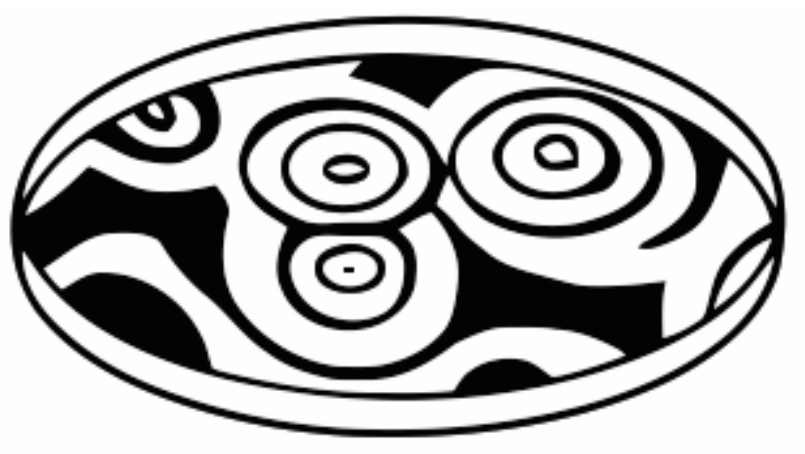

O conjunto BZ de reações químicas oscilatórias introduziu outros inúmeros sistemas novos, pela substituição de componentes na sua formulação original. Por exemplo, é possível obter oscilações utilizando catalizadores, tais como os pares, $\mathrm{Mn}$ (II)/Mn(III), $\mathrm{Fe}$ (II)/Fe(III), $\mathrm{Ru}$ (II)/Ru(III), $\mathrm{Cr}(\mathrm{II}) / \mathrm{Cr}$ (III) e $\mathrm{Co}$ (II)/Co(III) em vez do par $\mathrm{Ce}(\mathrm{III}) / \mathrm{Ce}(\mathrm{IV}){ }^{62}$

Dentre os modelos oscilantes conhecidos, o proposto pelo físico e matemático Vito Volterra exemplifica com integridade essa dinâmica peculiar. A construção teórica foi inspirada nos trabalhos do físico-químico Alfred Lotka, e por isso, é conhecida como Lotka-Volterra. O modelo consiste em três etapas irrevessíveis: ${ }^{61}$

$$
\begin{gathered}
A+X \rightarrow 2 X \\
X+Y \rightarrow 2 Y \\
Y \rightarrow P
\end{gathered}
$$

Onde $X$ e $Y$ são espécies autocalíticas, $A$ é uma fonte e $P$ um escoadouro. As reações podem ser descritas na forma de equações diferenciais: ${ }^{61}$

$$
\begin{aligned}
& \frac{d X}{d t}=k_{1}[X]-k_{2}[X][Y] \\
& \frac{d Y}{d t}=k_{2}[X][Y]-k_{3}[Y]
\end{aligned}
$$


A constante de velocidade é representada por $k_{x}$, com $x=1, \ldots, n^{\mathrm{o}}$ de reações químicas. Após resolver o problema cinético, ou seja, encontrar as soluções numéricas das equações diferenciais, um gráfico da dinâmica das espécies pode ser traçado: ${ }^{61}$

Figura 14. Solução numérica para 0 modelo de Lotka-Volterra $\operatorname{com} A=K_{1}=K_{2}=K_{3}=1.61$

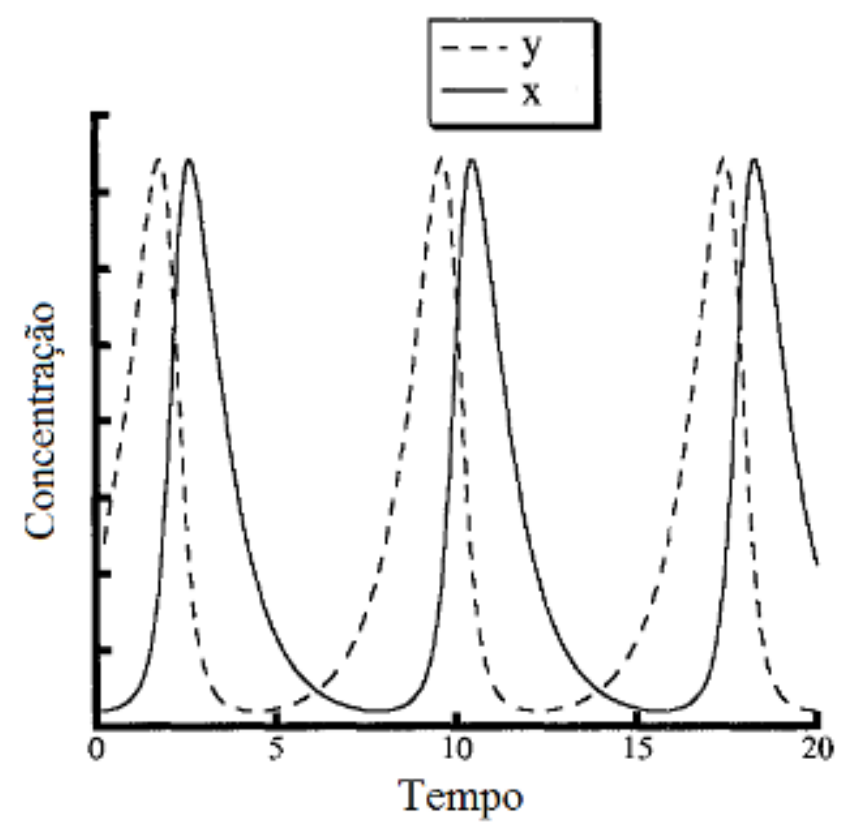

Fonte: EPSTEIN, $1998 .^{61}$

A propriedade chave para as equações de Lotka-Volterra, e da maioria dos sistemas que apresentam oscilações, é a autocatálise. Essa particularidade diz que a taxa de crescimento de uma espécie aumenta com a concentração de sua população. A oscilação em Lotka-Volterra acontece pela diferença de fases entre as produções da espécie $X$ e $Y$. Ou seja, a concentração da espécie $X$ aumenta porque A é uma fonte constante, e pela estequiometria das reações, o elemento $Y$ só poderá crescer após a subida de $X$. Quando $Y$ está no seu valor máximo, irá consumir $X$ mais rápido do que esse é capaz de ser produzido, e assim, a taxa de $X$ irá diminuir, acarretando na redução da concentração de $\mathrm{Y}$, que é eliminado pelo escoadouro. ${ }^{61}$ 


\subsection{MULTIESTABILIDADE}

Multiestabilidade é o fenômeno que descreve a situação onde um sistema apresenta dois ou mais estados de equilíbrio. Ocorre quando existe uma bifurcação do tipo sela-nó ${ }^{5}$ em sistemas que apresentam comportamento autocalítico. ${ }^{62}$

O estudo da multiestabilidade é crucial para o entendimento do funcionamento das células. Tal comportamento está presente em ciclos celulares, diferenciação celular, apoptose, na perda da homeostase em casos de câncer e até no aparecimento de diferentes fenótipos em uma população de seres unicelulares. ${ }^{63}$ Outra relevância está nas sinalizações celulares. Sistemas bioquímicos simples são capazes de comportamentos semelhantes a interruptores. A multiestabilidade é um dos mecanismos de comutação conhecidos, onde cada estado estacionário corresponde a um sinal em resposta a um estímulo. ${ }^{64}$ Sabe-se, também, que o processo evolutivo favorece as células que apresentam a capacidade de alternar entre diferentes estados operacionais em resposta as mudanças no ambiente celular. $^{65}$

As múltiplas estabilidades estão associadas com a presença de uma reação na rede, na qual, o produto favorece a retroalimentação da própria espécie. Por definição, a reação que apresenta retroalimentação é chamada de autocatalítica. Seja a reação genérica,

$$
A+n B \rightarrow(n+1) B
$$

caso o coeficiente estequiométrico, $n$, tenha os valores de uma, duas ou nenhuma unidade, os processos são denominados, respectivamente, autocalítico quadrático, cúbico ou não catalítico. Contudo, apesar da retroalimentação ser importante para a multiestabilidade, a ocorrência dessa particularidade sozinha não é suficiente para um sistema ser classificado como multiestável. ${ }^{65}$

Algebricamente, múltiplos estados são descritos pelas soluções dos estados estacionários de sistemas não lineares. Usando como exemplo o seguinte modelo teórico, cuja única variável é $x^{66}$ 


$$
\frac{d x}{d t}=-x^{3}+\mu x+\lambda
$$

Os coeficientes, $\mu$ e $\lambda$, são os parâmetros que caracterizam a dinâmica do modelo. Os estados estacionários são alcançados quando as velocidades das reações são nulas, isso é, quando o sistema entra em equilíbrio. Igualando a equação (26) a zero,

$$
x^{3}-\mu x-\lambda=0
$$

as três raízes (equação cúbica) de $x$ pode levar, ou todas reais, ou uma real e duas complexas, dependendo dos valores dos parâmetros dinâmicos. Os estados estacionários podem ser classificados como estáveis ou instáveis, sendo esse, quando uma pequena perturbação no sistema o deslocar para outro estado. ${ }^{66}$

Para a equação (27), quando $\lambda$ tende a zero, existem três estados estacionários que obedecem, qualitativamente, as características de estabilidades mostra na seguinte figura: 66

Figura 15. Comportamento da equação cúbica para $\mu$ constante $>0 .^{66}$

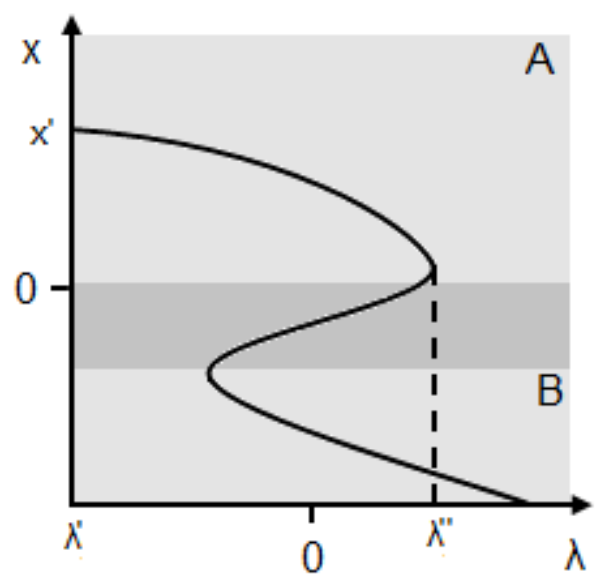

Os resultados localizados nas extremidades superior e inferior da curva sigmoidal, nas faixas claras, $A$ e $B$, apresentam estados estacionários estáveis, enquanto os posicionados na faixa escura são instáveis. Na Figura 15, para valores de $\lambda$ próximos de zero, existem três estados estacionários, por exemplo, quando 
$\lambda=0$, o parâmetro $\mathrm{x}$ no eixo das ordenadas pode apresentar três resultados. Experimentalmente, se o sistema se encontra na no ponto $\left(\lambda^{\prime}, x^{\prime}\right)$, e se aproxima de $\lambda$ " pela esquerda, a medida valor de $\lambda$ se torna mais positivo, o sistema mantém-se em $A$, até passar por $\lambda$ ", quando o estado estacionário salta para os valores da faixa $B$, seguindo a linha tracejada ${ }^{66}$, de cima para baixo, formando um comportamento de histerese. ${ }^{11}$ É possível perceber, então, que os estados estacionários no meio da curva, na faixa escura, são inacessíveis pelo sistema, e, portanto, são classificados como instáveis. ${ }^{66}$

Figura 16. Comportamento de histerese pode ser observado na transição entre os regimes biestáveis. O sistema, assim, alcança os valores menores que zero para $\mathrm{x}$, partindo de $x>0$, ou vice-versa, sem passar pelos estados instáveis. ${ }^{11}$

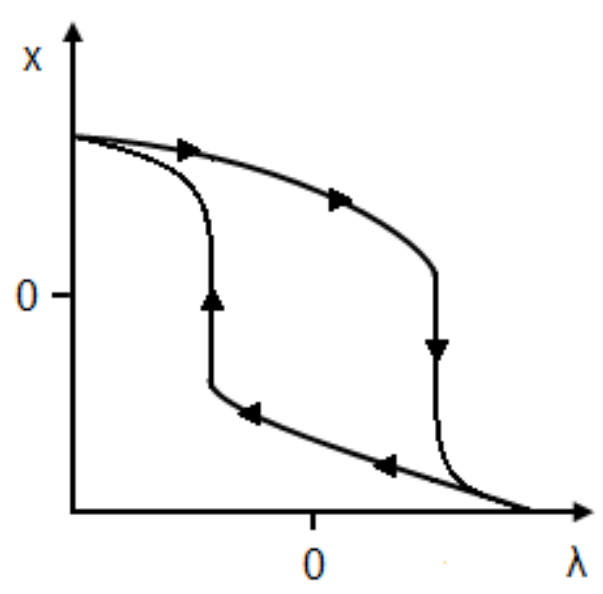

A multiestabilidade ocorre quando o sistema transita entre estados estacionários estáveis, conforme seus parâmetros dinâmicos são alterados. Para o exemplo da equação (27), existirão múltiplos estados estacionários possíveis, em função dos valores de $\mu$ e $\lambda^{: 66}$ 
Figura 17. Multiestabilidade na região plana, $(\mu, \lambda)$, onde existem três raízes reais para $x .^{66}$

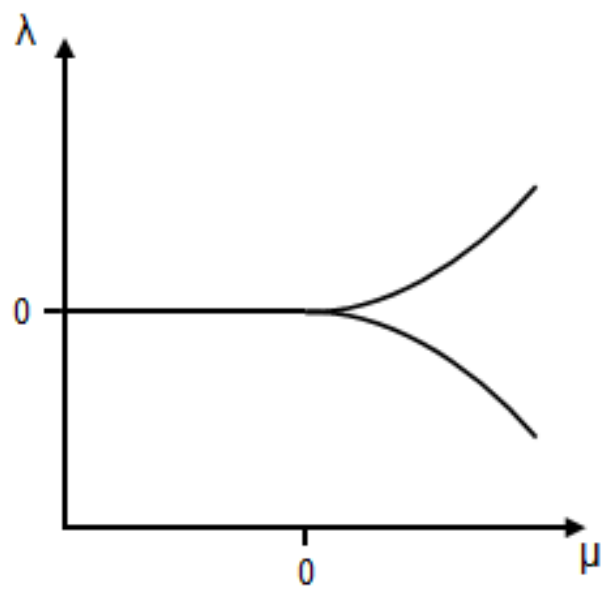

\subsection{MODELOS CINÉTICOS}

De forma geral, a modelagem bioquímica é o uso de elementos da matemática para descrever propriedades de interesse biológico, como por exemplo, as concentrações de um metabólito. Um modelo é eficiente quando consegue, valendo-se da simplicidade, descrever todas as propriedades que se deseja. Isso implica dizer que alguns aspectos do sistema podem ser negligenciados, contanto que não comprometa os resultados. ${ }^{4}$

Assim como um objeto biológico pode ser investigado por diversos métodos experimentais, também pode ser descrito por modelos matemáticos diferentes. ${ }^{4} \mathrm{Na}$ modelagem cinética, a forma usual de verificar a evolução temporal das concentrações em uma reação química é utilizar um conjunto de equações diferenciais ordinárias $(\mathrm{ODE})$ de primeiro grau, também chamadas de leis de velocidade da reação. ${ }^{67}$

Considerando a equação,

$$
A+B \rightarrow C
$$

a taxa de consumo de $A$ em função do tempo é dada pela derivada da concentração da espécie em respeito ao tempo: ${ }^{61}$ 


$$
\text { Taxa de consumo de } A=v_{A}=-\frac{d[A]}{d t}
$$

A estequiometria de (28) mostra que para cada unidade de $A$, uma unidade de $B$ é simultaneamente consumida e um $C$ é formado. Assim: ${ }^{61}$

$$
-\frac{d[A]}{d t}=-\frac{d[B]}{d t}=\frac{d[C]}{d t}
$$

Uma forma geral para representar a velocidade de qualquer espécie em uma reação química é:61

$$
v_{J}=\frac{1}{n_{J}} \frac{d[J]}{d t}
$$

Onde $n_{J}$ é o coeficiente estequiométrico da espécie $J$, e, convencionalmente, é positivo se $J$ for um produto, e negativo se for um reagente. ${ }^{61}$

A lei de velocidade é proporcional à concentração dos reagentes (algumas vezes, proporcional aos produtos ou espécies catalíticas) elevados a alguma potência. $^{61}$ A constante de proporcionalidade, que depende da temperatura do sistema, sua pressão e outros parâmetros físico-químicos, ${ }^{68}$ é chamada de constante de velocidade. Comumente as constantes de velocidade são calculadas experimentalmente medindo as concentrações das espécies em função do tempo. ${ }^{61}$

Os expoentes quais as concentrações estão elevadas determinam a ordem da reação e das espécies. Por exemplo, tomando a seguinte expressão de lei de velocidade,

$$
\frac{d[A]}{d t}=k[A]^{a}[B]^{b}
$$

diz-se que, a espécie $A$ é de ordem $a$, e a espécie $B$, de ordem $b$. A ordem da reação é definida pela soma das ordens das espécies, para a equação (32), a ordem é expressa por " $a+b$ ". As reações, cuja ordem de cada reagente é igual ao seu coeficiente estequiométrico, seguem uma lei de velocidade específica, a lei de ação 
de massas. ${ }^{61}$ Essa lei, proposta por Guldberg e Waage em 1864, determina a velocidade instantânea de uma reação química em termos das concentrações dos reagentes. ${ }^{68}$ As equações que se apoiam na lei de ação de massas devem, por regra, ser elementares ${ }^{61}$, isso significa que as reações acontecem em uma única etapa, com intermediários não detectáveis. ${ }^{69}$

\subsection{ANÁLISE DA REDE ESTEQUIOMÉTRICA}

A análise da rede estequiométrica foi proposta por Bruce Clarke, químico teórico, em 1980, como uma ferramenta para estudar dinâmicas oscilatórias. ${ }^{70}$ É um método de análise usado geralmente em reações que seguem a lei de ação de massas e fornece as condições necessárias e suficientes para exibir bifurcações que originam os fenômenos dinâmicos complexos. ${ }^{71}$

O princípio da análise da rede estequiométrica é definir novas variáveis e parâmetros ${ }^{72} \mathrm{com}$ intuito de decompor a rede química em um conjunto de reações que garantem ao sistema um estado estacionário para cada espécie. A principal vantagem desse método é o de poder fazer previsões sobre os sistemas sem definir valores específicos de equilíbrio ou constantes cinéticas. ${ }^{71}$

Uma rede estequiométrica é um conjunto de transformações que produzem ou extinguem entidades que estão correlacionadas por uma taxa fixa, isso significa que as espécies não podem ser produzias sem que haja uma taxa de consumo proporcional. É uma estrutura que não se aplica somente à química, mas também a economia, ecologia e o setor industrial. ${ }^{13}$

Supondo que uma rede de reações contém $x$ espécies $X$, e $r$ reações $R$, o coeficiente de produção ou consumo de uma espécie $X_{i}$ em uma reação $R_{j}$ é o elemento $n_{i j}$, o chamado coeficiente estequiométrico. $O$ conjunto de elementos $n_{i j}$ forma a matriz estequiométrica $\mathbf{N} .^{13} \mathrm{O}$ coeficiente estequiométrico, $n_{i j}$, é formado pelos elementos $\alpha_{i j}$ e $\beta_{i j}$, que representam a quantidade de espécies $X_{i}$ na reação $R_{j}$, nas etapas de produção e consumo, respectivamente. Cada coeficiente estequiométrico é do tipo ${ }^{71}$,

$$
n_{i j}=\beta_{\mathrm{ij}}-\alpha_{\mathrm{ij}}
$$


As reações químicas são classificadas entre reversíveis e irreversíveis. Durante a análise SNA as reações reversíveis formam duas equações distintas com diferentes constantes cinéticas, ou seja, são consideradas irreversíveis. Assim, cada uma das reações é uma coluna na matriz estequiométrica. ${ }^{13}$

Normalmente todas as espécies são importantes para o sistema, entretanto algumas unidades, chamadas de reagente principais, tem uma concentração elevada de tal forma que suas variações são imperceptíveis, fazendo com que a dinâmica seja insignificante. As espécies que tem interesse dinâmico são chamadas de intermediárias. Se os intermediários estão no estado estacionário, é possível, então, eliminar todos os reagentes principais e formar uma matriz estequiométrica puramente intermediária. Essa evolui em uma escala de tempo mais rápido e pode apresentar oscilações, multiestabilidades ou outras dinâmicas complexas. ${ }^{13}$

Qualquer modelo estequiométrico pode ser descrito por um conjunto de equações diferenciais de suas espécies intermediárias: ${ }^{73}$

$$
\frac{d[X]}{d t}=N \cdot v
$$

Onde $d[X] / d t$ é a derivada da concentração do vetor das espécies $X$ em função do tempo. O vetor das velocidades de reação é $\mathbf{v}$, já, $\mathbf{N}$, é a matriz dos coeficientes estequiométricos. Nos estados estacionários, as concentrações das espécies são constantes, portanto: ${ }^{73}$

$$
0=N \cdot v_{e e}
$$

$O$ vetor $\mathbf{v}_{\text {ee }}$, que representa $\mathrm{O}$ vetor das taxas de reação no estado estacionário, é uma combinação linear das colunas de uma matriz $\mathbf{E}$, denominada matriz das correntes extremas ${ }^{72}$ com a contribuição de um vetor $\mathbf{j}$, chamado vetor das taxas das correntes extremas. ${ }^{73}$

$$
v_{e e}=E . j
$$

A equação (36) descreve a decomposição dos estados estacionários em parâmetros que são, por definição, positivos. ${ }^{73}$ Tomando qualquer $\mathbf{v}_{\mathrm{ee}}$ constante é 
possível encontrar um vetor $\mathbf{j}$ formado por elementos não negativos, e, por outro lado, qualquer $\mathbf{j}$ positivo gera um vetor $\mathbf{v}_{\mathbf{e e}}$ também positivo. ${ }^{13}$

Diz-se que o vetor $\mathbf{v}_{\text {ee }}$ está em um espaço que contém um cone poliedral convexo, denominado $\mathrm{C}_{\mathrm{v}}$. Analogamente, o conjunto $\mathrm{C}_{\mathrm{v}}$ é como uma pirâmide quadrangular, porém, com um polígono ou poliedro na sua base. Cones não poliedrais, como uma casquinha de sorvete, possuem infinitas arestas enquanto os cones poliedrais possuem arestas finitas. ${ }^{13}$

Um cone convexo tem como propriedade o poder de descrever qualquer $\mathbf{v}_{\mathbf{e e}}$ do cone, como a soma de outros dois $\mathbf{v}_{\text {ee }}$ na fronteira. Isso, se o par de vetores $\mathbf{v}_{\text {ee }}$ for formado apenas por coeficientes positivos, e, a fronteira esteja em uma faceta do cone. A fronteira também é um cone convexo, porém de menor dimensão. Consequentemente, cada $\mathbf{v}_{\text {ee }}$ das fronteiras pode ser descrito pela soma de outros dois vetores em um cone convexo de menor dimensão. Repetir esse processo, eventualmente, vai levar a um cone de menor dimensão possível, as arestas. ${ }^{13}$

Assim, qualquer vetor $\mathbf{v}_{\mathrm{ee}}$ no cone $\mathrm{C}_{\mathrm{v}}$ pode ser descrito como a soma de outros vetores que estão nas arestas do cone $\mathrm{C}_{\mathrm{v}}$. Matematicamente falando, $\mathrm{a}$ equação, $v_{e e}=E . j$, tem o mesmo significado. $O$ vetor das velocidades no estado estacionário pode ser descrito com a soma de colunas da matriz E com a contribuição do vetor positivo j. ${ }^{13}$ As correntes extremas garantem um estado estacionário para cada espécie do sistema. ${ }^{71} \mathrm{Um}$ esquema ilustrando o cone $\mathrm{C}_{\mathrm{v}}$ está representado na figura 18.

O cálculo da matriz das correntes extremas envolve encontrar todas as soluções viáveis de: ${ }^{74}$

$$
V . v=w
$$

A matriz $\mathbf{V}$ é do tipo, $(\mathrm{d}+1) . \mathrm{r}$, onde abaixo de $d$ linhas linearmente independentes da matriz estequiométrica $\mathbf{N}$, existe uma linha de $r$ elementos igual a uma unidade. O vetor $\mathbf{w}$ é definido como, $w=\left[\left(d_{\text {elementos }}=0\right), 1\right]^{T} .^{74}$

A análise da estabilidade dos estados estacionários é executada pela linearização da equação geral do movimento dos estados entornos. ${ }^{73}$ Assim, a linearização se apoia no teorema de Hartman-Grobman, que, de maneira geral, demonstra a equivalência qualitativa de um sistema não linear e sua linearização em 
torno de um ponto específico ${ }^{75}$, desde que os autovalores da matriz de linearização tenham partes reais não nulas. ${ }^{74}$

Figura 18. Os vetores $\mathbf{v}_{\mathbf{e e}}$ formam um espaço tridimensional formado por $\mathbf{v}_{\mathbf{1}}$, $\mathbf{v}_{\mathbf{2}}$ e $\mathbf{v}_{\mathbf{3}}$. Esse espaço pode ser formado pela combinação linear das arestas de um subespaço, formado pelos vetores $\mathbf{E}_{1}$ e $\mathbf{E}_{2}$, da matriz das correntes extremas $\mathbf{E}$. Nesse sistema fictício, os estados estacionários são encontrados apenas no cone das correntes extremas, representado pela área cinza. ${ }^{76}$

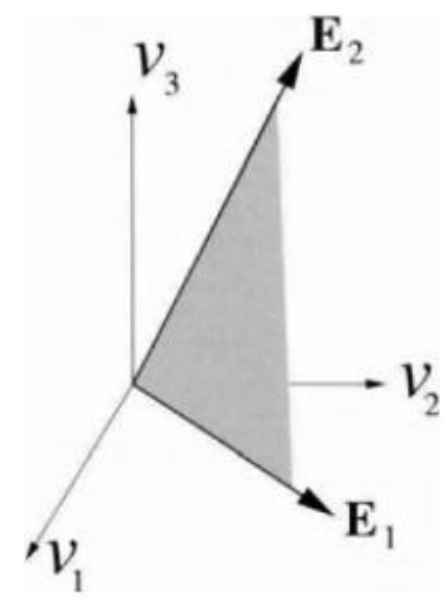

Fonte: DEUTSCH et al., 2004. ${ }^{76}$

A matriz de linearização é uma matriz jacobiana, $\mathbf{M}$, com a seguinte forma: ${ }^{73}$

$$
M\left(h, v_{e e}\right)=N \cdot \operatorname{diag}\left(v_{e e}\right) \cdot Y^{T} \cdot \operatorname{diag}(h)
$$

Usando a relação dada pela equação (9): ${ }^{73}$

$$
M(h, j)=N \cdot \operatorname{diag}(E \cdot j) \cdot Y^{T} \cdot \operatorname{diag}(h)
$$

Onde $\mathbf{h}$ é o vetor dos elementos $h_{\mathrm{i}}$, que indicam as concentrações das $i$ espécies no estado estacionário. A matriz das ordens das reações é chamada de matriz $\mathbf{Y}^{73}$

O estudo de estabilidade do sistema é determinado por $\mathbf{M}$. Se o componente real de todos os autovalores for negativo, o estado estacionário é estável, caso 
contrário, ou seja, se houver um ou mais autovalores positivos, o estado estacionário é instável, o que pode levar a bifurcações nos estados estacionários. Os autovalores de $\mathbf{M}$ são as raízes de seu polinômio característico. ${ }^{73}$

\subsection{TEORIA DAS BIFURCAÇÕES}

Considerando uma equação diferencial, se a variável independente não aparece explicitamente no lado direito, essa equação será classificada como autônoma. ${ }^{77}$ Por exemplo, se existir uma variável dependente do tempo, $x(t)$, como as concentrações de uma espécie durante uma reação, e $f$, a função que descreve tal variação: ${ }^{78}$

$$
\frac{d x}{d t}=f(x)
$$

Como $f$ não apresenta dependência explicita com o tempo, então essa função é autônoma. ${ }^{78}$ Um número real, $c$, é um ponto crítico, ou fixo, da equação (40) se $c$ for um zero de $f$, ou seja, $f(c)=0$. Quando $c$ é um ponto crítico, então, $x(t)=c$ é uma solução constante da equação autônoma e é denominada de solução de equilíbrio. Analisando o sinal da derivada, positivo ou negativo, é possível dizer quando uma solução não constante é crescente ou decrescente, respectivamente. ${ }^{77}$

Quando as soluções não constantes nas vizinhanças de um ponto crítico, $c$, convergem para esse ponto com o decorrer do tempo, os pontos fixos são chamados de atratores ou nós, no caso inverso, se eles divergem, o ponto crítico é um repulsor ou fonte. ${ }^{78} \mathrm{Um}$ diagrama denominado retrato de fase unidimensional, ou apenas retrato de fase, da equação diferencial esclarece a classificação dos pontos críticos, que dependem do comportamento, crescente ou decrescente de seus vizinhos. ${ }^{77}$ Um exemplo desse diagrama está esquematizado na Figura 19. 
Figura 19. Retrato de fase de equação. Nas vizinhanças de c', as soluções crescentes e decrescentes convergem para o ponto crítico, o classificando então, como ponto atrator. Diferente acontece em c", onde as soluções divergem do ponto, agora, repulsor. ${ }^{78}$

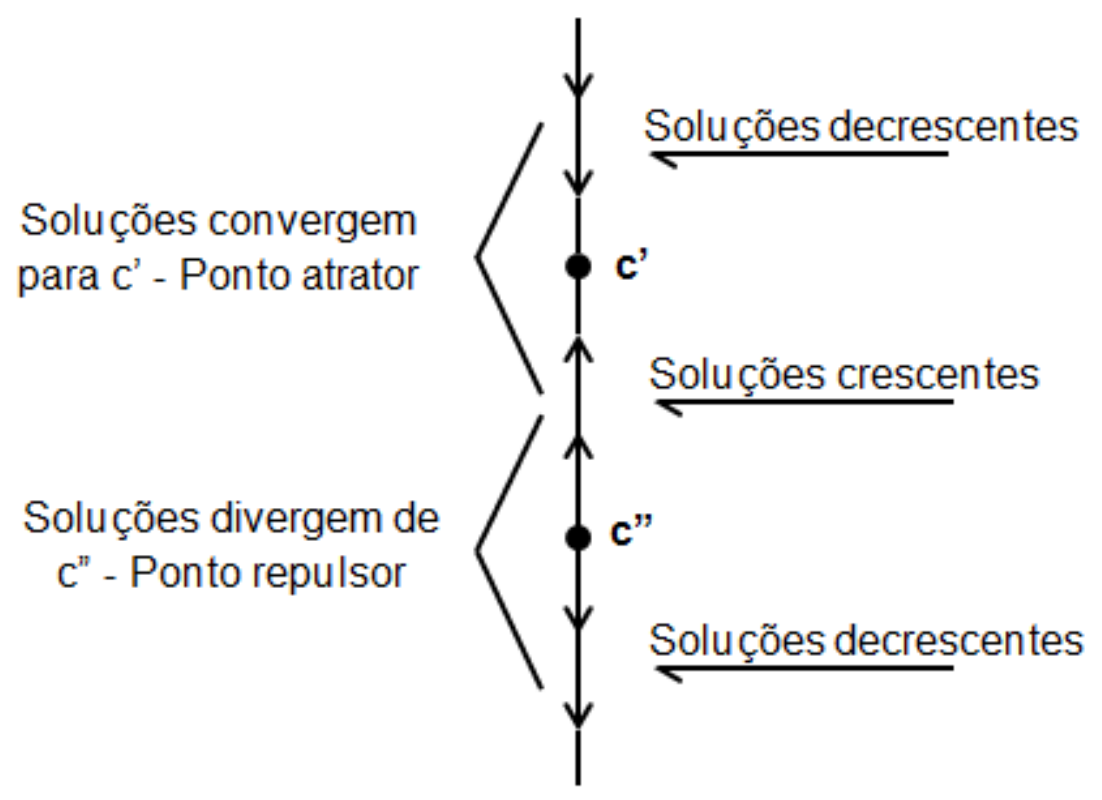

Equações como a (40) podem ser lineares ou não lineares, e são classificadas de acordo com o comportamento do resultado das derivadas. Tomando a equação $d x / d t=f(x)$, se a função tiver a forma $a x+b$, em que $a$ e $b$ são constantes independentes de $t$, por ser uma equação é autônoma, a derivada da função será, $d f / d t=a$. Como o resultado não depende de $x$, a equação é, portanto, linear. Em equações não lineares, o resultado é uma função de $x$, como acontece, por exemplo, nas funções trigonométricas e exponenciais da variável. ${ }^{78}$

Existe a possibilidade de um sistema não linear apresentar mais de um ponto crítico, ocasionando uma particularidade chamada bifurcação. Isso ocorre porque ao variar parâmetros dos pontos fixos, eles podem se unir ou bifurcarem em outros pontos. ${ }^{78}$ No geral, qualquer mudança qualitativa em um ponto crítico pode gerar uma bifurcação, tais alterações podem ser tanto a aniquilação, quanto a criação de novos pontos. Por exemplo, se um modelo apresenta um ponto crítico assintoticamente estável, $c$, regulado por um parâmetro $p$, e se, ao variar $p$ até um valor crítico, $p=p^{*}$, o equilíbrio tornar-se instável, então houve um bifurcação no ponto $\left(x, p^{*}\right){ }^{79}$ 
Dentre os tipos de bifurcações, são de interesse nesse trabalho, as bifurcações de Hopf e as do tipo sela-nó, responsáveis por oscilações e multiestabilidades, respectivamente. ${ }^{78}$

\subsubsection{BIFURCAÇÕES DE HOPF}

O caso mais simples e conhecido para o estudo das bifurcações de Hopf é o sistema bidimensional para as equações do tipo $d x / d t=f(x, \mu)$, ou seja, um sistema de equações diferenciais que dependem de um parâmetro $\mu^{80}$

Considerando as equações diferenciais: ${ }^{80}$

$$
\left(\begin{array}{l}
d x_{1} / d t \\
d x_{2} / d t
\end{array}\right)=\left(\begin{array}{cc}
\mu & -1 \\
1 & \mu
\end{array}\right)\left(\begin{array}{l}
x_{1} \\
x_{2}
\end{array}\right) \pm\left(x_{1}^{2}+x_{2}^{2}\right)\left(\begin{array}{l}
x_{1} \\
x_{2}
\end{array}\right)
$$

Supondo que o ponto de equilíbrio está na origem, $\left(x_{1}, x_{2}\right)=(0,0)$, e A, uma matriz jacobiana de forma,

$$
A=\left(\begin{array}{cc}
\mu & -1 \\
1 & \mu
\end{array}\right)
$$

e autovalores, " $\mu+i$ " e " $\mu-i$ ", ao introduzir uma variável complexa do tipo, $z=x_{1}+$ $i x_{2}$, a equação (42) poderá ser reescrita na sua forma complexa: ${ }^{80}$

$$
\frac{d z}{d t}=(\mu+i) z \pm z|z|^{2}
$$

A variável complexa $z$ pode ser representada como, $z=p e^{i \theta}$, fazendo com que o sistema de equações, $d x / d t=f(x, \mu)$, possa ser escrito na sua forma polar: $:^{80}$

$$
\frac{d p}{d t}=p\left(\mu \pm p^{2}\right)
$$

Quando o termo cúbico de (44) for negativo, por exemplo, é possível a caracterização de um ponto de bifurcação no sistema. Para o parâmetro $\mu$ igual ou menor a zero, existirá, na origem, pontos críticos atratores. Com $\mu>0$, a origem se 
torna um ponto repulsor e ocorre o aparecimento de um órbita fechada, denominada como ciclo limite. É um ciclo único, atrator e centrado na origem. Em outras palavras, quando um parâmetro real do sistema alcança seu valor crítico, ele fica retido em uma órbita atratora e periódica, de periodicidade em função do tempo. ${ }^{80}$

Figura 20. Diagramas de fase de uma bifurcação de Hopf. O comportamento do sistema muda com a variação do parâmetro $\mu$. Para a), $\mu<0$, surge, na origem, um ponto fixo atrator, no gráfico b), $\mu=0$, esse ponto se torna um nó fraco. Em c), $\mu>0$, o foco atrator agora é um ciclo limite. O diagrama d) demonstra a evolução da bifurcação em um espaço $\left(x_{1}, x_{2}, \mu\right) \cdot{ }^{80}$
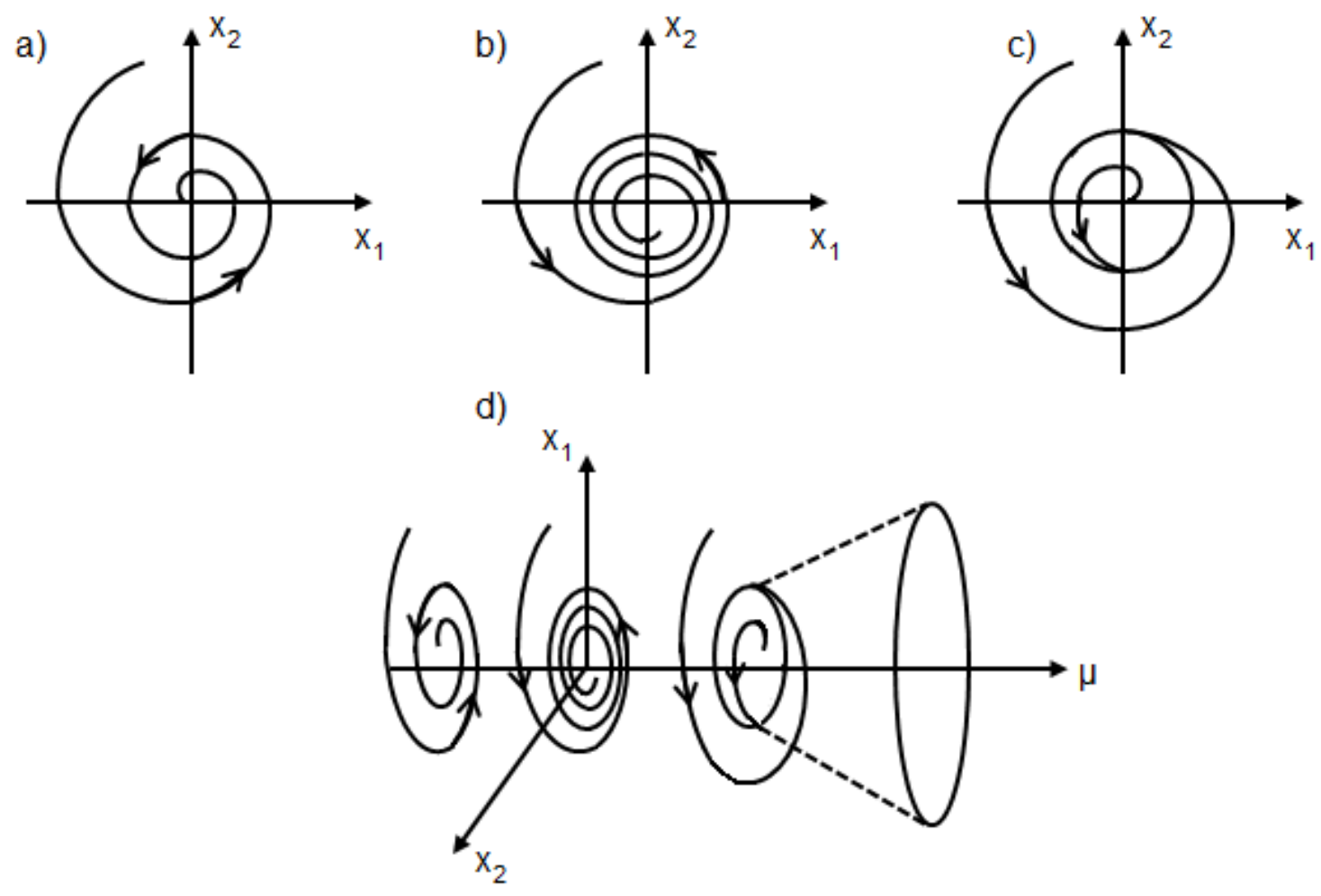

O requisito para o aparecimento de oscilações causadas pelas bifurcações de Hopf é um par de raízes complexas com a parte real positiva na matriz $\mathbf{M}$. Isso significa que o sistema de equações diferenciais apresenta um ponto fixo assintoticamente instável. ${ }^{81} \mathrm{O}$ critério de Routh-Hurwitz fornece a condição necessária e suficiente para identificar se um polinômio apresenta todas as raízes com parte real negativa, logo, se um polinômio não obedece ao critério de RouthHurwitz é um ótimo candidato a possuir uma bifurcação de Hopf. ${ }^{82}$ 
Para verificar se um polinômio segue a regra de Routh-Hurwitz, basta montar determinantes a partir de seus coeficientes. Seja um polinômio, $F(z)=a_{0} z^{n}+$ $a_{1} z^{n-1}+a_{2} z^{n-2}+\cdots+a_{n} z^{0}$, então, esses distintos determinantes menores são possíveis: $:^{82}$

$$
\begin{gathered}
\Delta_{1}=\left|a_{1}\right| \\
\Delta_{2}=\left|\begin{array}{ccc}
a_{1} & a_{3} \\
a_{0} & a_{2}
\end{array}\right| \\
\vdots \\
\Delta_{k}=\left|\begin{array}{cccc}
a_{1} & a_{3} & \cdots & 0 \\
a_{0} & a_{2} & \cdots & 0 \\
0 & a_{1} & \cdots & 0 \\
0 & a_{0} & \cdots & 0 \\
\vdots & \vdots & \vdots & \vdots \\
0 & 0 & \cdots & a_{n}
\end{array}\right|
\end{gathered}
$$

O polinômio não está de acordo com Routh-Hurwitz se algum desses determinantes menores apresentar um valor negativo. Para a análise de SNA é importante que Routh-Hurwitz não seja satisfeito, portanto, encontrar um determinante menor com sinal negativo é fundamental para determinar quais sistemas apresentam oscilações. ${ }^{82}$

\subsubsection{BIFURCAÇÕES DO TIPO SELA-NÓ}

A bifurcação sela-nó é um processo em que pontos críticos são criados ou destruídos, e para isso, varia-se o parâmetro de bifurcação fazendo com que dois pontos se aproximem e colidam, provocando a aniquilação mútua. Para exemplificar o mecanismo, considere a seguinte equação: ${ }^{79}$

$$
\frac{d x}{d t}=f(x, r)=r-x^{2}
$$

Onde $x \in \mathbb{R}$ e $r$, o parâmetro de bifurcação, $\in \mathbb{R}$. Para calcular os pontos de equilíbrio dessa equação basta fazer com que $d x / d t=0$, ou seja, $x= \pm \sqrt{-|r|}$. $^{79}$ 
Quando $r<0$, os pontos críticos são distintos, pois, $x= \pm \sqrt{r}$, apresenta duas raízes. Aproximando $r$ de zero por números negativos, os pontos fixos se colidem $\mathrm{e}$ formam um ponto crítico em $x=0$. Para $r>0$ não existe ponto de equilíbrio real, uma vez que quando, $|r|=r, x$ não possui raízes reais. Ocorre uma bifurcação do tipo sela-nó, quando, ao variar $r$ a partir de zero em direção dos números negativos, o ponto instável, $x=0$, dá origem a dois pontos distintos, um estável e outro instável. A Figura 21 descreve o comportamento das bifurcações. ${ }^{79}$

Figura 21. Diagramas de fase para $d x / d t=r-x^{2}$, quando a) $r=0$, b) $r<0$ e c) $r>0$. O gráfico d) representa um diagrama de bifurcação para a equação, onde as linhas tracejadas e contínuas diferenciam os pontos instáveis e estáveis, respectivamente. $^{79}$

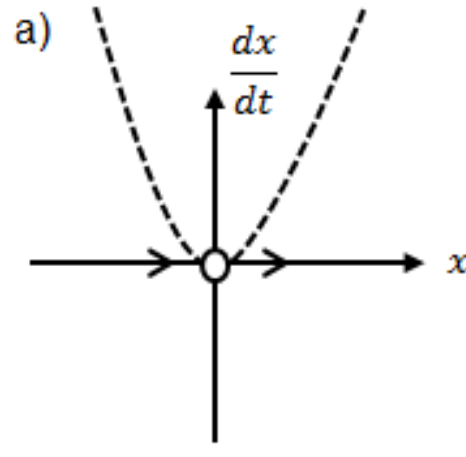

b)

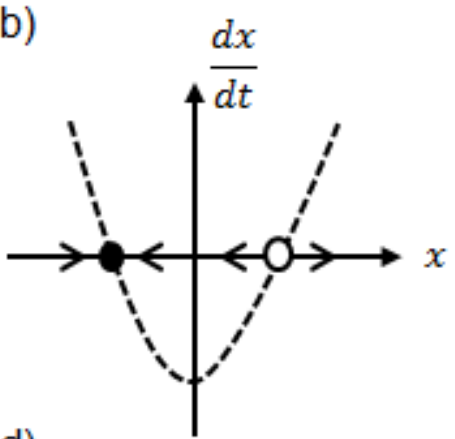

d)

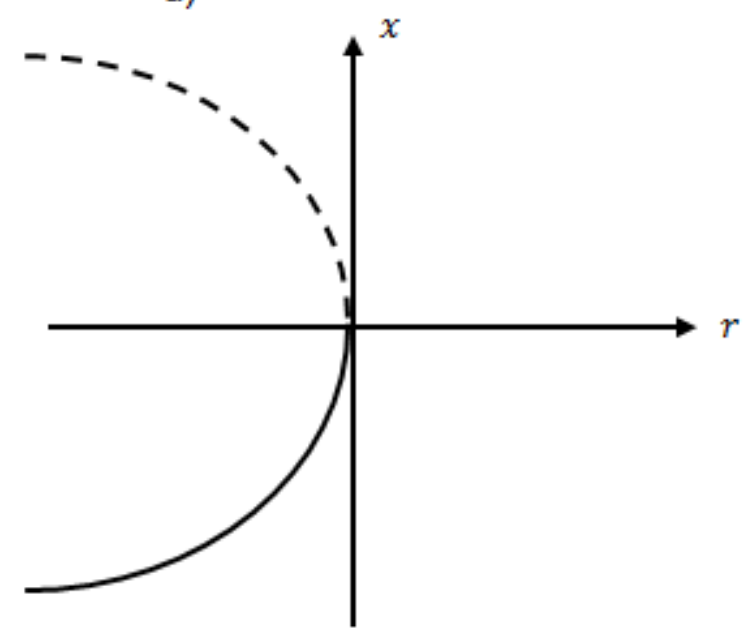

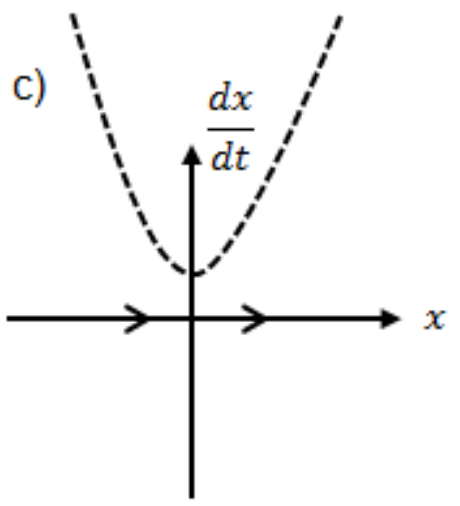


do sistema. No método de SNA, para ocorrer um fenômeno de multiestabilidade, a matriz de linearização, $\mathbf{M}$, deve apresentar uma única, e simples, raiz igual a zero. Essa qualidade é alcançada quando existe, um ou mais componentes negativos no termo independente do polinômio característico de $\mathbf{M}^{81}$

\subsection{ANÁLISE GRÁFICA DA REDE ESTEQUIOMÉTRICA}

A premissa da variante gráfica da SNA é fornecer uma análise gráfica-teórica para investigar condições necessárias para oscilações ou multiestabilidades, levando em conta apenas a estrutura das redes de reações químicas. ${ }^{14}$

Assim, um grafo bipartido deverá ser construído. Um grafo bipartido $G$ de um mecanismo químico é composto por dois conjuntos de vértices distintos, o conjunto de vértices $V_{1}$, das $n$ substâncias químicas, onde $V_{1}=\left\{A_{1}, A_{2}, \ldots, A_{n}\right\}$ e o conjunto $V_{2}$, das $n$ reações químicas, no qual $V_{2}=\left\{B_{1}, B_{2}, \ldots, B_{n}\right\}$. Um segmento é desenhado de $A_{k}$ para $B_{j}$ se e somente se a substância $A_{k}$ for um reagente da reação $B_{j}$, isto é, se o coeficiente estequiométrico, $\alpha_{k j}$, de $A_{k}$ em $B_{j}$, for positivo e não nulo. Similarmente, um arco liga os vértices $B_{j}$ e $A_{i}$ se e somente se $A_{i}$ for um produto da reação $B_{j}$ e $\beta_{j i}$ > 0 . Então o conjunto dos fragmentos, $E(G)$ é composto por $\left(A_{k}, B_{j}\right)$ e $\left(B_{j}, A_{i}\right)$ e um grafo bipartido é $G=\{V, E(G)\} \operatorname{com} V=\left\{V_{1}, V_{2}\right\}{ }^{14}$

Exemplo 1. Considerando a reação hipotética $A+B \stackrel{1}{\rightarrow} C$, com os reagentes, $A$ e $B, \mathrm{e}$ de produto $C$, gerado pela reação 1 , o seguinte grafo bipartido pode ser construído:

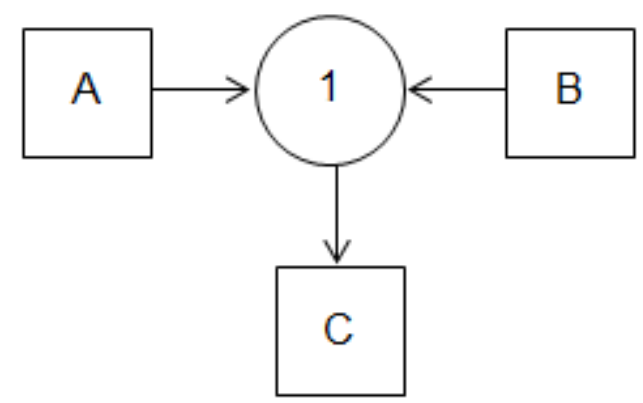

Sendo $\alpha_{k j} \beta_{j i}>1$, os $\operatorname{arcos}\left(A_{k}, B_{j}\right)$ e $\left(B_{j}, A_{i}\right)$ formam um caminho positivo $\left[A_{k}, B_{j}, A_{i}\right]$, que corresponde a produção de $A_{i}$ pelo reagente $A_{k}$, por intermédio da reação $B_{j}$. Semelhantemente, se $\alpha_{k j} \alpha_{i j}>1$, os $\operatorname{arcos}\left(A_{k}, B_{j}\right)$ e $\left(A_{i}, B_{j}\right)$ formam dois 
caminhos negativos distintos, $\left[\begin{array}{llllll}A_{k} & B_{j}, & A_{i}\end{array}\right]$ e $\left[\begin{array}{llll}A_{i} & B_{j} & A_{k}\end{array}\right]$ (o sublinhado identifica caminhos negativos), uma vez que $\alpha_{\mathrm{ij}} \alpha_{\mathrm{kj}}$ também é maior que uma unidade. ${ }^{14}$ Assim, no exemplo $1,[A, 1, C]$ e $[B, 1, C]$, formam dois caminhos positivos e $[A, 1, B]$ e $[B, 1$, A], outros dois caminhos negativos, totalizando quatro caminhos para o sistema. Um segmento $\left(A_{k}, B_{j}\right)$ que não forma um caminho em $G$, é denominados como uma aresta $\left[A_{k}, B_{j}\right] .^{14}$

Um ciclo $C$ de $G$ é uma sequência de caminhos distintos onde o último vértice $V_{1}$ inicia o caminho seguinte, assim, $\left\{\left[A_{1}, B_{1}, A_{2}\right],\left[A_{2}, B_{2}, A_{3}\right], \ldots,\left[A_{k-1}, B_{k-1}, A_{k}\right],\left[A_{k}\right.\right.$, $\left.\left.B_{k}, A_{1}\right]\right\}$, configura um ciclo. Um caso especial de ciclo são as reações autocatalíticas. Na reação $A+X \underset{\rightarrow}{\rightarrow} A$, existe um ciclo formado pelo caminho positivo $[\mathrm{A}, 1, \mathrm{~A}] .^{14}$

Um ciclo é denotado por,

$$
C=\left(\begin{array}{cccc}
A_{1} & A_{2} & \cdots & A_{k} \\
B_{1}, & B_{2} & \cdots & B_{k}
\end{array}\right)
$$

e o número de vértices $V_{1}$ determina a ordem do ciclo. ${ }^{14}$

Exemplo 2. Um ciclo $C_{1}$ pode ser composto, por exemplo, pelo caminho positivo $\left[A_{1}, B_{1}, A_{2}\right]$ e pelo negativo, $\left[\underline{A}_{2}, \underline{B}_{2}, A_{1}\right]$, nota-se que a direção da seta não determina o ciclo. Os caminhos negativos $\left[\underline{A}_{1}, \underline{B}_{1}, A_{2}\right]$ e $\left[\underline{A}_{2}, B_{1}, A_{1}\right]$ formam um ciclo $C_{2}$, mesmo que não aparente visualmente. ${ }^{14}$

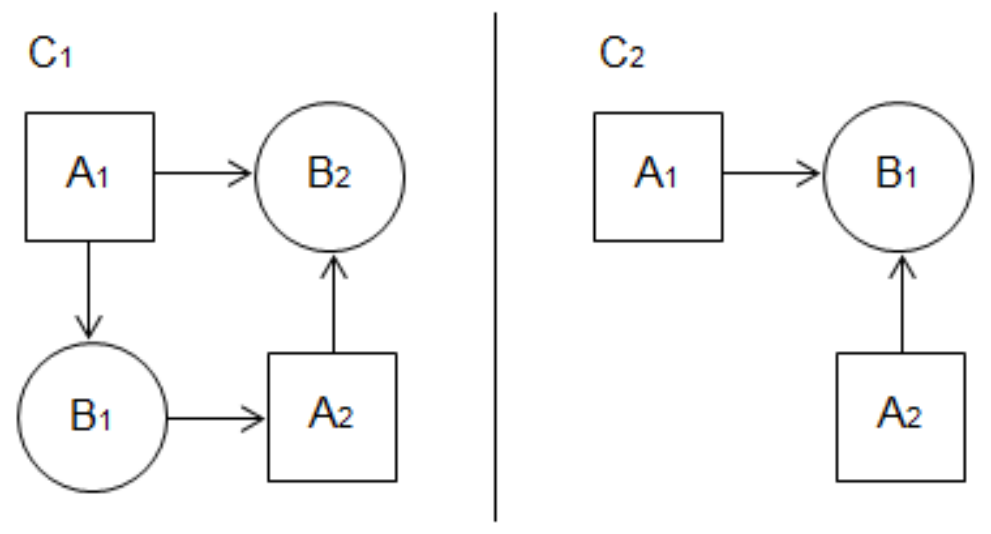


Um ciclo é positivo se contém números pares de caminhos negativos, e negativos se apresenta números ímpares de caminhos negativos. Para o exemplo 2 , $\mathrm{C}_{1}$ é um ciclo negativo e $\mathrm{C}_{2}$, positivo. ${ }^{14}$

Um subgrafo g é composto por ciclos e arestas de $\mathrm{G}$, mutuamente disjuntos, assim, $g=\left\{C_{1}, C_{2}, \ldots, C_{s}\right\}$, onde $C_{i}$ é um ciclo $C_{i}$ ou uma aresta $E_{i}$ de $G$, com $i=$ $1,2, \ldots, s$, onde cada vértice $V_{1}$ é o início de um único caminho ou aresta. $O$ número de vértices $V_{1}$ determina a ordem do subgrafo. Em um subgrafo o mesmo vértice $V_{2}$ pode ser visitado mais de uma vez. ${ }^{14}$

$\mathrm{O}$ conjunto de subgrafos $\mathrm{g}$, de mesma ordem $\mathrm{k}$ e com o mesmo conjunto de vértices $V_{1}=\left\{A_{1}, A_{2}, \ldots, A_{n}\right\}$ e $V_{2}=\left\{B_{1}, B_{2}, \ldots, B_{n}\right\}$, é chamado de fragmento $\mathrm{S}$ de ordem $\mathrm{k}$ e é denotado por: ${ }^{14}$

$$
S_{k}=\left(\begin{array}{cccc}
1 & 2 & \cdots & k \\
1 & 2 & \cdots & \cdots \\
1 & & k
\end{array}\right)
$$

Exemplo 3. Um fragmento $S_{2}=\left(\begin{array}{c}A \\ 1\end{array}, \begin{array}{l}B \\ 1\end{array}\right)$, de uma reação $A+B \stackrel{1}{\rightarrow} C$, possui dois subgrafos, $g_{1}=\left\{C_{1}\right\}=\left(\begin{array}{c}A \\ 1\end{array}, \begin{array}{l}B \\ 1\end{array}\right)$, formado pelos caminhos negativos $[\mathrm{A}, 1, \mathrm{~B}]$ e $[\mathrm{B}, 1, \mathrm{~A}]$ e $g_{2}=\left\{E_{1}, E_{2}\right\}=[A, 1],[B, 1]$. Apesar de matematicamente diferentes, os dois subgrafos são graficamente semelhantes: ${ }^{14}$
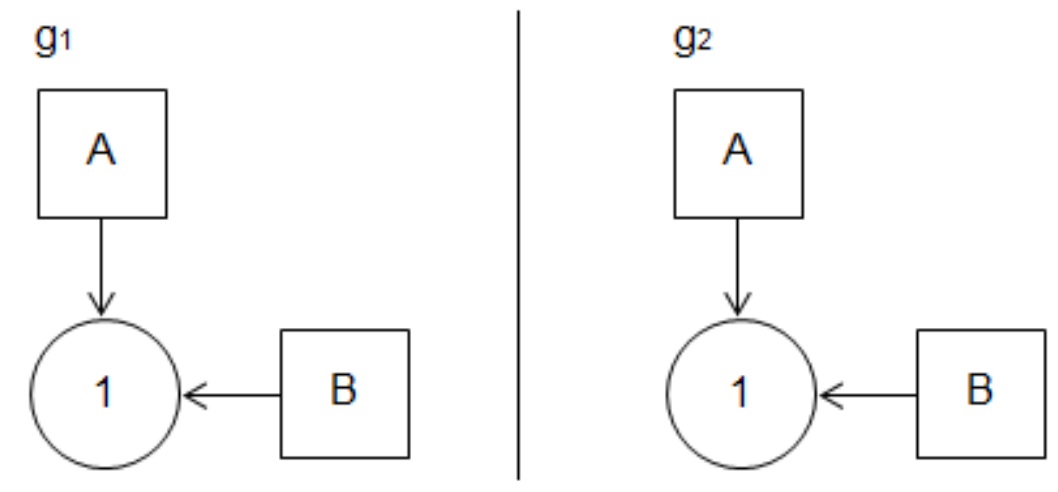

Um fragmento $S_{k}=\left(\begin{array}{l}1 \\ 1\end{array}, 2, \ldots, k\right), k$ é chamado crítico quando o coeficiente $K_{S_{k}}<0$, com: ${ }^{14}$

$$
K_{S_{k}}=\sum_{g \in S_{k}} K_{g}
$$


Onde o coeficiente $\mathrm{K}_{\mathrm{g}}$ é a soma dos produtórios das arestas e ciclos de $\mathrm{g}$,

$$
K_{g}=(-1)^{t_{g}}\left(\prod_{\left[A_{k}, B_{j}\right] \in g} \alpha_{k j}^{2} \prod_{C \in g} K_{C}\right)
$$

onde $t_{g}$ é a quantidade de ciclos g. $\mathrm{O}$ coeficiente $\mathrm{K}_{\mathrm{c}}$ é dado pela soma dos seguintes produtórios,

$$
K_{C}=\prod_{\underline{\left[A_{k}, B_{j}, A_{i}\right]} \in C}\left(-\alpha_{k j} \alpha_{i j}\right) \prod_{\left[A_{k}, B_{j}, A_{i}\right] \in C}\left(\alpha_{k j} \beta_{j i}\right)
$$

sendo os elementos $\alpha_{i j}$ e $\beta_{i j}$, a quantidade de espécies $X_{i}$ na reação $R_{j}$, como na reação (33). ${ }^{14}$

Assim $\mathrm{K}_{\mathrm{g}}<0$ se e somente se em $\mathrm{g}$ existir um número ímpar de ciclos positivos, uma vez que $K_{c}>0$ se $C$ for um ciclo positivo, e $K_{c}<0$, se $C$ for um ciclo negativo. Então, a condição necessária para um fragmento crítico é a existência de um subgrafo com números ímpares de ciclos positivos. Essa condição não é suficiente para fragmentos críticos. No exemplo $3 \circ$ fragmento $S_{2}$ contém dois subgrafos, $\quad K_{g_{1}}=(-1)\left(-\alpha_{A 1} \alpha_{B 1}\right)\left(-\alpha_{B 1} \alpha_{A 1}\right)=-1$ e $K_{g_{2}}=(-1)^{0}\left(\alpha_{A 1}{ }^{2}\right)\left(\alpha_{B 1}{ }^{2}\right)=1$, fazendo com que $K_{S_{2}}=-1+1=0$. O subgrafo $g_{1}$ é composto apenas por um ciclo positivo, pois esse contém dois caminhos negativos, e por isso contempla a condição necessária para fragmento crítico, porém não possui a condição suficiente. $^{14}$

Para a variante gráfica da SNA um fragmento crítico é necessário para o surgimento de dinâmicas complexas. Um fragmento crítico $S_{r}$ de $G$ é a condição necessária para multiestabilidades e um fragmento crítico $S_{k}$, com $k \leq 1<r$, para oscilações, sendo r o posto da matriz estequiométrica da rede de reações químicas. 14 


\section{METODOLOGIA}

A análise de SNA foi aplicada por um algoritmo construído no software Maxima 14.12.1, um software livre, para computação algébrica, licenciado pela GNU General Public License. Nas redes que contém oscilações, aplicou-se o critério de Routh-Hurwitz para avaliar a estabilidade da matriz linearizada. Os gráficos foram traçados, no software Maxima, resolvendo as equações cinéticas para cada modelo. Nos sistemas oscilatórios, utilizou-se o método Runge Kutta para construir os gráficos de evolução temporal. Todos os cálculos foram feitos em um computador de processador Inte/® Core $^{\mathrm{TM}}$ i3-3110M, CPU de 2,4 GHz e 4,0 GB de memória RAM. 


\section{RESULTADOS E DISCUSSÕES}

\subsection{OSCILAÇÕES NO MENOR MODELO TEÓRICO: UM CASO CLÁSSICO}

O modelo teórico demonstrado na equação (20) é considerado o menor sistema contendo bifurcação de Hopf, condição que gera uma dinâmica instável oscilatória na rede:

$$
\begin{aligned}
& X+A \stackrel{k_{1}}{\rightarrow} 2 X \\
& X+Y \stackrel{k_{2}}{\rightarrow} A+Y \\
& X \stackrel{k_{3}}{\rightarrow} Z \\
& Z \stackrel{k_{4}}{\rightarrow} Y \\
& Y \stackrel{k_{5}}{\rightarrow} A
\end{aligned}
$$

Existem duas aproximações para esse problema, a clássica, onde a espécie $A$ é um reagente principal, cuja concentração é tão elevada que se mantém constante durante a reação. E outra, menos comum, onde a espécie $A$ participa ativamente da reação, sendo uma das espécies intermediárias. Para o primeiro caso, as equações cinéticas são:

$$
\begin{gathered}
\frac{d[X]}{d t}=k_{1}[X]-k_{2}[X][Y]-k_{3}[X] \\
\frac{d[Y]}{d t}=k_{4}[Z]-k_{5}[Y] \\
\frac{d[Z]}{d t}=k_{3}[X]-k_{4}[Z]
\end{gathered}
$$

A matriz estequiométrica para a abordagem clássica do sistema é:

$$
N=\left[\begin{array}{ccccc}
1 & -1 & -1 & 0 & 0 \\
0 & 0 & 0 & 1 & -1 \\
0 & 0 & 1 & -1 & 0
\end{array}\right]
$$

O posto matricial, ou seja, a quantidade de linhas não nulas independentes, é igual a três, e para esse sistema, significa que não existe condição de conservação. 
A quantidade de condições de conservação pode ser facilmente calculada subtraindo a quantidade de linhas da matriz estequiométrica pelo posto matricial.

Resolvendo a equação (36), $v_{e e}=E . j$, para o modelo, é possível encontrar a matriz das correntes extremas, E, ou seja, a matriz que representa as reações mínimas do sistema, onde cada coluna é uma reação elementar e as linhas representam as equações que formam o subespaço dos estados estacionários:

$$
E=\left(\begin{array}{ll}
1 & 1 \\
1 & 0 \\
0 & 1 \\
0 & 1 \\
0 & 1
\end{array}\right)
$$

Cada vetor da matriz das correntes extremas pode ser representado graficamente, e para a equação (54), tem-se:

Figura 22. Representação gráfica das correntes extremas apresentadas em (54). $O$ vetor $E_{1}=\left(\begin{array}{lllll}1 & 1 & 0 & 0 & 0\end{array}\right)^{T}$ contém as reações as duas primeiras reações de (20). Enquanto $E_{2}=\left(\begin{array}{lllll}1 & 0 & 1 & 1 & 1\end{array}\right)^{T}$, todas, exceto a segunda. As correntes extremas devem exibir a conservação das espécies, formando um ciclo.

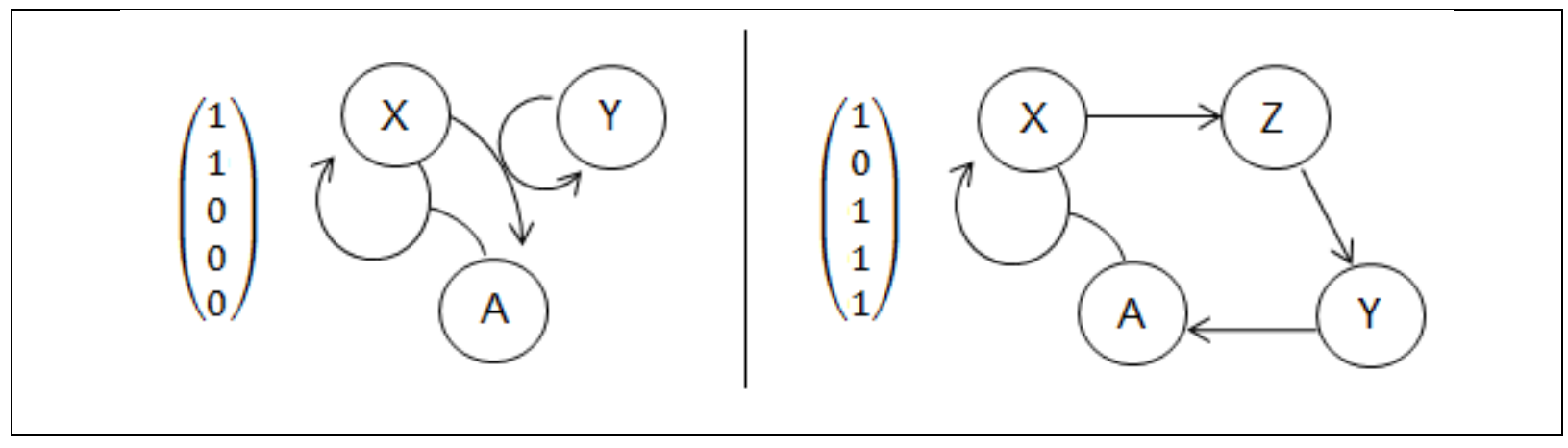

Das correntes extremas é possível aferir dois parâmetros, o vetor $\boldsymbol{j}$, dos caminhos das reações, em que cada elemento representa um vetor das correntes extremas, e um vetor $\boldsymbol{h}$, onde cada elemento é o inverso da concentração, no estado estacionário, de uma espécie participante da reação: 


$$
x=\frac{1}{\left[X_{e e}\right]}
$$

Para a matriz E em (54), $j=(h, i)^{T}$, pois a matriz das correntes extremas é composta por dois vetores, e $h=(x, y, z)^{T}$, uma vez que as espécies $\mathrm{X}, \mathrm{Y}$ e $\mathrm{Z}$ são os reagentes intermediários da rede. Com esses parâmetros, as constantes cinéticas de cada reação podem ser equacionadas. Fazendo $k_{r}=(E \cdot j)_{r} \prod_{i=1}^{n} h_{i}{ }^{Y}$, onde $\mathbf{Y}$ é a matriz das ordens das reações,

$$
\begin{gathered}
k_{1}=(h+i) x \\
k_{2}=(h) x y \\
k_{3}=(i) x \\
k_{4}=(i) z \\
k_{5}=(i) z
\end{gathered}
$$

Linearizar o sistema é construir uma matriz das jacobianas, $\mathbf{M}$, referente à concentração das espécies no estado estacionário. Tal matriz é uma contribuição das correntes extremas e os parâmetros de bifurcação, e pode ser calculada pela equação, $M(h, j)=N \cdot \operatorname{diag}(E \cdot j) \cdot Y^{T} \cdot \operatorname{diag}(h)$ :

$$
M=\left[\begin{array}{ccc}
0 & -h y & 0 \\
0 & -i y & i z \\
i x & 0 & -i z
\end{array}\right]
$$

A condição para oscilações é um par de raízes complexas com a parte real positiva na matriz $\mathbf{M}$. As raízes são calculadas fazendo o polinômio característico da matriz e para (57) o polinômio característico é:

$$
m^{3}+(i z+i y) m^{2}+\left(i^{2} y z\right) m+i^{2} x h y z
$$

Encontrar um par de raízes complexas com parte real positiva não é um cálculo trivial, por isso, usa-se o critério de Routh-Hurwitz para verificar a estabilidade do polinômio característico da matriz $\mathbf{M}$ de um sistema. Uma matriz de Routh-Hurwitz será instável, com dinâmicas não lineares, se apresentar um 
determinante menor que zero. A matriz de Routh-Hurwitz e seu determinante, para (58), são:

$$
\begin{gathered}
R=\left[\begin{array}{cc}
i z+i y & i^{2} x h y z \\
1 & i^{2} y z
\end{array}\right] \\
|R|=i^{3} y z^{2}+i^{3} y^{2} z-i^{2} x h y z
\end{gathered}
$$

Para a análise de SNA, o determinante de Routh-Hurwitz deve ser negativo. Como os parâmetros de bifurcação, ou seja, os elementos dos vetores j e $\mathbf{h}$, são por definição, sempre positivos, encontrar um termo negativo em $|R|$ é fundamental para verificar instabilidades. Assim, para (59), deve existir um conjunto de parâmetros $(h, i, x, y, z)$ que garantam um determinante negativo. Fazendo,

$$
\begin{gathered}
h=0.1 \\
i=0.01 \\
x=0.1 \\
y=0.1 \\
z=0.1
\end{gathered}
$$

o determinante em (59) será negativo, e isso assegura um par de raízes complexas com parte real positiva em (58). Com a condição necessária e suficiente para oscilações alcançada, substitui-se os parâmetros de (60) nas constantes cinéticas em (56).

$$
\begin{aligned}
& k_{1}=0.011 \\
& k_{2}=0.001 \\
& k_{3}=0.001 \\
& k_{4}=0.001 \\
& k_{5}=0.001
\end{aligned}
$$

Assim, a dinâmica oscilatória deve ser observada resolvendo as equações cinéticas do sistema. 
Figura 23. Comportamento oscilatório na concentração da espécie $X$ em função do tempo. Com $\mathrm{k}_{1}=0.011$ e $\mathrm{k}_{2}=\mathrm{k}_{3}=\mathrm{k}_{4}=\mathrm{k}_{5}=0.001$.

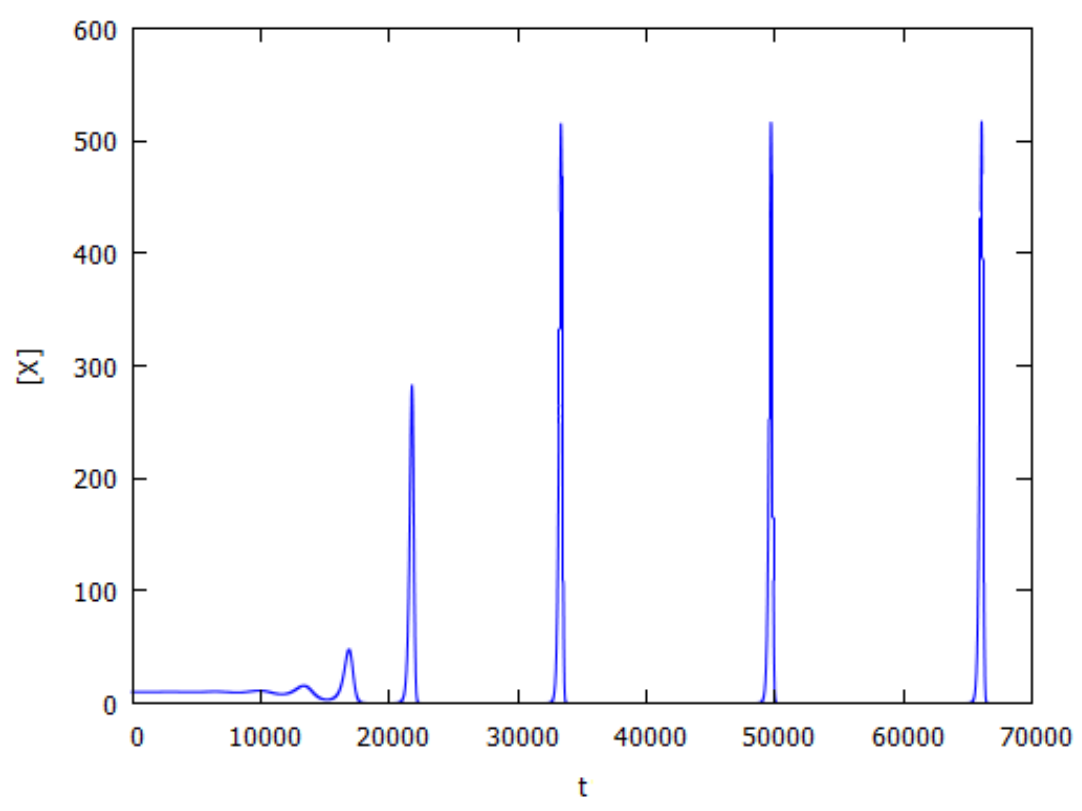

A reação autocatalítica é fundamental para oscilações no modelo. A concentração de $X$ aumenta numa taxa de $k_{1}[X]$ e diminui de acordo com, $k_{2}[X][Y]+k_{3}[X]$. Como $k_{1} \gg k_{2}+k_{3}$, a princípio, a concentração de $X$ irá crescer, até que em algum momento, suas taxas de produção e consumo serão iguais, isso, pois, a contribuição de $[Y]$ será suficiente grande para tal. No instante seguinte, a concentração de $X$ irá diminuir, uma vez que a taxa de consumo de $X$ será maior que de sua produção. As dinâmicas de $Z$ e $Y$ seguem a de $X$, então, apresentam o mesmo comportamento. $O$ decréscimo de $[X]$ será seguido por $[Z]$ e depois $[Y]$, permitindo que as oscilações ocorram.

Quando $k_{1}=k_{2}=k_{3}=k_{4}=k_{5}=0.001$ não é possível observar oscilações. A dinâmica é estável, também, quando $k_{1} \ll k_{2}+k_{3}$. A frequência entre os picos pode ser controlada alterando as constantes de equilíbrio químico. Quanto menor a diferença entre $k_{1}$ e $k_{2}+k_{3}$, maior será a frequência das ondas. 
Figura 24. Cima. A dinâmica oscilatória é extinta quando $k_{1}=k_{2}=k_{3}=$ $k_{4}=k_{5}=0.001$, evoluindo rapidamente para o estado estacionário, onde ocorre $\circ$ desaparecimento da espécie $X$ pelo escoadouro $A$. Baixo. A frequência entre as oscilações é alterada ao modificar as constantes cinéticas, para esse modelo, quando menor a diferença entre $k_{1}$ e $k_{2}+k_{3}$, maior a frequência, até que as constantes se igualem e o sistema perca a capacidade oscilatória.
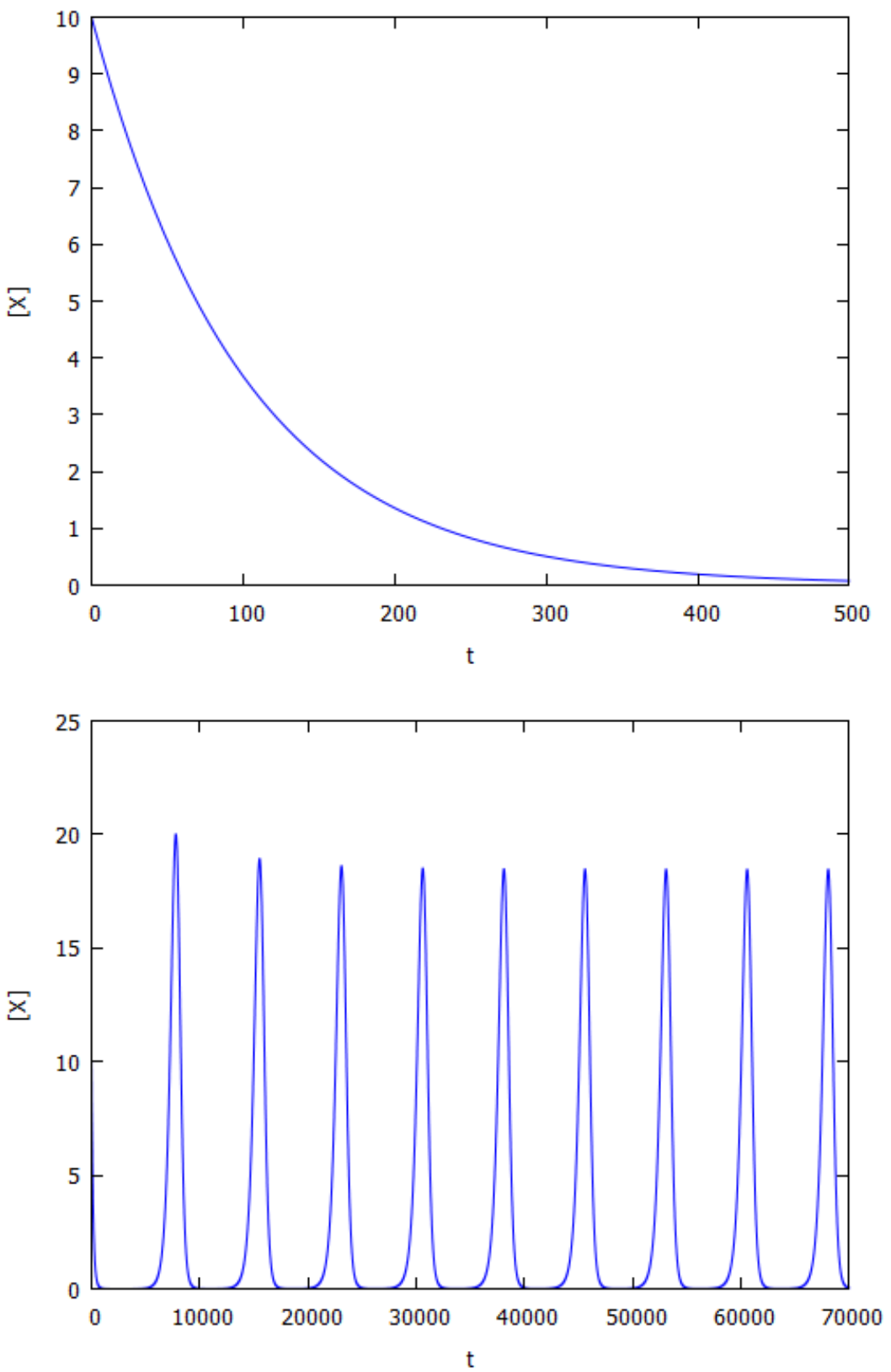
Pela variante gráfica, pode-se encontrar a condição necessária para oscilações. O posto matricial de (53) é $r=3$, e por isso, é necessário um fragmento crítico, de ordem dois ou um. O fragmento $S_{1}=\left(\begin{array}{l}X \\ 1\end{array}\right)$ é um ótimo candidato para alcançar a qualidade de crítico, pois esse apresenta um número ímpar de ciclos positivos.

Figura 25. O fragmento $S_{2}=\left(\begin{array}{l}X \\ 1\end{array}\right)$ é composto por dois subgrafos, $g_{1}=C=[X, 1, X] \mathrm{e}$ $g_{2}=[X, 1]$. Como, $K_{S_{1}}=g_{1}+g_{2}=-2+1-1$, o fragmento é crítico.

$\mathrm{S}_{2}$

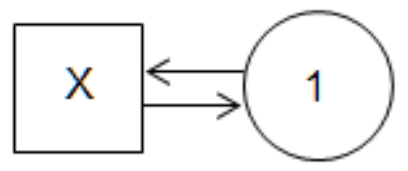

$g_{2}$

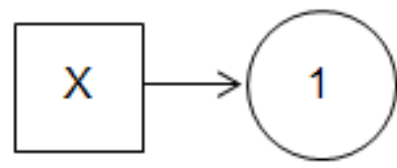

$g_{1}$

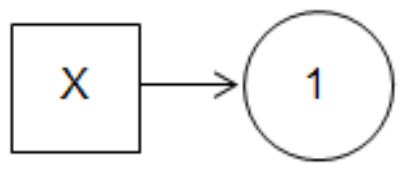

No entanto, a reação autocatalítica sozinha não é responsável pela dinâmica complexa, a reação de retroalimentação negativa também é necessária, e isso pode ser confirmada pela análise gráfica de SNA.

Figura 26. $O$ fragmento $S_{2}=\left(\begin{array}{l}X \\ 2\end{array}, \frac{Y}{2}\right)$ contém três subgrafos distintos, $g_{1}=C=([\mathrm{X}, 2, \mathrm{Y}],[\mathrm{Y}, 2, \mathrm{X}]), g_{2}=[C=([Y, 2, Y])],[X, 2]$ e $g_{3}=[X, 2],[Y, 2]$. Um fragmento é crítico quando $K_{S_{k}}<0$. Assim, $K_{S_{2}}=g_{1}+g_{2}+g_{3}=-1-1+1=-1$.

$\mathrm{S}_{2}$

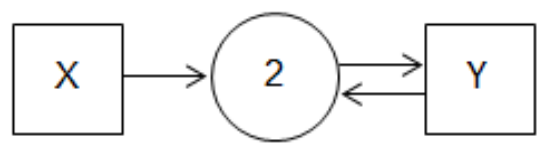

$g_{2}$

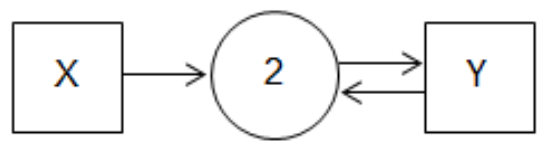

g1

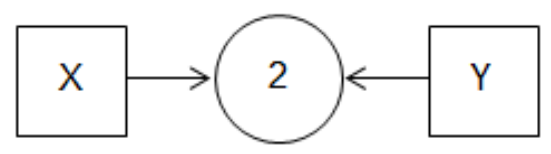

g3

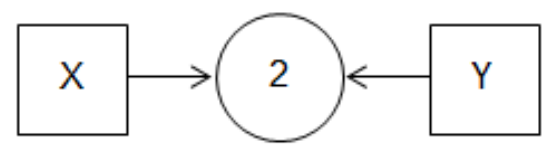




\subsection{OSCILAÇÕES NO MENOR MODELO TEÓRICO: UM CASO EXTRAORDINÁRIO}

Um caso extraordinário do menor modelo contendo bifurcação de Hopf é considerar a espécie $A$ como uma espécie intermediária, participando ativamente da dinâmica da rede de reações, assim, a matriz estequiométrica de sua rede é:

$$
N=\left[\begin{array}{ccccc}
1 & -1 & -1 & -1 & 0 \\
0 & 0 & 0 & 1 & -1 \\
0 & 0 & 1 & -1 & 0 \\
-1 & 1 & 0 & 0 & 1
\end{array}\right]
$$

Seu posto matricial é $r=3$, isso significa que a matriz estequiométrica é composta por três linhas linearmente independentes, e uma das linhas é uma combinação linear das outras três. A condição de conservação é, então, a diferença entre o posto matricial e a quantidade de linhas da matriz. Assim, a rede apresenta uma condição de conservação. Para descobrir quais espécies se conservam no sistema, somam-se as linhas da matriz, até que o resultado dê nulo. Em (62), somando as quatro linhas, o resultado é um vetor nulo, como cada linha da matriz estequiométrica equivale a uma espécie do sistema, a condição de conservação é $[X]+[Y]+[Z]+[A]=$ constante.

As equações diferenciais são:

$$
\begin{gathered}
\frac{d[X]}{d t}=k_{1}[A][X]-k_{2}[X][Y]-k_{3}[X] \\
\frac{d[Y]}{d t}=k_{4}[Z]-k_{5}[Y] \\
\frac{d[Z]}{d t}=k_{3}[X]-k_{4}[Z] \\
\frac{d[A]}{d t}=k_{2}[X][Y]+k_{5}[Y]-k_{1}[X][A]
\end{gathered}
$$

Uma segunda forma de calcular a condição de conservação é somar as equações diferencias. Portanto, $d[X] / d[t]+d[Y] / d[t]+d[Z] / d[t]+d[A] / d[t]=0$. As duas abordagens apresentam o mesmo conjunto de correntes extremas, logo, espera-se, que se uma reação apresentar uma dinâmica complexa, sua análoga 
também deve possuir. Isso é possível, pois, cada matriz das correntes extremas é única e representa propriedades características e, por isso, duas redes de reações com as mesmas correntes extremas apresentam uma dinâmica semelhante. Após a parametrização, encontraram-se as dinâmicas oscilatórias das espécies:

Figura 27. Comportamento oscilatório na concentração da espécie $X$ em função do tempo quando $k_{1}=0.0011, k_{2}=0.1, k_{3}=0.01, k_{4}=0.001 e k_{5}=0.01$.

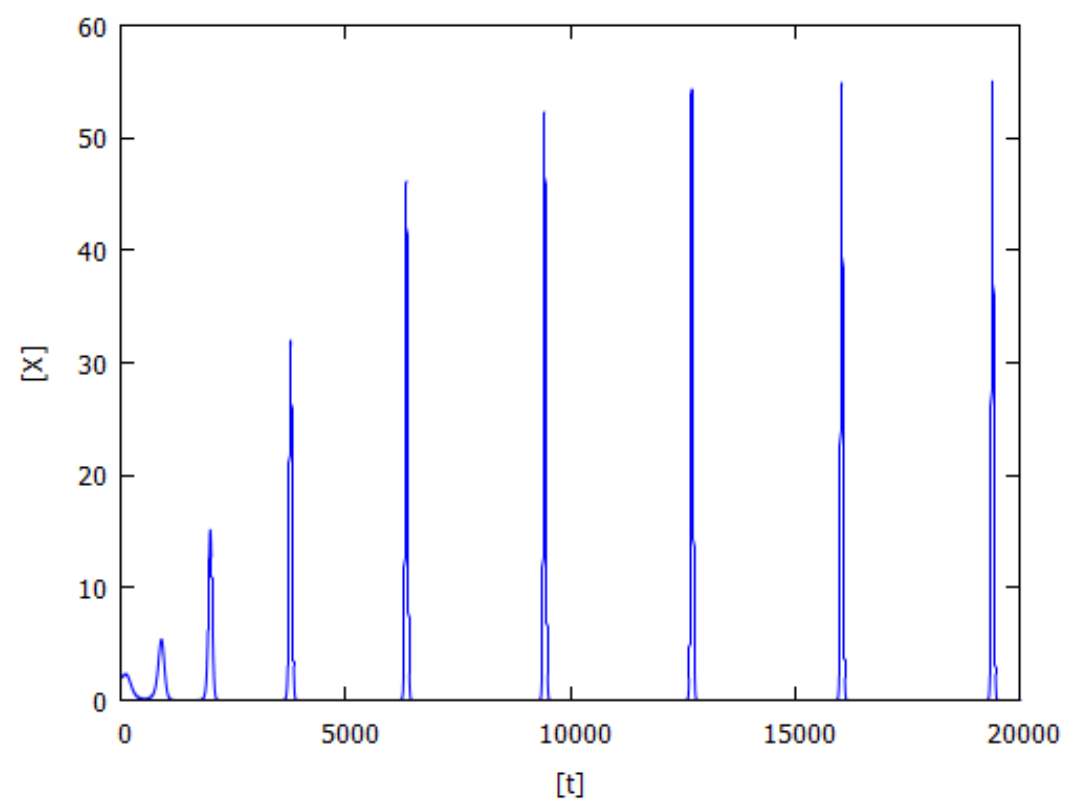

Como esperado, por terem as mesmas correntes extremas, também foram encontradas oscilações no sistema em que a espécie $A$ participa diretamente da reação. É possível projetar um gráfico que relaciona a evolução temporal de duas espécies, como na próxima figura.

As espécies partem da sua concentração inicial, no ponto (9,2), expressas em unidades arbitrárias, e oscilam ao longo do tempo, até alcançarem uma órbita atratora, chamada de ciclo limite. A dinâmica fica retida no ciclo limite, orbitando ao longo do seu perímetro, até que alguma perturbação no sistema modifique sua dinâmica. 
Figura 28. Comportamento oscilatório na concentração das espécies $X$ e $Z$ em função do tempo quando $k_{1}=0.0011, k_{2}=0.1, k_{3}=0.01, k_{4}=0.001$ e $k_{5}=0.01$. As espécies oscilam no quadrante positivo, pois os parâmetros de bifurcação garantem que as espécies possuam concentrações sempre maiores que zero.

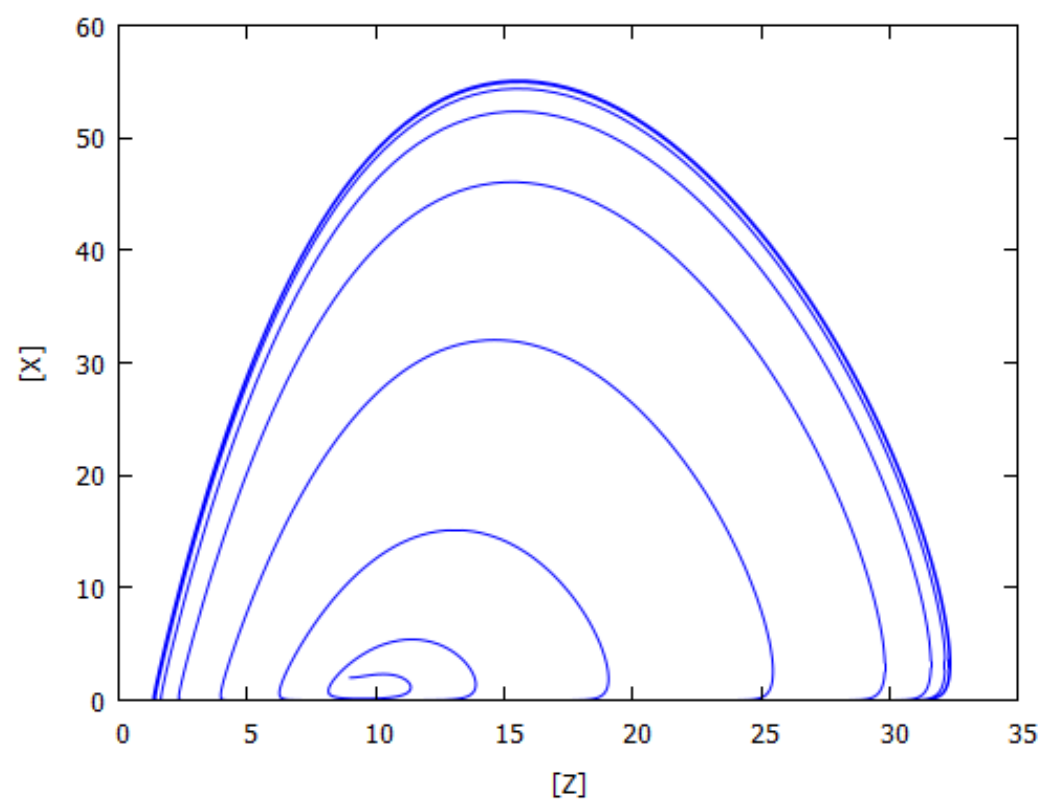

\subsection{OSCILAÇÕES NO MENOR MODELO CÍCLICO TEÓRICO}

O sistema demonstrado em (21) representa o menor modelo cíclico que contém oscilações:

$$
\begin{gathered}
A \stackrel{k_{1}}{\rightarrow} B \\
B \stackrel{k_{2}}{\rightarrow} C \\
C \stackrel{k_{3}}{\rightarrow} D \\
D \stackrel{k_{4}}{\rightarrow} E \\
E+A \stackrel{k_{5}}{\rightarrow} 2 A
\end{gathered}
$$


Sua matriz estequiométrica possui posto matricial, $r=4$, e por isso possui apenas uma condição de conservação, $[A]+[B]+[C]+[D]+[E]=$ constante. Sua matriz $\mathbf{N}$ possui a seguinte forma:

$$
N=\left[\begin{array}{ccccc}
-1 & 0 & 0 & 0 & 1 \\
1 & -1 & 0 & 0 & 0 \\
0 & 1 & -1 & 0 & 0 \\
0 & 0 & 1 & -1 & 0 \\
0 & 0 & 0 & 1 & -1
\end{array}\right]
$$

A análise gráfica de sua estequiometria fornece a condição necessária para instabilidades. Tendo posto matricial igual a quatro, para haver oscilações, deve existir um fragmento crítico que contenha de um a três vértices $V_{1}$, vértices, esses, que indicam as espécies no grafo bipartido. Um fragmento pode ser crítico se, nos subgrafos que o compõe, existir um número ímpar de ciclos positivos. Sendo assim, o fragmento $S_{1}=\left(\begin{array}{c}A \\ 5\end{array}\right)$ corresponde à condição necessária.

Figura 29. O fragmento $S_{2}=\left(\begin{array}{c}A \\ 5\end{array}\right)$, constituído por dois subgrafos diferentes, $g_{1}=C=[A, 5, A]$ e $g_{2}=[A, 5]$. Para ser considerado crítico, um fragmento deve apresentar $K_{S_{k}}<0$. Assim, $K_{2}=g_{1}+g_{2}=-2+1=-1$.

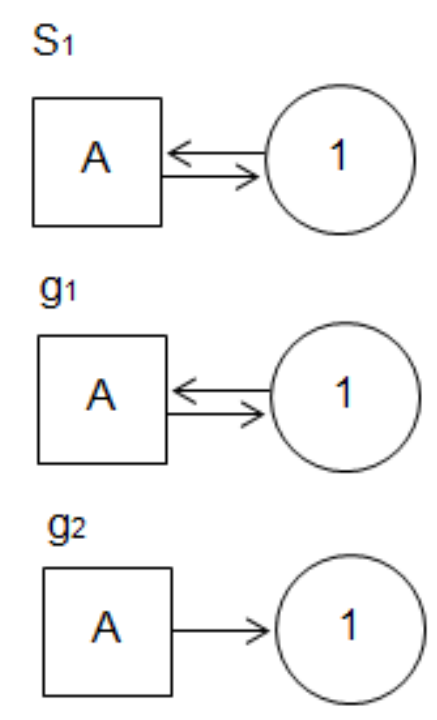

Mesmo que nos fragmentos de maior ordem não seja possível evidenciar a criticidade do sistema, por haver ao menos um fragmento crítico, a condição 
necessária para oscilações estará satisfeita. $O$ cálculo da matriz das correntes extremas é a primeira ação realizada para se determinar a condição suficiente para o aparecimento da dinâmica oscilatória. Para a rede, a matriz das correntes extremas é composta por um único vetor:

Figura 30. Matriz E das correntes extremas. Para o modelo em (21), é composta por apenas um único vetor, $E=\left(\begin{array}{lllll}1 & 1 & 1 & 1 & 1\end{array}\right)^{T}$. Sua representação gráfica equivale à própria rede, isso significa que só existe um caminho que leva ao objetivo da rede, no caso, a produção da espécie $A$.

$$
E=\left(\begin{array}{l}
1 \\
1 \\
1 \\
1 \\
1
\end{array}\right)
$$

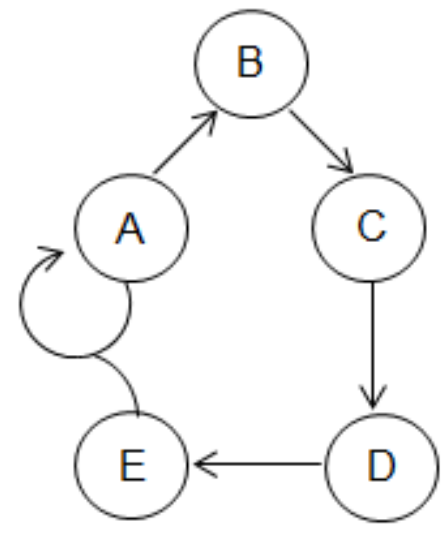

Essa peculiaridade concede a rede duas características. Por um lado, apresentar um único vetor extremo demonstra a simplicidade da rede, porém, também diz respeito à robustez do sistema. Como existe apenas um caminho para produção de $A$, qualquer processo que pare uma das etapas, resultará na extinção das espécies e a perda da funcionalidade da rede.

Das correntes extremas verificam-se os parâmetros de bifurcação, elementos dos vetores $\mathbf{j}$ e $\mathbf{h}$. Como a matriz das correntes extremas possui apenas um vetor, só existe um elemento contido em $\mathbf{j}$, assim, $j=(h)^{T}$. O vetor das concentrações no estado estacionário, $\mathbf{h}$, é composto por cinco elementos, $j=(a b c d e)^{T}$. Fazendo, $k_{r}=(E . j)_{r} \prod_{i=1}^{n} h_{i}{ }^{Y}$, as constantes cinéticas são parametrizadas em função dos vetores $\mathbf{j}$ e $\mathbf{h}$ : 


$$
\begin{aligned}
k_{1} & =(h) a \\
k_{2} & =(h) b \\
k_{3} & =(h) c \\
k_{4} & =(h) d \\
k_{5} & =(h) a e
\end{aligned}
$$

A matriz M, das jacobianas, também é uma contribuição das correntes extremas. É necessária no cálculo das condições suficientes para constatação das bifurcações de Hopf, responsáveis pelas oscilações. Resolvendo, $M(h, j)=N \cdot \operatorname{diag}(E \cdot j) . Y^{T} \cdot \operatorname{diag}(h)$, se tem:

$$
M=\left[\begin{array}{ccccc}
0 & 0 & 0 & 0 & h e \\
h a & -h b & 0 & 0 & 0 \\
0 & h b & -h c & 0 & 0 \\
0 & 0 & h c & -h d & 0 \\
-h a & 0 & 0 & 0 & -h e
\end{array}\right]
$$

A condição necessária e suficiente para bifurcações de Hopf é um par de raízes complexas com a parte real positiva. As raízes de $\mathbf{M}$ advêm do cálculo do seu polinômio característico. O critério de Routh-Hurwitz é usado para investigar a estabilidade do polinômio característico de $\mathbf{M}$. Caso o determinante de Routh-Hurwitz seja negativo, então a matriz $\mathbf{M}$ apresentará instabilidades, isto é, possuirá um par de raízes complexas com parte real positiva.

$$
\begin{aligned}
& a^{2} b e^{3} h^{6}+a^{2} c e^{3} h^{6}+a^{2} d e^{3} h^{6}+a b^{3} e^{2} h^{6}-a b^{2} c d e h^{6}+a b^{2} c e^{2} h^{6}+2 a b^{2} d e^{2} h^{1} \\
& \quad+a b^{2} e^{3} h^{6}-a b c^{2} d e h^{6}+a b c^{2} e^{2} h^{6} \overline{-a b c d^{2} e h^{6}}+2 a b c d e^{2} h^{6}+2 a b c e^{3} h \\
& \quad+2 a b d^{2} e^{2} \frac{a b}{h^{6}+a b d e^{3}} h^{6}+a c^{3} e^{2} h^{6}+a c^{2} d e^{2} h^{6}+a c^{2} e^{3} h^{6}+a c d^{2} e^{2} h^{6} \\
& \quad+2 a c d e^{3} h^{6}+a d^{3} e^{2} h^{6}+a d^{2} e^{3} h^{6}+b^{3} c^{2} d h^{6}+b^{3} c^{2} e h^{6}+b^{3} c d^{2} h^{6}+b^{3} c d \\
& \quad+b^{3} c e^{2} h^{6}+b^{2} c^{3} d h^{6}+b^{2} c^{3} e h^{6}+2 b^{2} c^{2} d^{2} h^{6}+3 b^{2} c^{2} d e h^{6}+2 b^{2} c^{2} e^{2} h^{6} \\
& \quad+b^{2} c d^{3} h^{6}+3 b^{2} c d^{2} e h^{6}+3 b^{2} c d e^{2} h^{6}+b^{2} c e^{3} h^{6}+b c^{3} d^{2} h^{6}+2 b c^{3} d e h^{6} \\
& \quad+b c^{3} e^{2} h^{6}+b c^{2} d^{3} h^{6}+3 b c^{2} d^{2} e h^{6}+3 b c^{2} d e^{2} h^{6}+b c^{2} e^{3} h^{6}+b c d^{3} e h^{6} \\
& \quad+3 b c d^{2} e^{2} h^{6}+b c d e^{3} h^{6}+c^{3} d^{2} e h^{6}+c^{3} d e^{2} h^{6}+c^{2} d^{3} e h^{6}+2 c^{2} d^{2} e^{2} h^{6} \\
& \quad+c^{2} d e^{3} h^{6}+c d^{3} e^{2} h^{6}+c d^{2} e^{3} h^{6}
\end{aligned}
$$

O determinante da matriz de Routh-Hurwitz, R, em (67), apresenta três termos negativos e por isso, deve existir uma combinação de parâmetros de bifurcação que façam com que $|R|<0$. Tomando os valores, 


$$
\begin{gathered}
h=1 \\
a=2 \\
b=0.008 \\
c=0.008 \\
d=0.002 \\
e=0.0001
\end{gathered}
$$

o determinante de $\mathbf{R}$ será negativo, e o polinômio característico de $\mathbf{M}$, em (66), se torna:

$$
\begin{aligned}
p_{M}(x)=x^{5}+ & 0.0181 x^{4}+0.0002978 x^{3}+0.0000037376 x^{2} \\
& +1.92128 x
\end{aligned}
$$

Resolvendo a equação (69), dentre as cinco raízes, existe um par de raízes complexas com parte real positiva. Com os parâmetros em (68), as constantes cinéticas ficam:

$$
\begin{gathered}
k_{1}=2 \\
k_{2}=0.008 \\
k_{3}=0.008 \\
k_{4}=0.002 \\
k_{5}=0.0002
\end{gathered}
$$

A solução das equações diferenciais, com as constantes cinéticas acima, apresenta dinâmica oscilatória para o menor modelo oscilatório cíclico. 


$$
\begin{gathered}
\frac{d[A]}{d t}=-k_{1}[A]+k_{5}[\mathrm{~A}][\mathrm{E}] \\
\frac{d[B]}{d t}=k_{1}[A]-k_{2}[\mathrm{~B}] \\
\frac{d[C]}{d t}=k_{2}[B]-k_{3}[\mathrm{C}] \\
\frac{d[D]}{d t}=k_{3}[C]-k_{4}[\mathrm{D}] \\
\frac{d[E]}{d t}=k_{4}[D]-k_{5}[\mathrm{~A}][\mathrm{E}]
\end{gathered}
$$

Figura 31. Comportamento oscilatório na concentração da espécie $A$ em função do tempo quando $k_{1}=2, k_{2}=0.008, k_{3}=0.008, k_{4}=0.002$ e $k_{5}=0.0002$.

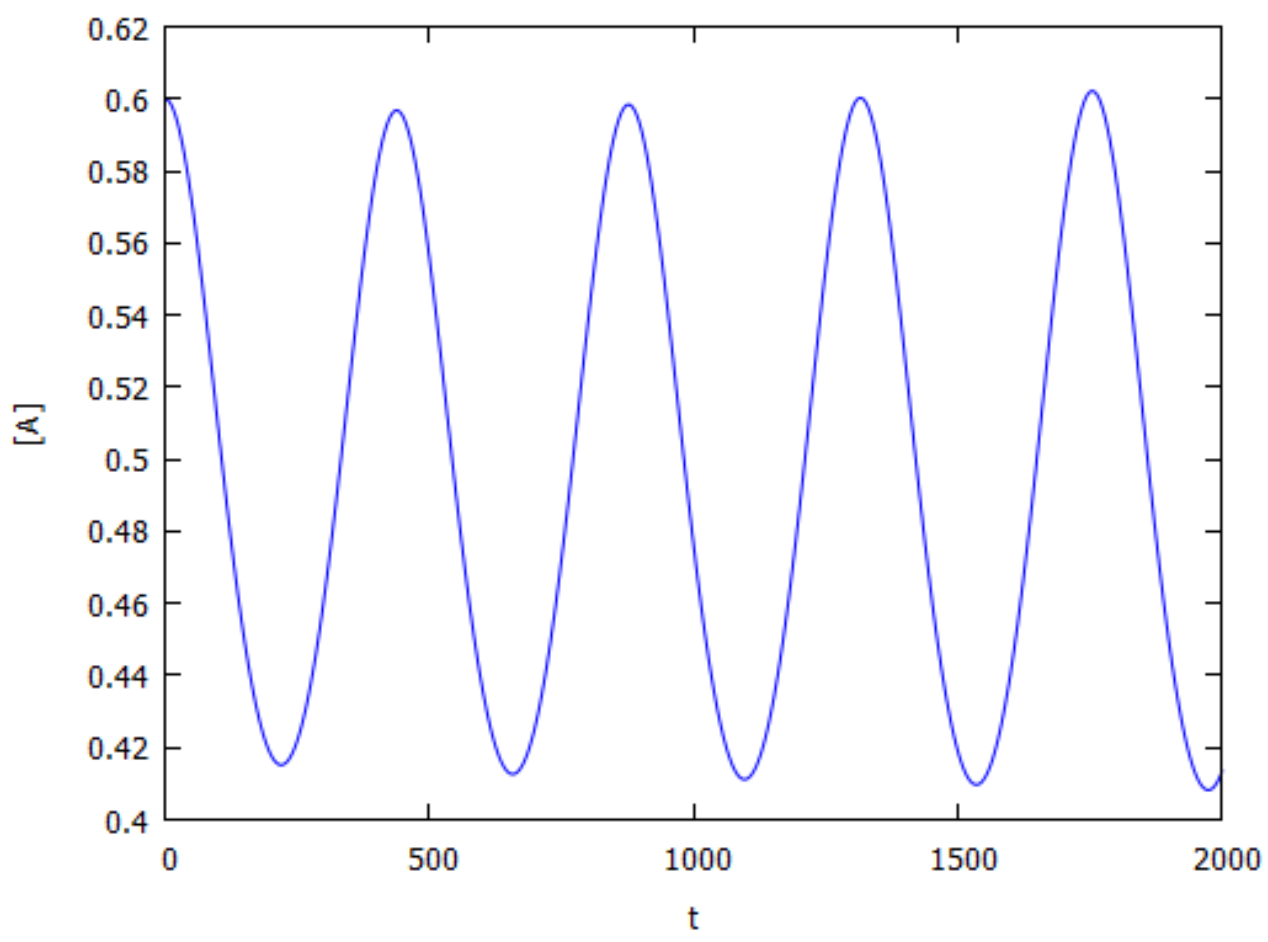

A matriz das correntes extremas fornece informações sobre a robustez da rede, de acordo com o fluxo de reações. Outra forma de averiguar a robustez da rede, agora em função das constantes cinéticas, é realizar uma análise de bifurcação. 
Figura 32. Com $k_{1}=2, k_{4}=0.002 e k_{5}=0.0002$, a área cinza mostra em quais valores do conjunto $\left(k_{2}, k_{3}\right)$ existirá oscilações. Isso indica uma parcela da robustez do sistema, pois, caso alguma perturbação modifique as constantes cinéticas, como por exemplo, a temperatura, ou $\mathrm{o} \mathrm{pH}$ do meio reacional, contanto que o novo conjunto de constantes se encontre no espaço destacado, o sistema ainda irá apresentar dinâmica oscilatória.

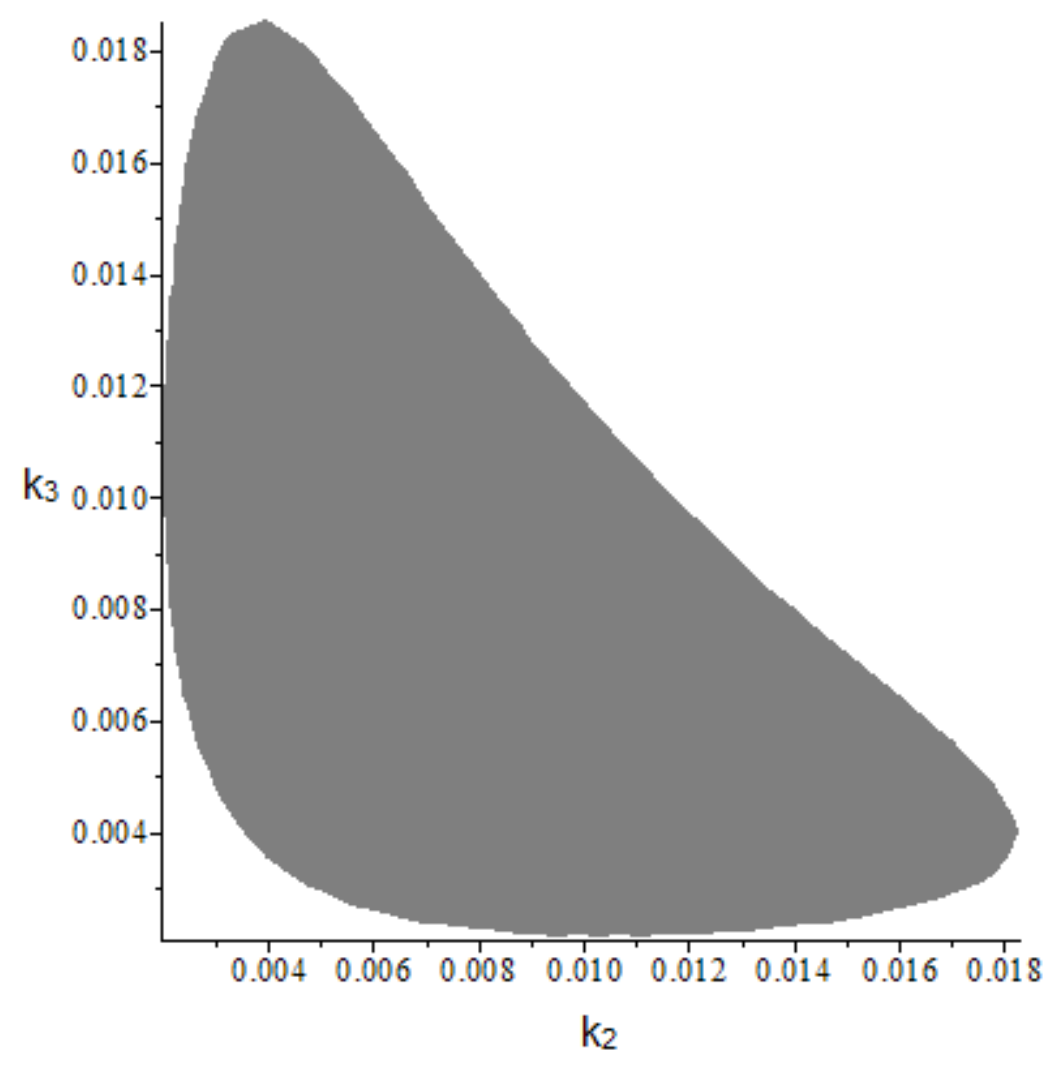

A análise da figura 32 mostra um corte em uma hipersuperfície. Acrescentando mais uma variável no sistema: 
Figura 33. 1) Análise de bifurcação em razão das constantes cinéticas, $k_{2}, k_{3}, k_{4}$, quando $k_{1}=2 e k_{5}=0.0002$. Essa análise demonstra a robustez do sistema de acordo com suas constantes cinéticas. 2) Rotação no eixo $x$. 3) Rotação no eixo $y$. 4) Rotação no eixo $z$. Enquanto a figura 32 representa um corte na superfície representada abaixo, essa constitui apenas uma fração de uma hipersuperfície de infinitas $n$ dimensões.

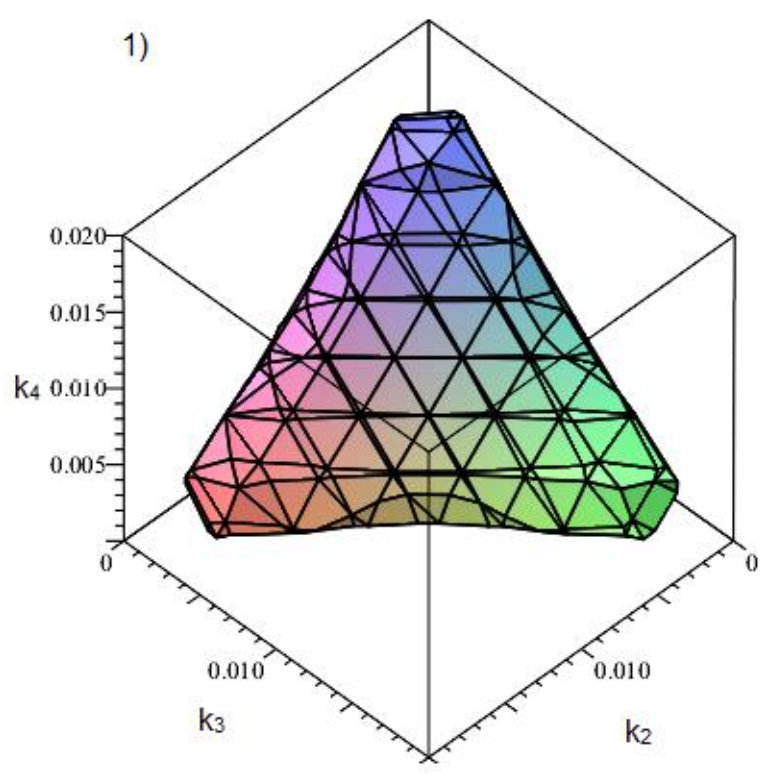

3)

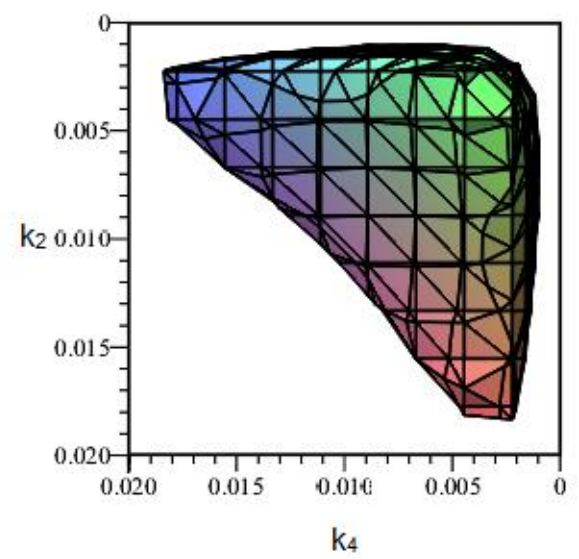

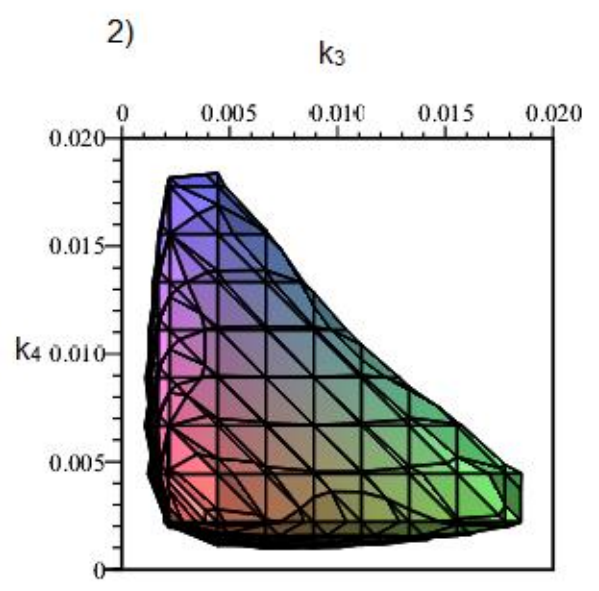

4)

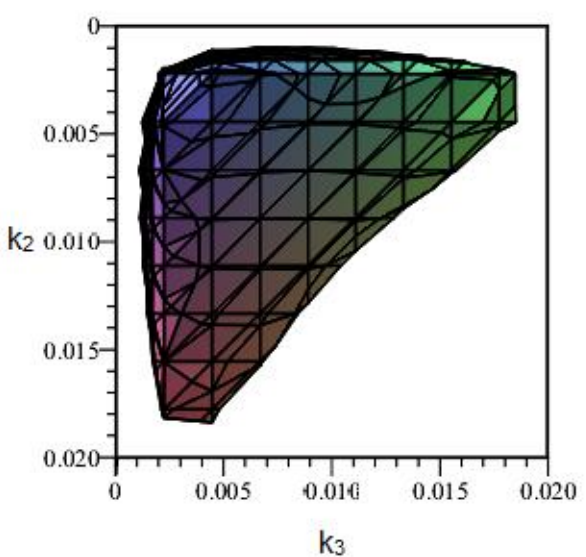

Para ser considerado um modelo mínimo, a rede deve apresentar o menor número de espécies ou reações necessárias para evidenciar o fenômeno oscilatório, assim, caso uma espécie, ou uma reação, seja retirada do sistema, o modelo deverá apresentar somente uma dinâmica estável. A análise pela SNA gráfica mostrou que 
a reação autocatalítica é fundamental para observar a dinâmica instável, mas não consegue prever alterações no sistema que dizem respeito a quantidade de espécies participantes. Tomando o modelo:

$$
\begin{gathered}
A \stackrel{k_{1}}{\rightarrow} B \\
B \stackrel{k_{2}}{\rightarrow} C \\
C \stackrel{k_{3}}{\rightarrow} D \\
D+A \stackrel{k_{5}}{\rightarrow} 2 A
\end{gathered}
$$

Após o cálculo da matriz das correntes extremas, e a linearização do sistema em função dos parâmetros de bifurcação, a determinante da sua matriz de Routh-Hurwitz não apresenta a condição para instabilidades, ou seja, não apresenta um termo negativo:

$$
\begin{gathered}
|R|=a d^{2} h^{3}+b^{2} c h^{3}+b^{2} d h^{3}+b c^{2} h^{3}+2 b c d h^{3}+b d^{2} h^{3}+c^{2} d h^{3} \\
+c d^{2} h^{3}
\end{gathered}
$$

Logo, é necessário ao menos cinco espécies, para que o modelo cíclico, com uma reação autocatalítica, apresente oscilações.

\subsection{MULTIESTABILIDADE NO MENOR MODELO TEÓRICO}

Com o menor número de complexos, de componentes conectados e espécies, o modelo quadrático em (22) é a menor rede de reações químicas multiestável:

$$
\begin{aligned}
& 3 A \stackrel{k_{1}}{\rightarrow} A+2 B \\
& A+2 B \stackrel{k_{2}}{\rightarrow} 3 B \\
& 3 B \stackrel{k_{3}}{\rightarrow} 2 A+B \\
& 2 A+B \stackrel{k_{4}}{\rightarrow} 3 A
\end{aligned}
$$


O sistema apresenta uma matriz estequiométrica com posto igual a uma unidade. Isso significa que existe apenas uma condição de conservação no sistema, no caso, a concentração da espécie $A$, somada coma a concentração a espécie $B$ deve ser sempre um valor constante:

$$
N=\left(\begin{array}{cccc}
-2 & -1 & 2 & 1 \\
2 & 1 & -2 & -1
\end{array}\right)
$$

Como $r=1$, pela análise gráfica da rede estequiométrica, a condição necessária para multiestabilidade é um fragmento crítico de ordem um, ou seja, um fragmento composto por ciclos ou arestas de um vértice $V_{1}$. Para ser um fragmento crítico deve existir um subgrafo com um número ímpar de ciclos positivos, e, no modelo, existem quatro ciclos positivos de um vértice:

$$
\begin{gathered}
3 A \stackrel{k_{1}}{\rightarrow} A \\
2 B \stackrel{k_{2}}{\rightarrow} 3 B \\
3 B \stackrel{k_{3}}{\rightarrow} B \\
2 A \stackrel{k_{4}}{\rightarrow} 3 A
\end{gathered}
$$

No entanto, apenas dois ciclos formam um fragmento crítico. A condição necessária e suficiente para um fragmento ser crítico é possuir um coeficiente $K_{S_{k}}<0$. As equações com $\mathrm{k}_{1}$ e $\mathrm{k}_{3}$ formam ciclos positivos, mas possuem $K_{S_{k}}=0 \mathrm{e}$ por isso não podem ser críticos. Essas reações são ciclos de retroalimentação negativa. Os ciclos de retroalimentação negativa, quando formados por apenas uma espécie, sempre terão $K_{S_{k}} \geq 0$. Já os ciclos de retroalimentação positiva com uma espécie, ou seja, as reações autocatalíticas, sempre formam condições necessárias para instabilidades. A exemplo de (75), as equações com $\mathrm{k}_{2}$ e $\mathrm{k}_{4}$ possuem $K_{S_{k}}=-2$.

O modelo possui quatro vetores de correntes extremas, e por isso, o vetor $\mathbf{j}$ possui quatro elementos, $j=(h i j k)^{T}$, e o vetor $\mathbf{h}, j=(a b)^{T}$.

$$
E=\left(\begin{array}{llll}
1 & 1 & 0 & 0 \\
0 & 0 & 2 & 1 \\
1 & 0 & 1 & 0 \\
0 & 2 & 0 & 1
\end{array}\right)
$$


Da matriz $\mathbf{E}$ formam-se as constantes cinéticas normalizadas nos parâmetros de bifurcação,

$$
\begin{gathered}
k_{1}=(h+i) a^{3} \\
k_{2}=(2 j+k) a b^{2} \\
k_{3}=(h+j) b^{3} \\
k_{4}=(2 i+k) a^{2} b
\end{gathered}
$$

e também a matriz de linearização, $\mathbf{M}$ :

$$
M=\left[\begin{array}{cc}
(-6 h-2 i-2 j+k) a & (2 j-k+6 h+2 i) b \\
(2 j-k+6 h+2 i) a & (-6 h-2 i-2 j+k) b
\end{array}\right]
$$

Para os sistemas multiestáveis, a condição necessária e suficiente para o aparecimento de bifurcação do tipo sela-nó, é uma raiz nula. Isso é possível quando o polinômio característico apresenta pelo menos um elemento negativo no coeficiente independente do polinômio. Assim:

$$
p_{M}(x)=x^{2}+(2 b j-b k+6 b h+2 b i-a k+6 a h+2 a i) x
$$

Dividindo a equação pela variável $x$,

$$
p_{M}(x)=x+(2 b j-b k+6 b h+2 b i-a k+6 a h+2 a i)
$$

o polinômio apresenta agora dois termos negativos no termo independente. Assim, deve existir um conjunto de parâmetros de bifurcação que façam com que $(2 b j-b k+6 b h+2 b i-a k+6 a h+2 a i)=0$. Analiticamente, o coeficiente $k$ está presente apenas nos termos negativos, portanto $k$ deve ser suficientemente grande para anular os termos positivos. 
Fazendo,

$$
\begin{gathered}
a=1 \\
b=1 \\
h=0.125 \\
i=0.125 \\
j=3 \\
k=7
\end{gathered}
$$

o polinômio apresenta uma raiz nula, permitindo multiestabilidade na rede. Assim, as constantes cinéticas que promove uma bifurcação do tipo sela-nó são:

$$
\begin{gathered}
k_{1}=0.25 \\
k_{2}=13 \\
k_{3}=3.125 \\
k_{4}=7.25
\end{gathered}
$$

Essas constantes garantem a existência de uma bifurcação do tipo sela-nó, no entanto, sistema ainda não apresenta multiestabilidade. Para que o fenômeno ocorra, deve acontecer alguma perturbação nas constantes cinéticas, que leve o sistema em direção à multiestabilidade. Quando $k_{4}=7.0$, por exemplo, o sistema sai do ponto de bifurcação e se encaminha para um estado multiestável. Por outro lado, se $k_{4}=7.5$, o sistema apresenta apenas um estado estacionário.

Tabela 3. Múltiplos estados para o menor modelo multiestável, com, $k_{1}=0.25, k_{2}=13, k_{3}=3.125$ e $k_{4}=7.0$. $\bigcirc$ modelo apresenta três estados estacionários, dois estáveis e um instável, sendo esse, o segundo estado estacionário. A concentração da espécie no estado estacionário é representada em $\left[\mathrm{X}_{\mathrm{ee}}\right]$.

\begin{tabular}{cccc}
\hline \hline Espécie & $1^{\underline{\mathrm{a}}}\left[\mathrm{X}_{\mathrm{ee}}\right]$ & $2^{\mathrm{a}}\left[\mathrm{X}_{\mathrm{ee}}\right]$ & $3^{\mathrm{a}}\left[\mathrm{X}_{\mathrm{ee}}\right]$ \\
\hline \hline $\mathrm{A}$ & 0.91 & 1.12 & 1.84
\end{tabular}


Variando a constante cinética $\mathrm{k}_{4}$, é possível construir um gráfico da análise de bifurcação. Tal gráfico é uma curva sigmoidal, onde cada ponto é um estado estacionário, podendo ser estável ou instável.

Figura 34. Análise de bifurcação em razão da constante cinética $\mathrm{k}_{4} \mathrm{e}$ a concentração de $A$, quando $k_{1}=0.25, k_{2}=13, k_{3}=3.125$. Essa análise demonstra a robustez do sistema de acordo com suas constantes cinéticas. A área escura demonstra para quais constantes cinéticas existem múltiplos estados estacionários.

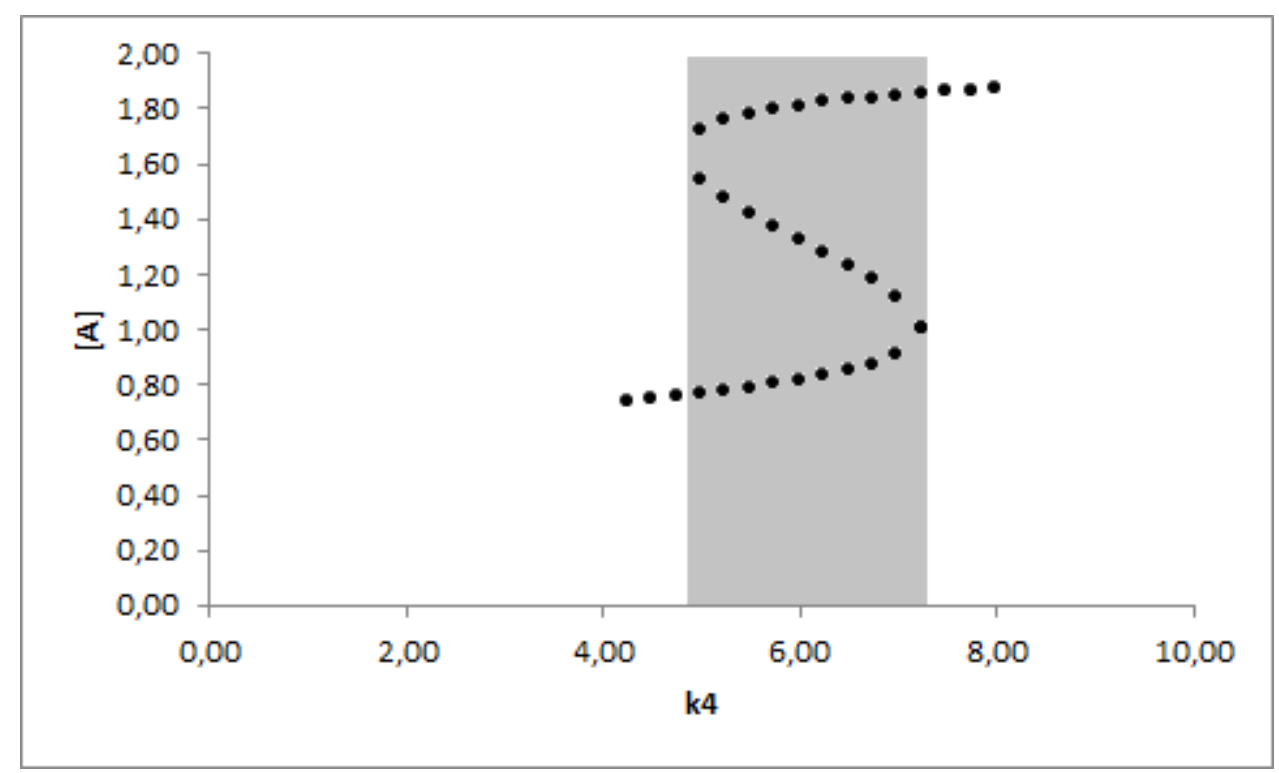

\subsection{OSCILAÇÕES DE CÁLCIO NO CÍLIO OLFATIVO}

As oscilações de cálcio participam do mecanismo de adaptação sensorial de curto prazo. A adaptação previne a saturação dos neurônios olfativos e permitem com que as células trabalhem com uma gama de intensidade de estímulos. O modelo para oscilações de cálcio nos cílios olfativos segue nas equações: 


$$
\begin{gathered}
0_{\stackrel{k_{1}}{\rightarrow}} A \\
A_{\rightarrow}^{k_{2}} A+B \\
4 B_{\stackrel{k_{3}}{\rightarrow}} C \\
C \stackrel{k_{4}}{\rightarrow} B \\
A+C \stackrel{k_{5}}{\rightarrow} C \\
\stackrel{k_{6}}{\rightarrow} 0
\end{gathered}
$$

Onde a espécie $A$ representa os três canais iônicos regulados por nucleotídeos cíclicos, $C N G^{a}, C N G^{f}$ e $C N G^{i}, B$ é o cátion $\mathrm{Ca}^{2+}$ e $C$, o complexo formado pela calmodulina coordenado a quatro íons $\mathrm{Ca}^{2+}, \mathrm{CaM4}$. O mecanismo de adaptação sensorial começa com a abertura dos canais iônicos, que permitem a entrada de cálcio na célula, para formar, então, um complexo com a proteína calmodulina, que age inibindo os canais iônicos, principais responsáveis pela transdução de estímulos olfativos. Como em (3), o modelo possui as equações diferenciais:

$$
\begin{gathered}
\frac{d[A]}{d t}=k_{1}-k_{5}[A][C] \\
\frac{d[B]}{d t}=k_{2}[A]-4 k_{3}[B]^{2}+4 k_{4}[C]-k_{6}[B]^{\varepsilon} \\
\frac{d[C]}{d t}=k_{3}[B]^{2}-k_{4}[C]
\end{gathered}
$$

O expoente $\varepsilon$ deve ter um valor menor que 0,05 para evidenciar oscilações, e para essa dissertação, nos cálculos realizados, usou-se $\varepsilon=0$. Sua matriz estequiométrica é:

$$
N=\left(\begin{array}{cccccc}
1 & 0 & 0 & 0 & -1 & 0 \\
0 & 1 & -4 & 4 & 0 & -1 \\
0 & 0 & 1 & -1 & 0 & 0
\end{array}\right)
$$

Tendo um posto $r=3$, não existem condições de conservação. Pela análise de SNA, para existir oscilações, deve existir um fragmento crítico contendo duas ou 
uma espécie. Tal fragmento pode ser crítico se possuir um ciclo positivo. Com duas espécies, existe apenas um ciclo positivo, formado pelas equações:

$$
\begin{aligned}
& 4 B_{\rightarrow}^{k_{3}} C \\
& C \stackrel{k_{4}}{\rightarrow} 4 B
\end{aligned}
$$

O ciclo é um dos componentes do fragmento $S_{2}=\left(\begin{array}{l}B \\ 3\end{array}, \begin{array}{l}C \\ 4\end{array}\right)$. Esse fragmento é formado pelos subgrafos, $g_{1}=C=([B, 3, C][C, 4, B])$ e $g_{2}=[B, 3]$ e $[C, 4]$. A primeira vista, o fragmento $S_{2}=\left(\begin{array}{c}B \\ 3\end{array}, \begin{array}{l}C \\ 4\end{array}\right)$ não pode ser crítico, pois $K_{2}=g_{1}+g_{2}=-16+16+$ $1=1$. Porém, a rede apresenta uma peculiaridade. Mesmo que sejam necessários quatro íons de $\mathrm{Ca}^{2+}$, a cinética é considerada de segunda ordem. Isso significa que o coeficiente estequiométrico, $\alpha_{\mathrm{B} 3}$ é diferente da ordem de reação $\mathrm{K}_{\mathrm{B} 3}$. Assim, o termo que rege o peso das arestas, $\alpha_{\mathrm{kj}}{ }^{2}$, na equação (50), torna-se $\alpha_{\mathrm{kj}} K_{\mathrm{kj}} \cdot{ }^{35}$

Portanto, o coeficiente $K_{S_{k}}$ do fragmento $S_{2}=\left(\begin{array}{c}B \\ 3\end{array}, \begin{array}{c}C \\ 4\end{array}\right)$ se transforma em $K_{2}=g_{1}+g_{2}=-16+8+1=-7$, possibilitando oscilações para o sistema. A matriz das correntes extremas é:

$$
E=\left(\begin{array}{lll}
0 & 1 & 0 \\
0 & 0 & 1 \\
1 & 0 & 0 \\
1 & 0 & 0 \\
0 & 1 & 0 \\
0 & 0 & 1
\end{array}\right)
$$

Assim, as constantes cinéticas para a rede oscilatória de cálcio são parametrizadas em:

$$
\begin{gathered}
k_{1}=(i) \\
k_{2}=(j) a \\
k_{3}=(h) b^{4} \\
k_{4}=(h) c \\
k_{5}=(i) a c \\
k_{6}=(j) b
\end{gathered}
$$


Linearizando o sistema, a matriz das jacobianas, $\mathbf{M}$, com $M(h, j)=$ $N . \operatorname{diag}(E . j) . Y^{T} . \operatorname{diag}(h)$ :

$$
M=\left[\begin{array}{ccc}
-i a & 0 & -i c \\
j a & -8 h b & 4 h c \\
0 & 2 h b & -h c
\end{array}\right]
$$

Para que ocorram oscilações, devem existir raízes complexa com parte real positiva no polinômio característico da matriz $\mathbf{M}$ :

$$
x^{3}+(h c+8 h b+i a) x^{2}+(h c i a+8 b i a h) x+2 b h c j a i
$$

O determinante da matriz de Routh-Hurwitz deve apresentar um termo negativo para que ocorram oscilações no sistema.

$$
\begin{gathered}
|R|=h^{2} c^{2} i a+16 h^{2} c b i a+64 h^{2} b^{2} i a+i^{2} a^{2} h c+8 i^{2} a^{2} b h \\
-2 b h c j a i
\end{gathered}
$$

Como esse determinante possui um termo negativo, -2 bhcjai, existe uma combinação de parâmetro (a, b, c, j, h, i), que faz com que $|R|<0$. Encontrar um $\mid R /$ menor que zero, significa descobrir um conjunto de parâmetros que possibilitam uma dinâmica oscilatória na rede. Analiticamente, uma possibilidade para tal, é fazer com que $j \gg h$ e $j \gg i$, pois, o parâmetro $j$ está presente, apenas, no termo negativo de (89). Tomando, numericamente,

$$
\begin{gathered}
a=0.1 \\
b=0.1 \\
c=10 \\
h=0.01 \\
i=0.1 \\
j=1
\end{gathered}
$$

tem-se um $/ R /$ da equação (89) negativo e um par de raízes complexas com parte real positiva da equação (88). Isso significa que tais parâmetros proporcionam 
oscilações na rede. Como as constantes cinéticas estão parametrizadas pelos componentes dos vetores $\mathbf{h}$ e $\mathbf{j}$, como demonstrado na equação (86), pode-se fazer:

$$
\begin{gathered}
k_{1}=0.1 \\
k_{2}=0.1 \\
k_{3}=0.0001 \\
k_{4}=0.1 \\
k_{5}=0.1 \\
k_{6}=0.1
\end{gathered}
$$

Com esses valores, é possível traçar gráfico, em função das constantes cinéticas, que mapeia as regiões que contém oscilações. Por exemplo:

Figura 35. Análise de bifurcação, tomando $k_{3}=0.0001, k_{4}=k_{6}=0.1$ e $k_{5}=10 k_{1} k_{2}$, a área escura mostra onde existem oscilações.

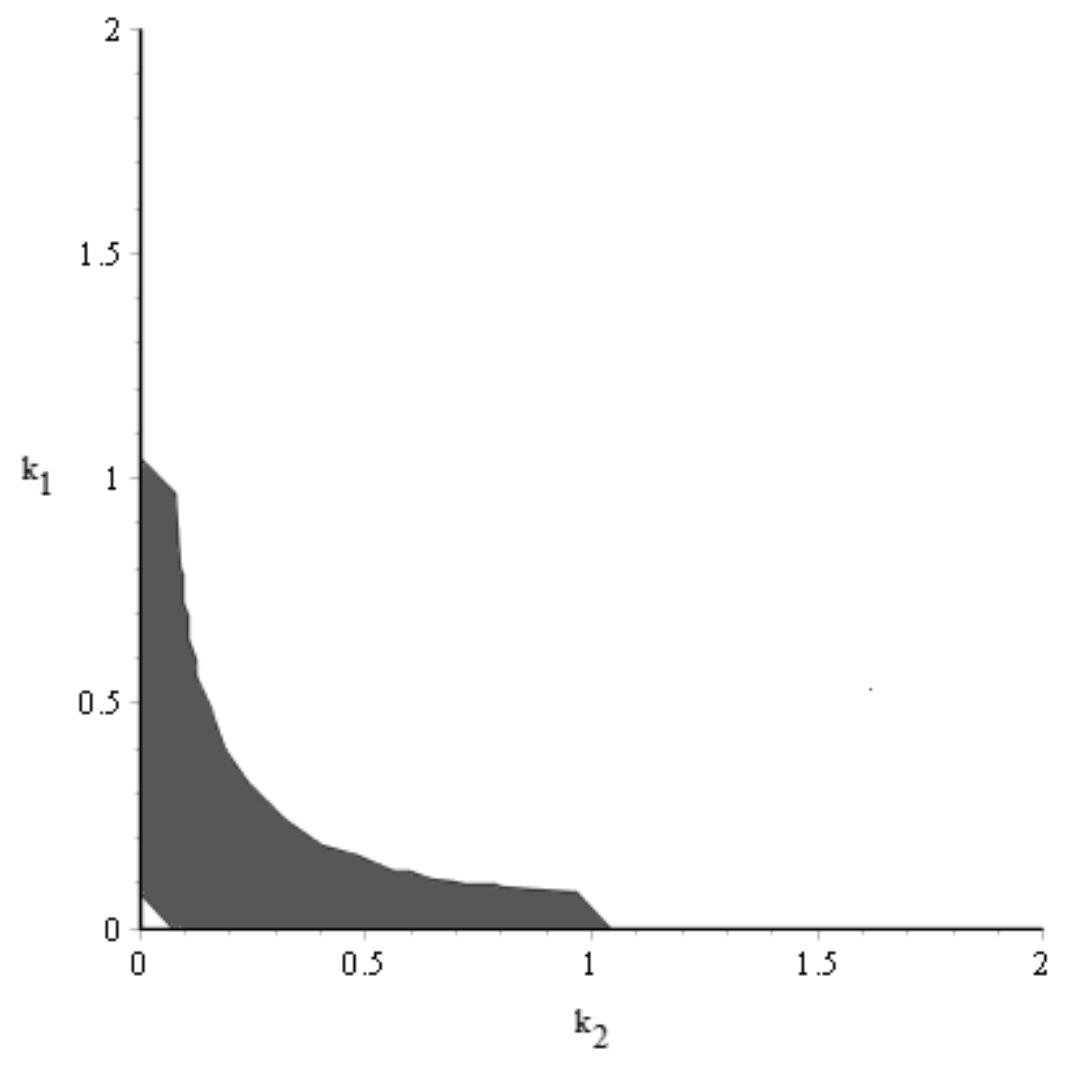


Encontrar essa região é primordial para compreender a dinâmica instável do sistema. Se o modelo for verossímil, pode ser uma importante ferramenta para os experimentalistas, que confrontam os dados empíricos com os teóricos para elucidar um problema. Esse gráfico é apenas uma fatia de uma hipersuperfície para a dinâmica complexa, e, ajustando os parâmetros, pode-se encontrar um conjunto de constantes cinéticas que se adapte à realidade bioquímica.

Usando um conjunto de constantes cinéticas fornecido pelo gráfico da figura 8, com o propósito de resolver as equações cinéticas de (3), é possível traçar um gráfico que ilustra as oscilações nas concentrações das espécies:

Figura 36. Oscilações na concentração de $B$, íons de $\mathrm{Ca}^{2+}$, em função do tempo. Com $k_{1}=k_{2}=k_{4}=k_{5}=k_{6}=0.1$ e $k_{3}=0.0001$.

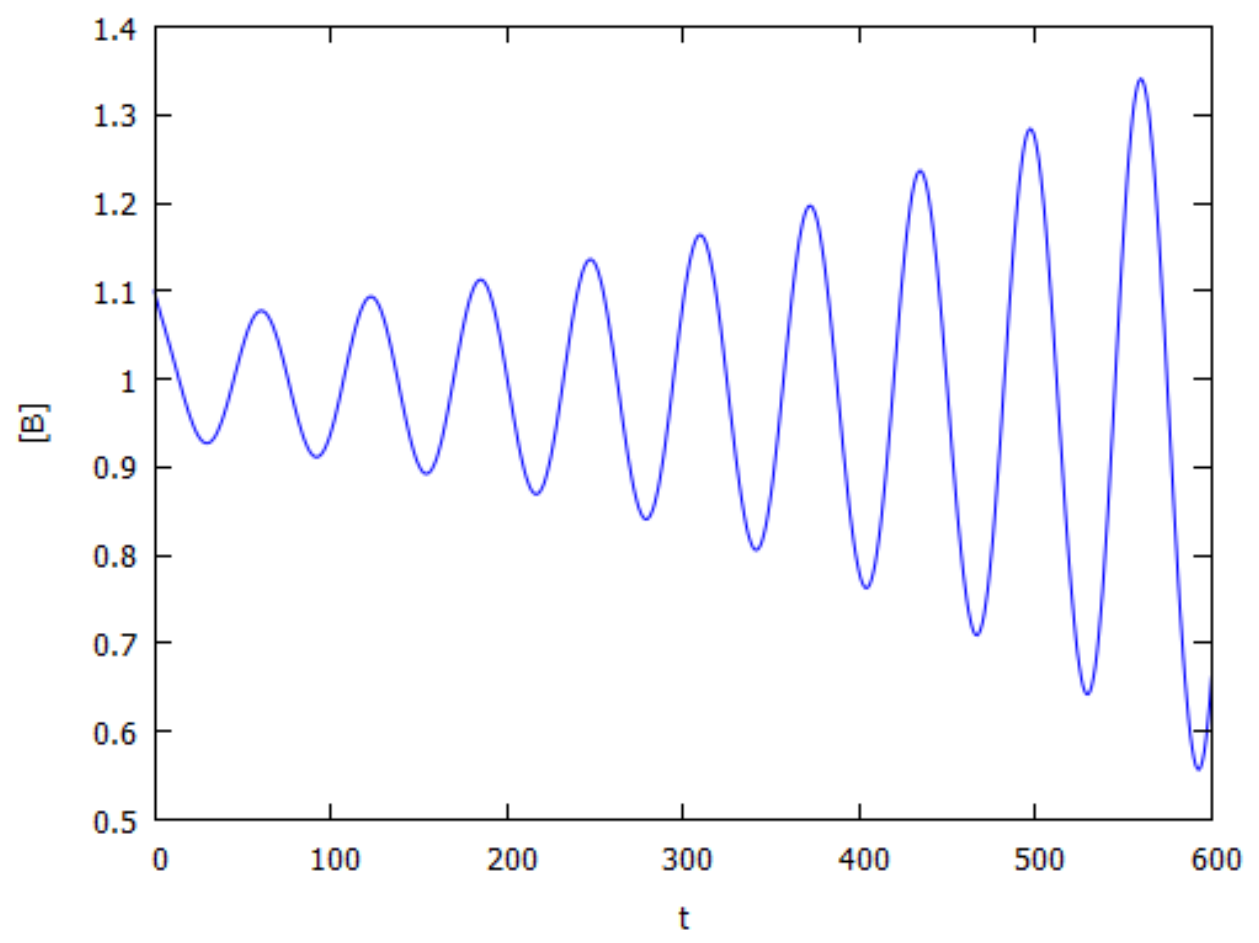

Assim, o íon de cálcio entra na célula por intermédio do canal iônico, forma o complexo, inibe o canal, provocando a adaptação sensorial, para então, ocorrer um decréscimo na sua concentração célula, formando uma oscilação. 


\subsection{OSCILAÇÕES NA VIA GLICOLÍTICA}

A dinâmica oscilatória da via glicolítica é evidenciada experimentalmente, principalmente nas células da levedura Saccharomyces cerevisiae. Nesse fungo, a fosfofrutoquinase atua como centro das oscilações. Devido à similaridade das vias, o modelo de oscilações na glicólise pode ser transporta para outros seres, inclusive os humanos. No entanto, ainda não se sabe sobre a função das oscilações na manutenção da via. Assim, Sel'kov (1968) propôs um modelo baseado na autoregulação.

$$
\begin{gathered}
0 \stackrel{k_{1}}{\rightarrow} A T P \\
A T P+P F K\left|A D P \stackrel{k_{2}}{\rightarrow} A T P\right| P F K \mid A D P \\
A T P|P F K| A D P \stackrel{k_{3}}{\rightarrow} A T P+P F K \mid A D P \\
A T P|P F K| A D P \stackrel{k_{4}}{\rightarrow} P F K \mid A D P+A D P \\
A D P \stackrel{k_{5}}{\rightarrow} 0 \\
2 A D P+P F K_{\rightarrow}^{k_{6}} P F K \mid A D P \\
P F K \mid A D P \stackrel{k_{6}}{\rightarrow} 2 A D P+P F K
\end{gathered}
$$

A premissa do modelo é a conversão do ATP em ADP. A enzima PFK forma um complexo, PFK|ADP, ao ligar-se com duas moléculas de ADP. A conversão acontece quando a molécula de ADP se coordena ao complexo, formando uma molécula de ADP. O modelo pode ser expresso na sua forma reduzida:

$$
\begin{gathered}
0 \stackrel{k_{1}}{\rightarrow} A \\
A+B \stackrel{k_{2}}{\rightarrow} C \\
C \stackrel{k_{3}}{\rightarrow} A+B \\
C \stackrel{k_{4}}{\rightarrow} B+D \\
D_{\rightarrow}^{k_{5}} 0 \\
2 D+E \stackrel{k_{6}}{\rightarrow} B \\
B \stackrel{k_{7}}{\rightarrow} 2 D+E
\end{gathered}
$$


Onde $A$ representa uma molécula de ATP, a espécie $B$ é um complexo formado por um ADP e uma enzima PFK, $C$ é um segundo complexo, formado por $B$ e um ATP. Os compostos $D$ e $E$ são, respectivamente, a molécula de ADP e enzima fosfofrutoquinase, PFK. Assim, o modelo apresenta o sistema de equações diferenciais:

$$
\begin{gathered}
\frac{d[A]}{d t}=k_{1}-k_{2}[A][B]+k_{3}[C] \\
\frac{d[B]}{d t}=-k_{2}[A][B]+k_{3}[C]+k_{4}[C]+k_{6}[D]^{2}[E]-k_{7}[B] \\
\frac{d[C]}{d t}=k_{2}[A][B]-k_{3}[C]-k_{4}[C] \\
\frac{d[D]}{d t}=k_{4}[C]-k_{5}[D]-2 k_{6}[D]^{2}[E]+2 k_{7}[B] \\
\frac{d[D]}{d t}=-k_{6}[D]^{2}[E]+k_{7}[B]
\end{gathered}
$$

Esse modelo apresenta a seguinte matriz estequiométrica:

$$
N=\left(\begin{array}{ccccccc}
1 & -1 & 1 & 0 & 0 & 0 & 0 \\
0 & -1 & 1 & 1 & 0 & 1 & -1 \\
0 & 1 & -1 & -1 & 0 & 0 & 0 \\
0 & 0 & 0 & 1 & -1 & -2 & 2 \\
0 & 0 & 0 & 0 & 0 & -1 & 1
\end{array}\right)
$$

O posto da matriz em (92) é igual a quatro. Isso significa que o sistema apresenta uma condição de conservação, sendo $[B]+[C]+[E]=$ constante. Pela variante gráfica da SNA, o fenômeno oscilatório necessita de um fragmento crítico de ordem entre um e três. Usando a teoria de grafos, um grafo bipartido pode ser construído para o modelo: 
Figura 37. Grafo bipartido para o modelo em (10).

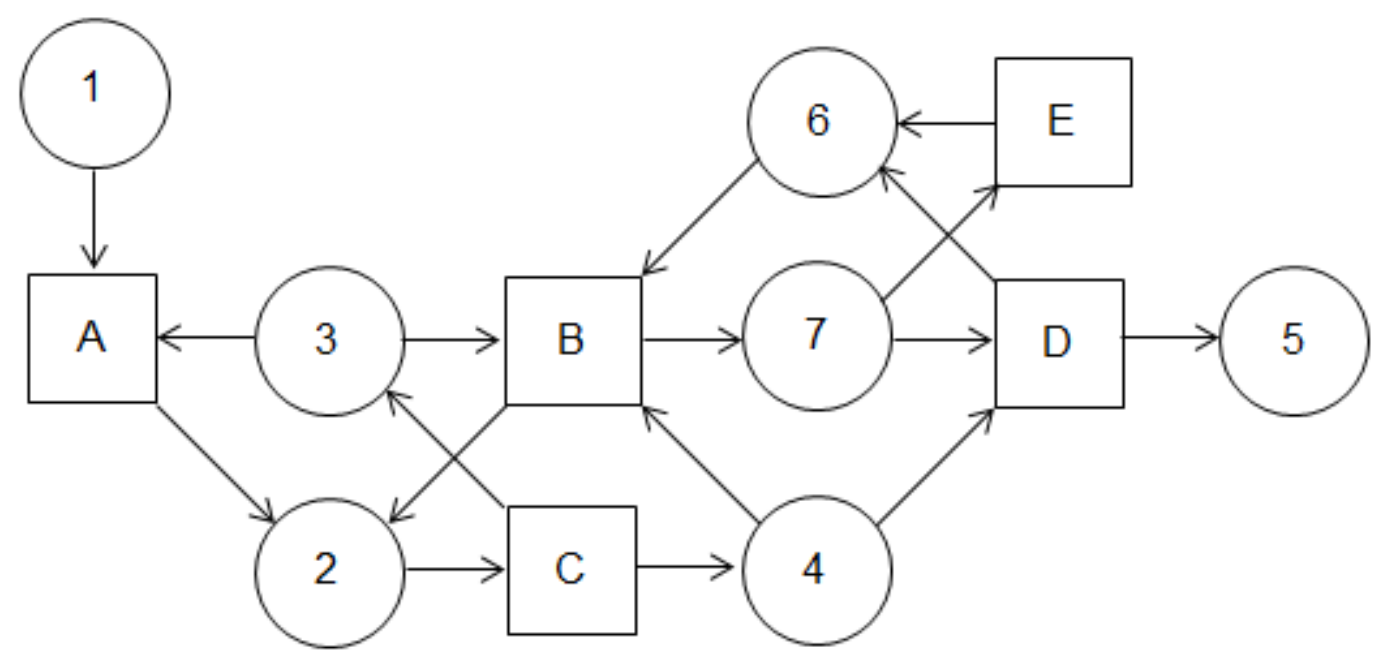

O grafo bipartido apresenta uma grande quantidade de ciclos, contendo dois e três vértices $\mathrm{V} 1$, porém, o fragmento $S_{3}=\left(\begin{array}{c}B \\ 2\end{array}, \begin{array}{l}C \\ 4\end{array}, \frac{D}{6}\right)$ é o único composto por ciclos e arestas mutuamente disjuntos e que apresenta criticidade. Sendo assim:

Figura 38. O fragmento $S_{3}=\left(\frac{B}{2}, \underset{4}{C}, \frac{D}{6}\right)$ é constituído por três subgrafos distintos, $g_{1}=C=([B, 2, C],[C, 4, D],[D, 6, B]), \quad g_{2}=\left[C=([B, 2, C],[C, 4, B]],[D, 6], \quad g_{3}=\right.$ $[B, 2],[C, 4],[D, 6]$. Para ser considerado crítico, um fragmento deve apresentar $K_{S_{k}}<0$. Assim, $K_{3}=g_{1}+g_{2}+g_{3}=-2-4+4=-2$.
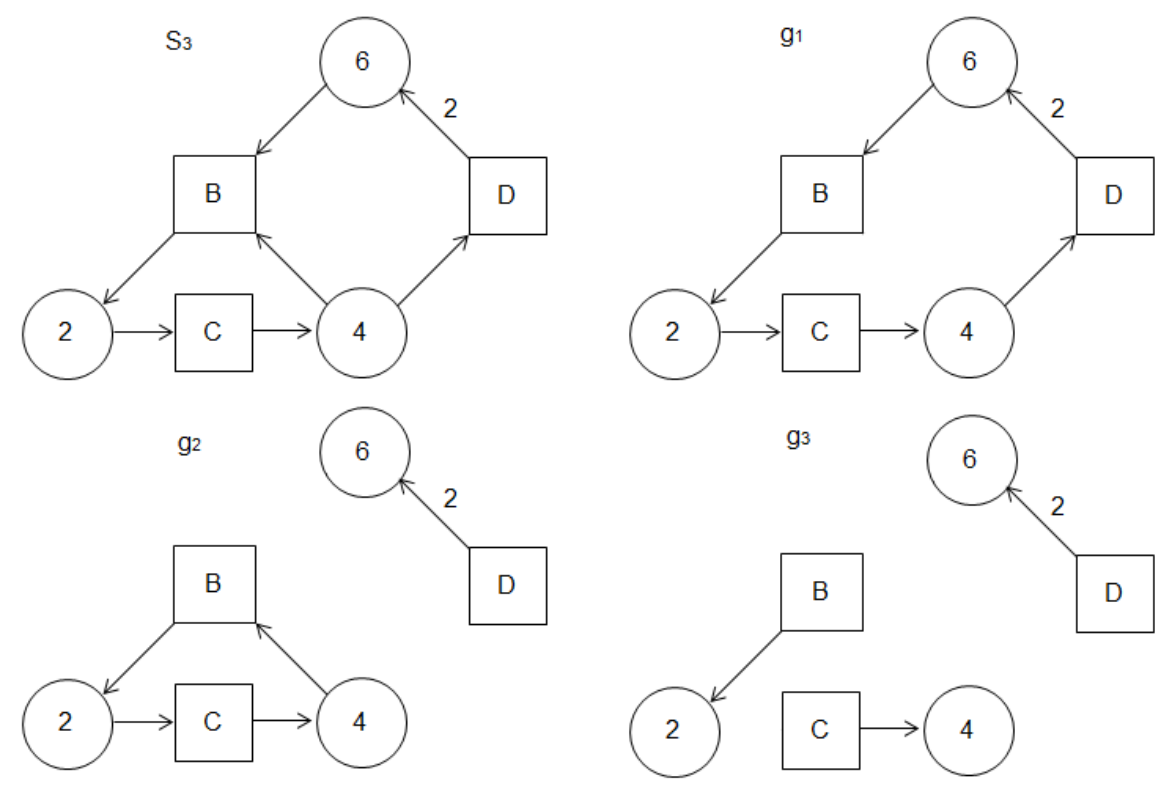
A análise gráfica coincide com os resultados já publicados. ${ }^{14} \mathrm{O}$ modelo possui três vetores de correntes extremas, e por isso, seu vetor $\mathbf{j}$ tem três elementos, $j=(h i j)^{T}$, e o vetor $\mathbf{h}, j=(a b c d e)^{T}$.

$$
E=\left(\begin{array}{lll}
0 & 1 & 0 \\
1 & 1 & 0 \\
1 & 0 & 0 \\
0 & 1 & 0 \\
0 & 1 & 0 \\
0 & 0 & 1 \\
0 & 0 & 1
\end{array}\right)
$$

Cada vetor da matriz das correntes extremas pode ser representado graficamente, como visto na seguinte imagem:

Figura 39. Representação gráfica das correntes extremas apresentadas em (93).

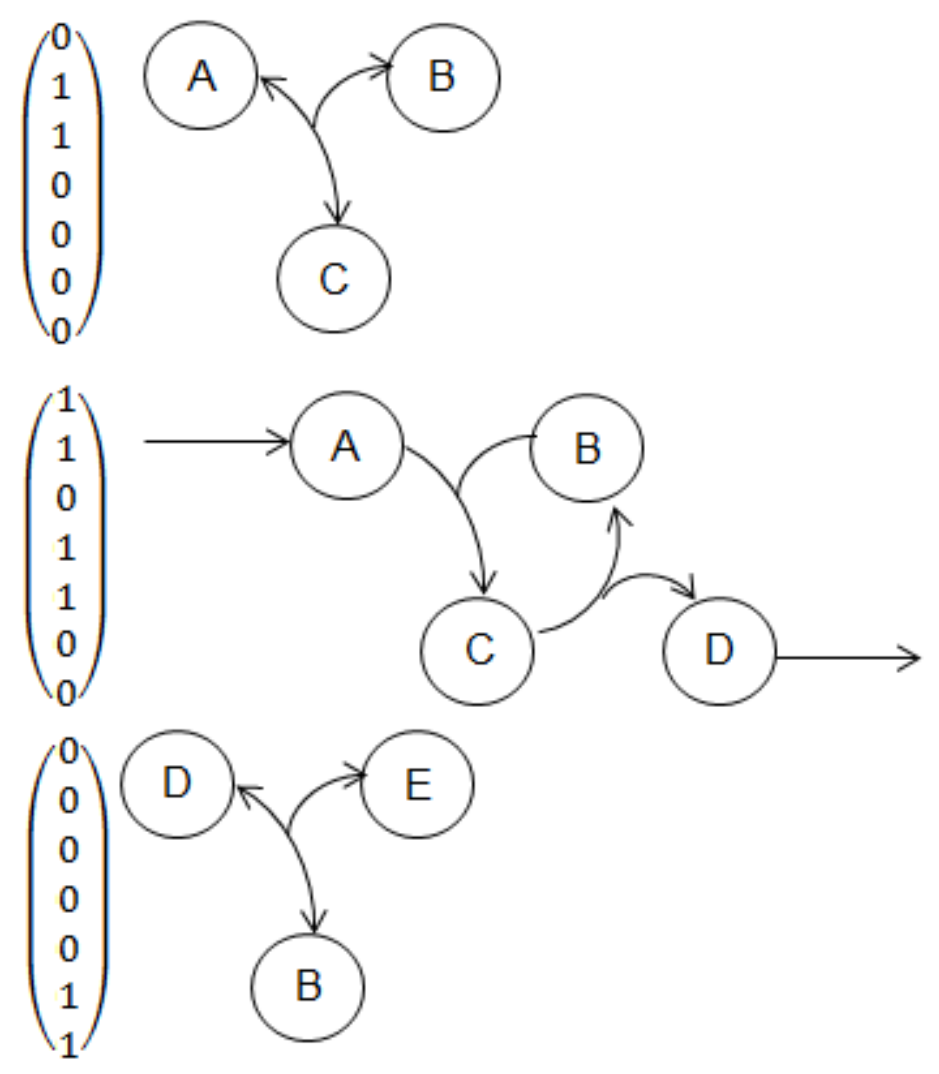


Pela contribuição das correntes extremas, e os vetores, j e $\mathbf{h}$, fazendo, $k_{r}=(E . j)_{r} \prod_{i=1}^{n} h_{i}{ }^{Y}$, as constantes cinéticas são parametrizadas em:

$$
\begin{gathered}
k_{1}=(i) \\
k_{2}=(h+i) a b \\
k_{3}=(h) c \\
k_{4}=(i) c \\
k_{5}=(i) d \\
k_{6}=(j) d^{2} e \\
k_{7}=(j) b
\end{gathered}
$$

A matriz de linearização $\mathbf{M}$ também é uma contribuição das correntes extremas. A instabilidade do sistema se reflete nos autovalores da matriz $\mathbf{M}$, caso nessa ocorra uma inversão de pelo menos um sinal dos componentes dos sues autovalores, a matriz é instável, possibilitando dinâmicas complexas. Os autovalores são as raízes do polinômio característico da matriz:

$$
\begin{aligned}
& p_{M}(x)=x^{5}+(a h+a i+b h+b i+b j+c h+c i+d i+4 d j+e j) x^{4} \\
& +\left(a b h j+a b i j+a c h i+a c i^{2}+a d h i+4 a d h j+a d i^{2}\right. \\
& +4 a d i j+a e h j+a e i j+b c h j+b c i j+b d h i+4 b d h j \\
& +b d i^{2}+5 b d i j+b e h j+b e i j+c d h i+4 c d h j+c d i^{2} \\
& +4 c d i j+c e h j+c e i j+d e i j) x^{3} \\
& +\left(a b c h i j+a b c i^{2} j+a b d h i j+a b d i^{2} j+a x d h i^{2}\right. \\
& +4 a c d h i j+a c d i^{3}+4 a c d i^{2} j+a c e h i j+a c e i^{2} j
\end{aligned}
$$

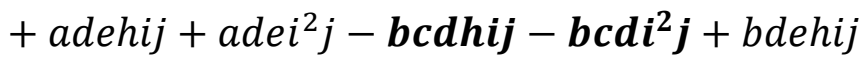

$$
\begin{aligned}
& \left.+b d e i^{2} j+c d e h i j+c d e i^{2} j\right) x^{2} \\
& +\left(a b c d h i^{2} j+a b c d i^{3} j+a c d e h i^{2} j+a c d e i^{3} j\right) x
\end{aligned}
$$

Como o polinômio característico apresenta dois valores negativos, na análise de instabilidade, não será necessário o uso da matriz de Routh-Hurwitz. Pela regra dos sinais de Descartes, o número de raízes positivas é igual ao número de permutação de sinais nos termos de um polinômio. Isto é, quando os termos são colocados em ordem decrescente de grau, para existência de duas raízes com parte 
real positiva, necessárias para bifurcação de Hopf, deve existir duas trocas de sinais no polinômio característico de $\mathbf{M}$. Assim, deve existir um conjunto de parâmetros de bifurcação, que garanta com que, abchij $+a b c i^{2} j+a b d h i j+a b d i^{2} j+a x d h i^{2}+$ $4 a c d h i j+a c d i^{3}+4 a c d i^{2} j+a c e h i j+a c e i^{2} j+a d e h i j+a d e i^{2} j-b c d h i j-b c d i^{2} j+$ $b d e h i j+b d e i^{2} j+c d e h i j+c d e i^{2} j<0$, pois, se tal inequação for uma verdade, o polinômio característico irá apresentar duas raízes com parte real positiva. Fazendo,

$$
\begin{gathered}
a=0.1 \\
b=1 \\
c=1 \\
d=1 \\
e=0.1 \\
h=0.1 \\
i=0.1 \\
j=0.1
\end{gathered}
$$

o polinômio característico em (95) torna-se:

$$
p_{M}(x)=x^{5}+1.03 x^{4}+0.2492 x^{3}-0.00016 x^{2}+0.000022 x
$$

Tal polinômio não apresenta apenas duas raízes positivas, mas sim, duas raízes complexas com parte real positiva, condição necessária e suficiente para bifurcações de Hopf que causam oscilações. Com esses parâmetros de bifurcação, se tem as seguintes constantes cinéticas:

$$
\begin{gathered}
k_{1}=0.1 \\
k_{2}=0.02 \\
k_{3}=0.1 \\
k_{4}=0.1 \\
k_{5}=0.1 \\
k_{6}=0.01 \\
k_{7}=0.1
\end{gathered}
$$


Parta observar oscilações no sistema, basta resolver a dinâmica da concentração das espécies, com as constantes acima:

Figura 40. Oscilações em função do tempo na concentração da enzima fosfofrutoquinase, $E$. Com $k_{1}=k_{3}=k_{4}=k_{5}=k_{7}=0.1, k_{2}=0.02$ e $k_{6}=0.01$.

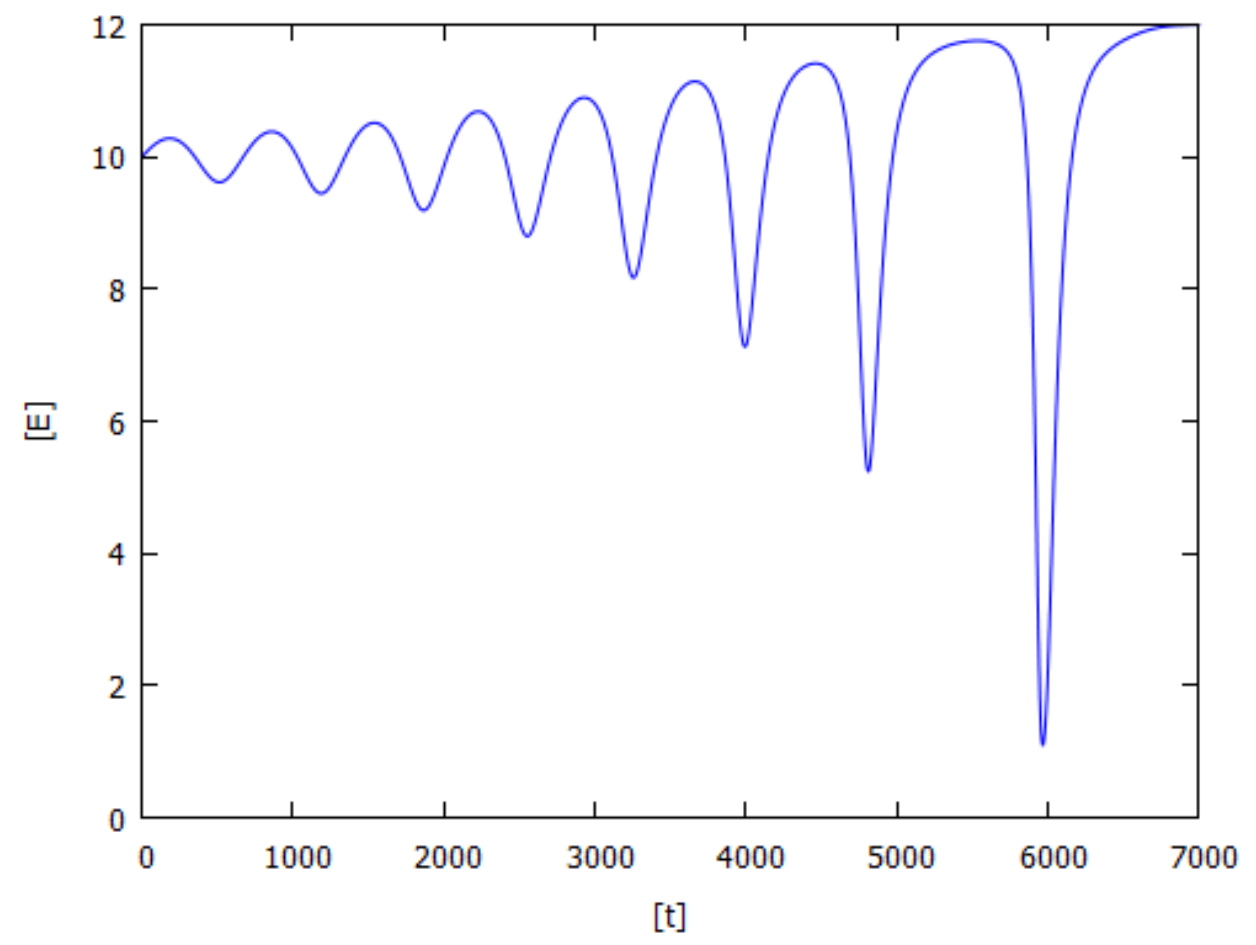

\subsection{ESTADOS MÚLTIPLOS E NA REAÇÃO DE PEROXIDASE-OXIDASE}

O modelo de multiestabilidade na rede da reação de peroxidase-oxidase, segue as seguintes equações, descritas por (17):

$$
\begin{gathered}
S_{\rightarrow}^{k_{1}} 0 \\
0 \stackrel{k_{2}}{\rightarrow} S \\
S+E \stackrel{k_{3}}{\rightarrow} E S \\
E S_{\stackrel{k_{4}}{\rightarrow} E} \\
S+E S_{\rightarrow}^{k_{5}} E S_{2} \\
E S_{2} \stackrel{k_{6}}{\rightarrow} S+E S
\end{gathered}
$$


Como a análise da dinâmica pela SNA não depende dos mecanismos de interação e sim da estequiometria da rede, a equação acima pode ser simplificada:

$$
\begin{aligned}
& A \stackrel{k_{1}}{\rightarrow} 0 \\
& 0 \stackrel{k_{2}}{\rightarrow} A \\
& A+B \stackrel{k_{3}}{\rightarrow} C \\
& C \stackrel{k_{4}}{\rightarrow} B \\
& A+C \stackrel{k_{5}}{\rightarrow} D \\
& D \stackrel{k_{6}}{\rightarrow} A+C
\end{aligned}
$$

As espécies $A, B, C$ e $D$, correspondem, respectivamente, ao substrato $\mathrm{H}_{2} \mathrm{O}_{2}$, á enzima peroxidase e os complexos $E S$ e $E S_{2}$, formados por uma enzima com uma e duas unidades do substrato. O complexo $E S_{2}$ representa a forma inativa da enzima. Assim, o conjunto de equações diferenciais que regem o sistema é:

$$
\begin{gathered}
\frac{d[A]}{d t}=-k_{1}[A]+k_{2}-k_{3}[A][B]-k_{5}[A][C]+k_{6}[D] \\
\frac{d[B]}{d t}=-k_{3}[A][B]+k_{4}[C] \\
\frac{d[C]}{d t}=+k_{3}[A][B]-k_{4}[C]-k_{5}[A][C]+k_{6}[D] \\
\frac{d[D]}{d t}=+k_{5}[A][C]-k_{6}[D]
\end{gathered}
$$

A seguinte matriz, $\mathbf{N}$, represeta a matriz estequiométrica do sistema (17):

$$
N=\left(\begin{array}{cccccc}
-1 & 1 & -1 & 0 & -1 & 1 \\
0 & 0 & -1 & 1 & 0 & 0 \\
0 & 0 & 1 & -1 & -1 & 1 \\
0 & 0 & 0 & 0 & 1 & -1
\end{array}\right)
$$

O posto matricial de (99) é igual a três, ou seja, na matriz existem três linhas linearmente independentes. Subtraindo o número totais de linhas da matriz pelo seu posto matricial, calcula-se a quantidade de condições de conservação do sistema, assim, existe apenas uma condição de conservação. Analisando a matriz 
estequiométrica e as equações diferenciais que compõe o modelo, é possível desvendar quais espécies constituem a conservação do sistema. Somando as três últimas linhas da matriz (99) ou os lados esquerdos de $d[B] / d t, d[C] / d t$ e $d[D] / d t$ em (40), ambos resultados devem ser zero, por isso, a condição de conservação é $B+C+D=$ constante. A rede pode ser representada pelo grafo bipartido:

Figura 41. Grafo bipartido para o modelo em (99).

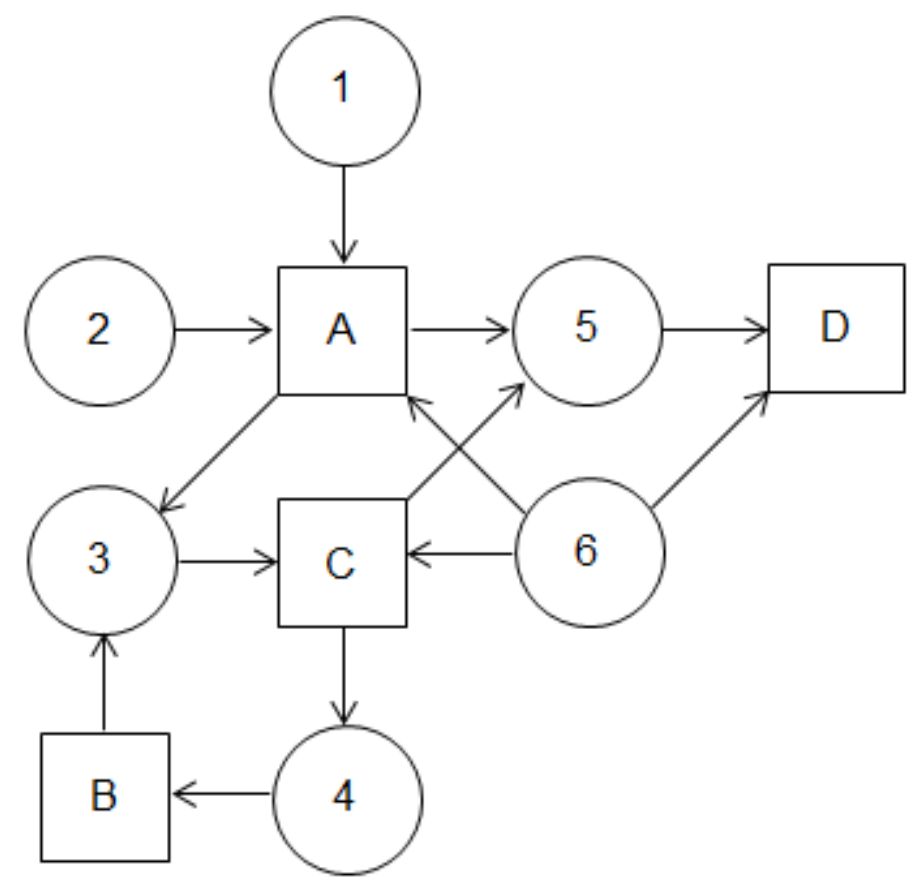

Para a ocorrência de multiestabilidade, é necessário um fragmento crítico de ordem igual ao posto da matriz estequiométrica do sistema, ou seja, um fragmento de ordem três.

Figura 42. O fragmento $S_{3}=\left(\frac{A}{3}, \frac{B}{4}, \frac{C}{5}\right)$ é constituído por três subgrafos distintos, $g_{1}=C=([A, 3, B],[B, 4, C],[C, 5, A]), \quad g_{2}=\left[C=([B, 3, C],[C, 4, B]],[A, 5], \quad g_{3}=\right.$ $[A, 5],[B, 3],[C, 4]$. Para ser considerado crítico, um fragmento deve apresentar $K_{S_{k}}<0$. Assim, $K_{3}=g_{1}+g_{2}+g_{3}=-1-1+1=-1$. 

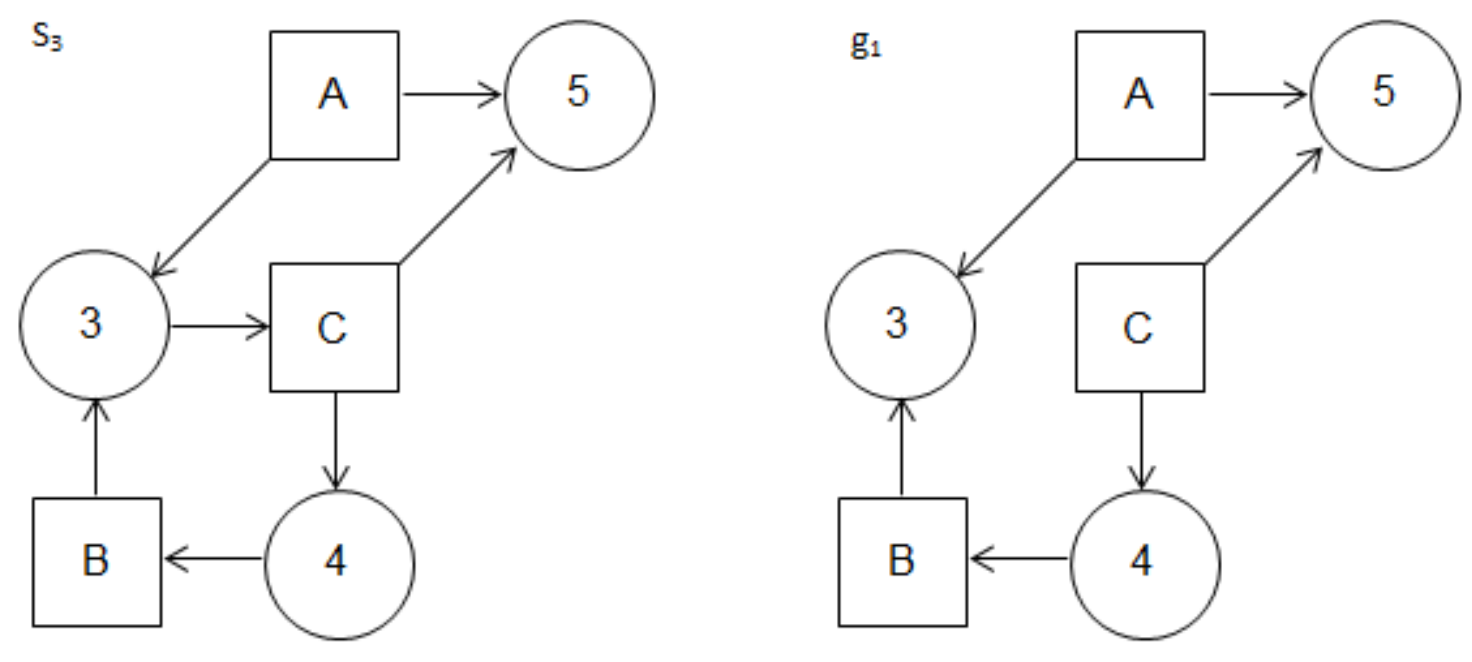

$\mathrm{g}_{2}$

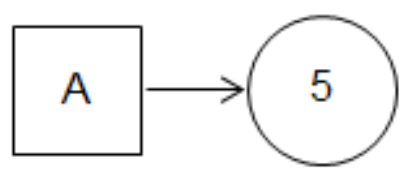

$g_{3}$
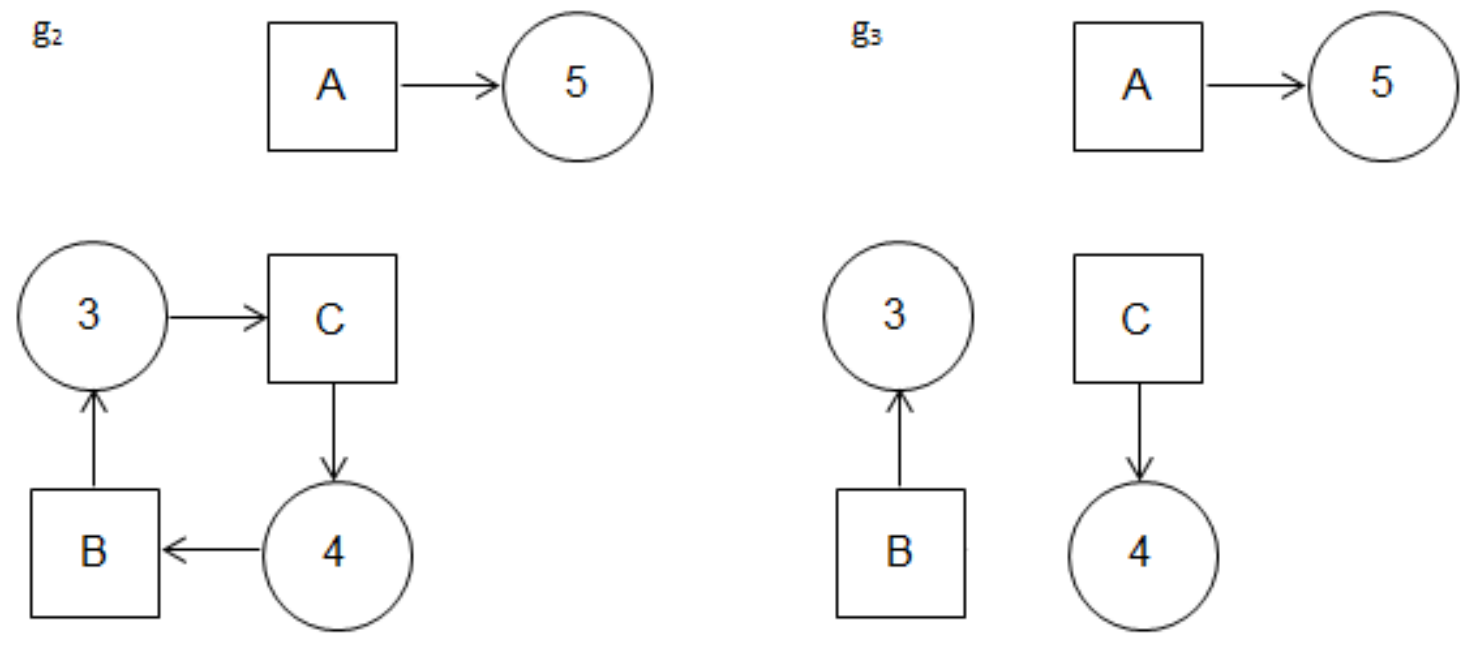

A análise gráfica coincide com os resultados já publicados. ${ }^{14} \mathrm{~A}$ matriz das correntes extremas, E, é:

$$
E=\left(\begin{array}{lll}
1 & 0 & 0 \\
1 & 1 & 0 \\
0 & 1 & 0 \\
0 & 1 & 0 \\
0 & 0 & 1 \\
0 & 0 & 1
\end{array}\right)
$$

Como a matriz $\mathbf{E}$ apresenta três correntes extremas, o vetor $\mathbf{j}$ deve apresentar três elementos, assim, j pode ser descrito como, $j=(h, i, j)^{T}$. O vetor $\mathbf{h}$, que representa o inverso das concentrações, deve possuir quatro elementos, um para 
cada espécie da reação, $h=(a, b, c, d)^{T}$. As constantes cinéticas do modelo foram parametrizadas nos elementos de $\mathbf{j}$ e $\mathbf{h}$, pela equação, $k_{r}=(E . j)_{r} \prod_{i=1}^{n} h_{i}{ }^{Y}$ :

$$
\begin{gathered}
k_{1}=(h) a \\
k_{2}=(h+i) \\
k_{3}=(i) a b \\
k_{4}=(i) c \\
k_{5}=(j) a c \\
k_{6}=(j) d
\end{gathered}
$$

Fazendo, $M(h, j)=N \cdot \operatorname{diag}(E \cdot j) \cdot Y^{T} \cdot \operatorname{diag}(h)$, é possível construir uma matriz jacobiana linearizada, M. A análise por SNA se resume a verificar a estabilidade da matriz $\mathbf{M}$, para isso, verifica-se seus autovalores. Para que ocorra multiestabilidade, é necessário que a matriz $\mathbf{M}$ apresente uma única raiz nula, e para isso, seu polinômio característico deve conter um termo negativo no termo independente da variável. Para o modelo da peroxidase-oxidase, o termo independente do polinômio característico da matriz $\mathbf{M}$ possui um componente negativo:

$$
c j i b a h+j d c i a h+j d i b a h+i^{2} c a j d-a j i^{2} b c
$$

Logo, deve existir um conjunto de parâmetros (a, b, c, d, h, i, j), que fazem com que $c j i b a h+j d c i a h+j d i b a h+i^{2} c a j d-a j i^{2} b c=0$. Tomando:

$$
\begin{gathered}
a=1 \\
b=1,375 \\
c=1 \\
d=1 \\
h=0,01 \\
i=0,1 \\
j=1
\end{gathered}
$$


O termo independente do polinômio característico é zero, sendo essa a condição necessária e suficiente para o surgimento de estados múltiplos no sistema. Substituindo os valores de (105) nas constantes cinéticas em (103):

$$
\begin{gathered}
k_{1}=0,01 \\
k_{2}=0,11 \\
k_{3}=0,1375 \\
k_{4}=0,1 \\
k_{5}=1 \\
k_{6}=1
\end{gathered}
$$

Espera-se que com esse conjunto de constantes cinéticas o sistema apresente estados múltiplos. Resolvendo a equação (40) com as constantes de (106):

Tabela 4. Múltiplos estados para reação de peroxidase-oxidase.

\begin{tabular}{lccc}
\hline \hline Espécie & $1^{1^{a}}\left[\mathrm{X}_{\text {ee }}\right]$ & $2^{\mathrm{a}}\left[\mathrm{X}_{\mathrm{ee}}\right]$ & 3 $^{\mathrm{a}}\left[\mathrm{X}_{\mathrm{ee}}\right]$ \\
\hline $\mathrm{A}$ & 0,41 & 2,94 & 6,65 \\
$\mathrm{~B}$ & 1,88 & 0,20 & 0,05 \\
$\mathrm{C}$ & 1,06 & 0,81 & 0,43 \\
\hline \hline
\end{tabular}

Onde $\left[X_{\text {ee }}\right]$ é a concentração, em unidades arbitrárias, da espécie $X$ no estado estacionário. A tabela 4 foi organizada para demonstrar os três estados estacionários, dois estáveis e um instável, para cada espécie no modelo, sendo a segunda concentração de cada espécie, instável. Variando as constantes cinéticas, pode-se traçar um gráfico sigmoidal que ilustra para quais existem estados múltiplos:

Figura 43. Tomando $\mathrm{k}_{1}=0.01, \mathrm{k}_{2}=0.11, \mathrm{k}_{3}=0.1375, \mathrm{k}_{4}=0.1$ e $\mathrm{k}_{6}=1$, variando $\mathrm{o}$ valor de $k_{5}$, traça-se um gráfico entre a constante cinética e a concentração no estado estacionário de (a) do substrato $\mathrm{H}_{2} \mathrm{O}_{2}$, (b) da enzima peroxidase e (c) um complexo enzima-substrato. A área escura indica onde existem múltiplos estados. 


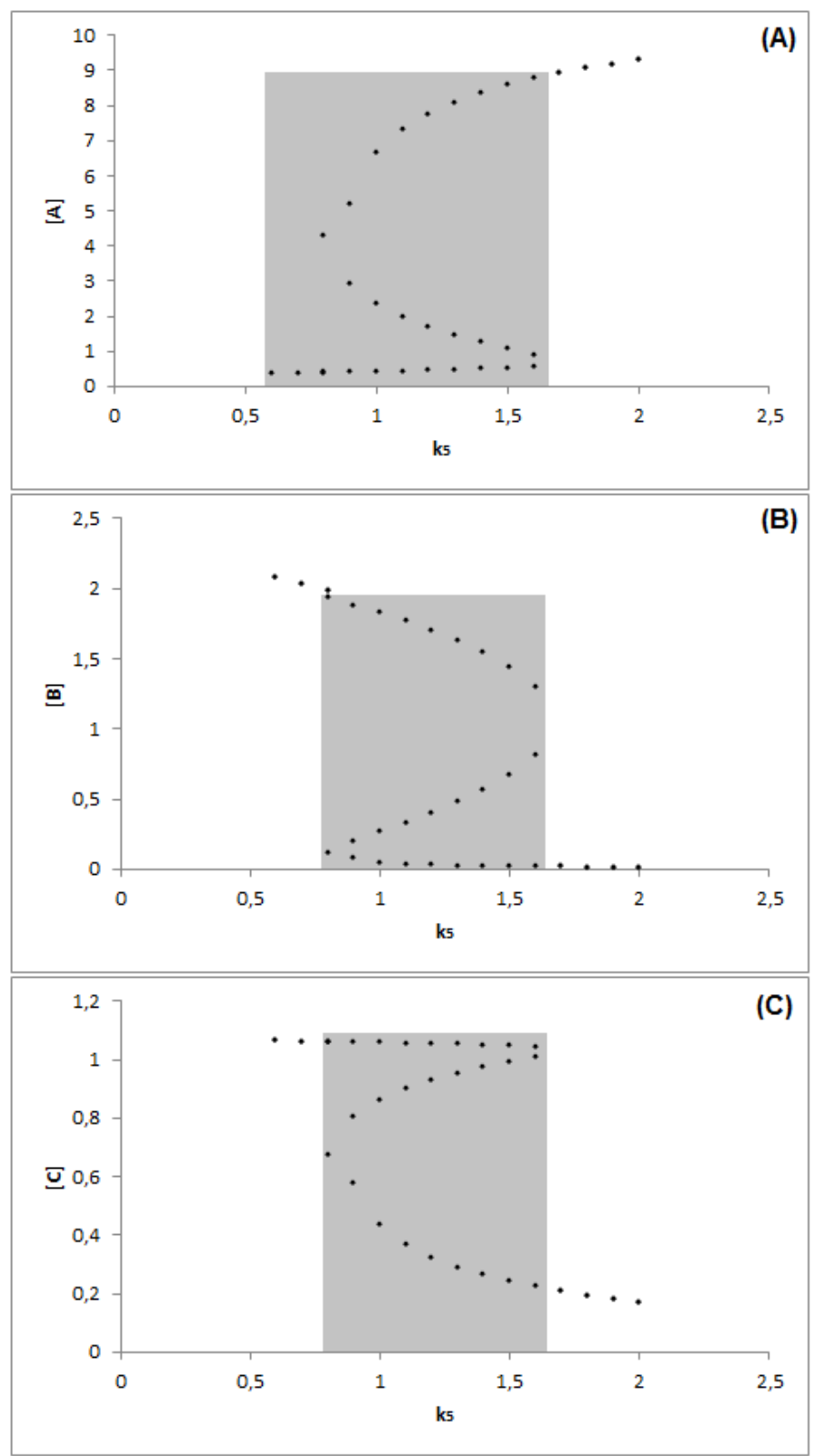

\subsection{ESTADOS MÚLTIPLOS NA EMBRIOGÊNESE DA DROSOPHILA MELANOGASTER}

Um dos genes responsáveis pela morfogênese do segmento anterior na mosca Drosophila melanogaster é o chamado hunchback. No embrião, é distribuído fortemente na parte anterior e apresenta uma lacuna chegando ao meio da estrutura. A lacuna observada na distribuição da proteína hunchback pode ser consequência de uma biestabilidade espacial na sua dinâmica. $O$ seguinte modelo 
(19) biestável se ajusta ao padrão de distribuição das proteínas responsáveis pela formação da estrutura anterior na Drosophila melanogaster:

$$
\begin{aligned}
& 0 \rightarrow{ }^{K 1} \mathrm{~B} \\
& \mathrm{~B}+\mathrm{b}_{0} \rightarrow^{K 2} \mathrm{~b}_{1} \quad \mathrm{~B}+\mathrm{b}_{3} \rightarrow^{K 11} \mathrm{~b}_{4} \quad \mathrm{H}+\mathrm{h}_{0} \rightarrow^{K 20} \mathrm{~h}_{1} \\
& \mathrm{~b}_{1} \rightarrow^{K 3} \mathrm{~B}+\mathrm{b}_{0} \quad \mathrm{~b}_{4} \rightarrow^{K 12} \mathrm{~B}+\mathrm{b}_{3} \quad \mathrm{~h}_{1} \rightarrow^{K 21} \mathrm{H}+\mathrm{h}_{0} \\
& \mathrm{~b}_{1} \rightarrow^{K 4} \mathrm{~b}_{1}+\mathrm{H} \quad \mathrm{b}_{4} \rightarrow^{K 13} \mathrm{~b}_{4}+\mathrm{H} \quad \mathrm{h}_{1} \rightarrow \rightarrow^{K 22} \mathrm{~h}_{1}+\mathrm{H} \\
& \mathrm{B}+\mathrm{b}_{1} \rightarrow^{K 5} \mathrm{~b}_{2} \quad \mathrm{~B}+\mathrm{b}_{4} \rightarrow^{K 14} \mathrm{~b}_{5} \quad \mathrm{H}+\mathrm{h}_{1} \rightarrow^{K 23} \mathrm{~h}_{2} \\
& \mathrm{~b}_{2} \rightarrow^{K 6} \mathrm{~B}+\mathrm{b}_{1} \quad \mathrm{~b}_{5} \rightarrow^{K 15} \mathrm{~B}+\mathrm{b}_{4} \quad \mathrm{~h}_{2} \rightarrow^{K 24} \mathrm{H}+\mathrm{h}_{1} \\
& \mathrm{~b}_{2} \rightarrow{ }^{K 7} \mathrm{~b}_{2}+\mathrm{H} \quad \mathrm{b}_{5} \rightarrow{ }^{K 16} \mathrm{~b}_{5}+\mathrm{H} \quad \mathrm{h}_{2} \rightarrow{ }^{K 25} \mathrm{~h}_{2}+\mathrm{H} \\
& \mathrm{B}+\mathrm{b}_{2} \rightarrow^{K 8} \mathrm{~b}_{3} \quad \mathrm{~B}+\mathrm{b}_{5} \rightarrow^{K 17} \mathrm{~b}_{6} \quad \mathrm{H} \rightarrow^{K 26} 0 \\
& \mathrm{~b}_{3} \rightarrow^{K 9} \mathrm{~B}+\mathrm{b}_{2} \quad \mathrm{~b}_{6} \rightarrow^{K 18} \mathrm{~B}+\mathrm{b}_{5} \\
& \mathrm{~b}_{3} \rightarrow{ }^{K 10} \mathrm{~b}_{3}+\mathrm{H} \quad \mathrm{b}_{6} \rightarrow^{K 19} \mathrm{~b}_{6}+\mathrm{H} \quad \mathrm{B} \rightarrow \rightarrow^{K 27} 0
\end{aligned}
$$

A matriz estequiométrica dessa rede é uma matriz $\mathbf{N}$ de ordem $(12 \times 27)$ e posto matricial, $r=10$, como visto na seguinte imagem. $O$ tamanho da rede estequiométrica inviabiliza a análise por SNA, uma vez que o cálculo das correntes extremas consumiria bastante tempo computacional. Isto posto, a estratégia para analisar a rede é simplificá-la, sem que isso altere o significado bioquímico da mesma.

Figura 44. Matriz estequiométrica para o modelo biestável para a embriogênese da Drosophila melanogaster.

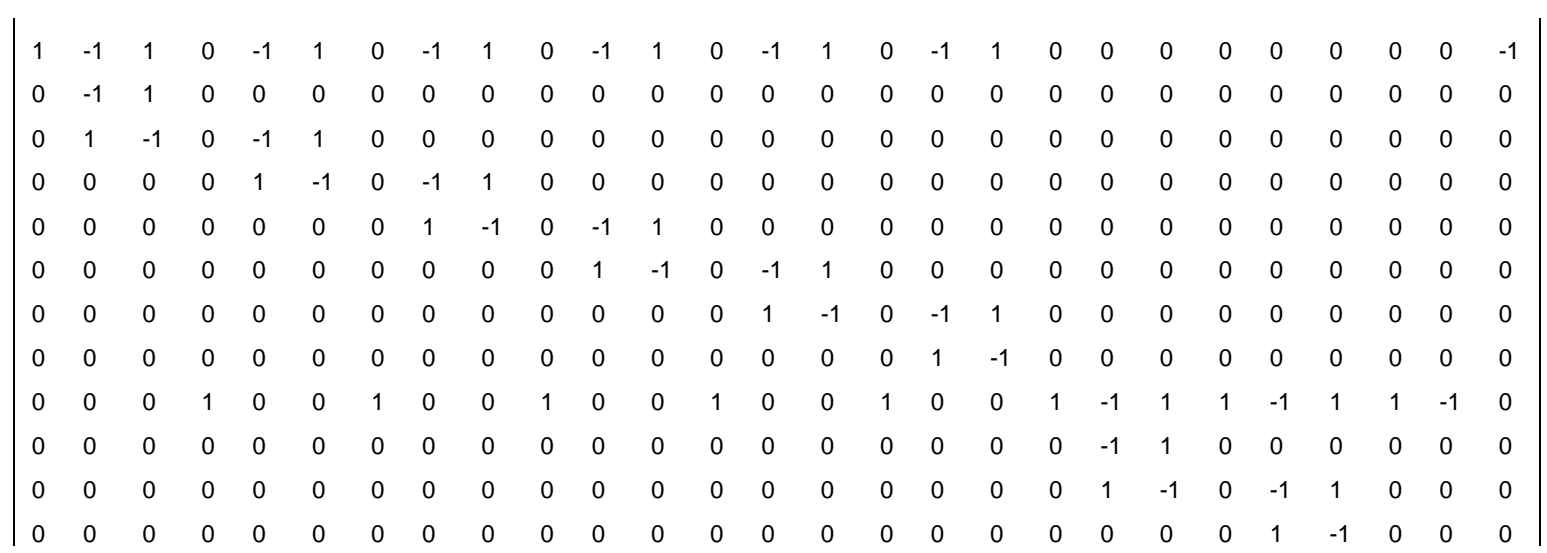


Diferente das outras redes, que possuíam a menor quantidade de espécies ou reações que possibilita a dinâmica instável, acredita-se que o modelo de autoregulação para biestabilidade na Drosophila melanogaster pode ser reduzido. Assim, a análise gráfica por SNA será utilizada, não para verificar a condição necessária para o surgimento de multiestabilidade, e sim para obter um subgrafo reduzido que apresente sozinho a condição necessária e suficiente para multiestabilidade.

Para que essa suposição seja verdadeira, deve existir um fragmento crítico, de ordem igual ou menor a dez e idêntico a um fragmento na rede diminuta. A coerência biológica também deve ser levada em conta, isto é, a nova rede deve possuir pelo menos a formação da proteína hunchback pela expressão da bicoid e a auto-regulação da rede pela hunchback. O fragmento $S_{5}=\left(\begin{array}{c}b_{2}, H \\ 4\end{array}, \begin{array}{l}H_{1}, \\ h_{1}, \\ h_{2}\end{array}, \begin{array}{l}h_{3} \\ 3\end{array}\right)$ possui criticidade e é, também, um fragmento de uma rede menor.

Figura 45. Fragmento $S_{5}=\left(\begin{array}{c}b_{2} \\ 4\end{array}, \begin{array}{l}H \\ 1\end{array}, \begin{array}{l}h_{1} \\ 1\end{array}, \frac{h_{2}}{2}, \begin{array}{l}h_{3} \\ 3\end{array}\right)$. É um fragmento crítico da rede autoregulatória e deve ser um fragmento crítico para a rede diminuta. Dentre outros fatores, sua criticidade é devida a três ciclos positivos. A escolha de um fragmento com cinco vértices obedeceu a coerência biológica do modelo e o número mínimo de reações que garantisse a criticidade do sistema.

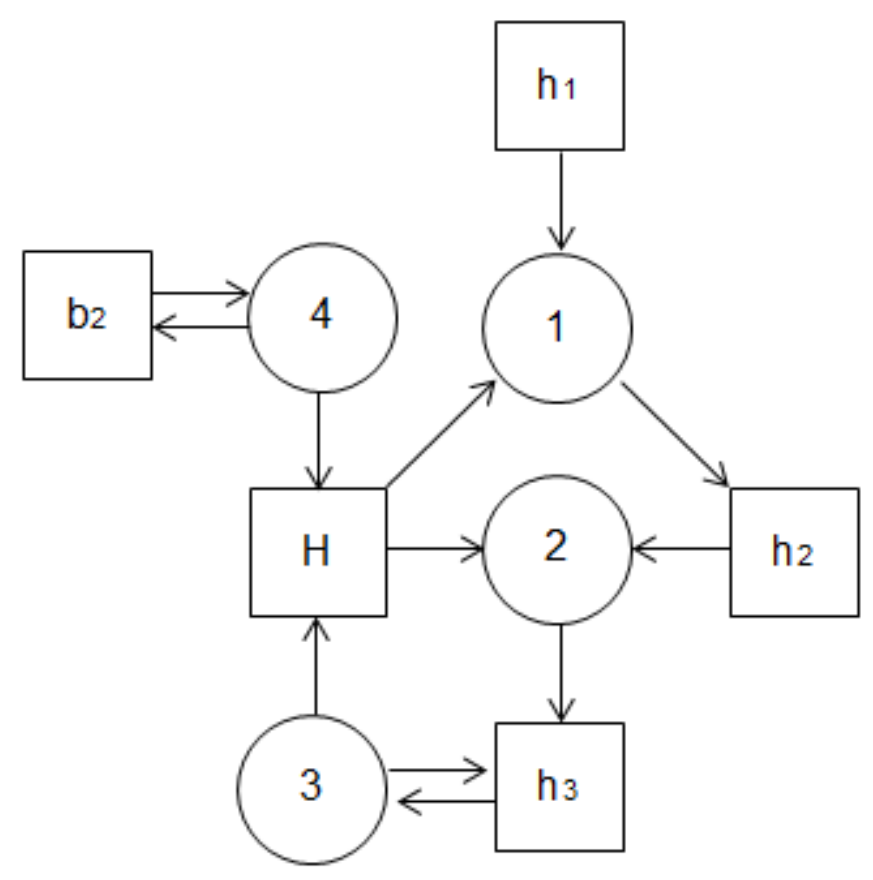


A presença de duas reações de auto-regulação da rede pela proteína huchback é importante, pois sem ela, o fragmento apresenta um número par de ciclos positivos, impossibilitando a multiplicidade. Para descobrir a rede diminuta, basta usar as reações que envolvem os elementos desse fragmento, assim, tal rede é composta por dois conjuntos de reações auto-regulatórias da hunchback e outro conjunto envolvendo o sítio bicoid, como visto na seguinte equação:

$$
\begin{gathered}
0 \stackrel{k_{1}}{\rightarrow} B \\
B+b_{0} \stackrel{k_{2}}{\rightarrow} b_{1} \\
b_{1} \stackrel{k_{3}}{\rightarrow} B+b_{0} \\
b_{1} \stackrel{k_{4}}{\rightarrow} b_{1}+H \\
H+h_{0} \stackrel{k_{5}}{\rightarrow} h_{1} \\
h_{1} \stackrel{k_{6}}{\rightarrow} H+h_{0} \\
h_{1} \stackrel{k_{7}}{\rightarrow} h_{1}+H \\
H+h_{1} \stackrel{k_{8}}{\rightarrow} h_{2} \\
h_{2} \stackrel{k_{9}}{\rightarrow} H+h_{1} \\
h_{2} \stackrel{k_{10}}{\rightarrow} h_{2}+H \\
H \stackrel{k_{11}}{\rightarrow} 0 \\
B \stackrel{k_{12}}{\rightarrow} 0
\end{gathered}
$$

A matriz estrequiométrica da rede acima é, então,

$$
N=\left(\begin{array}{cccccccccccc}
1 & -1 & 1 & 0 & 0 & 0 & 0 & 0 & 0 & 0 & 0 & -1 \\
0 & -1 & 1 & 0 & 0 & 0 & 0 & 0 & 0 & 0 & 0 & 0 \\
0 & 1 & -1 & 0 & 0 & 0 & 0 & 0 & 0 & 0 & 0 & 0 \\
0 & 0 & 0 & 1 & -1 & 1 & 1 & -1 & 1 & 1 & -1 & 0 \\
0 & 0 & 0 & 0 & -1 & 1 & 0 & 0 & 0 & 0 & 0 & 0 \\
0 & 0 & 0 & 0 & 1 & -1 & 0 & -1 & 1 & 0 & 0 & 0 \\
0 & 0 & 0 & 0 & 0 & 0 & 0 & 1 & -1 & 0 & 0 & 0
\end{array}\right)
$$

e possui um posto matricial, $r=5$. Isso significa que 0 fragmento crítico, $S_{3}=\left(\begin{array}{c}b_{2} \\ 4\end{array}, \frac{H}{1}, \frac{h_{1}}{1}, \frac{h_{2}}{2}, \frac{h_{3}}{3}\right)$, é o fragmento multiestável dessa rede. Para essa rede, a matriz das correntes extremas, E, foi calculada: 


$$
E=\left(\begin{array}{lllllll}
0 & 0 & 0 & 0 & 1 & 0 & 0 \\
1 & 0 & 0 & 0 & 0 & 0 & 0 \\
1 & 0 & 0 & 0 & 0 & 0 & 0 \\
0 & 0 & 0 & 1 & 0 & 0 & 0 \\
0 & 1 & 0 & 0 & 0 & 0 & 0 \\
0 & 1 & 0 & 0 & 0 & 0 & 0 \\
0 & 0 & 0 & 0 & 0 & 1 & 0 \\
0 & 0 & 1 & 0 & 0 & 0 & 0 \\
0 & 0 & 1 & 0 & 0 & 0 & 0 \\
0 & 0 & 0 & 0 & 0 & 0 & 1 \\
0 & 0 & 0 & 1 & 0 & 1 & 1 \\
0 & 0 & 0 & 0 & 1 & 0 & 0
\end{array}\right)
$$

Das correntes extremas afere-se o vetor $\mathbf{j}$ dos caminhos das reações, com sete elementos, um para cada vetor extremo, $j=(h i j k l m n)^{T}$, já o vetor $\mathbf{h}$, é o vetor das concentrações das espécies no estado estacionário, e possui tantos elementos quantas espécies participantes da rede, $h=(a b c d e f g)^{T}$. As constantes cinéticas são descritas pelos parâmetros de bifurcação, como se segue:

$$
\begin{gathered}
k_{1}=(l) \\
k_{2}=(h) a b \\
k_{3}=(h) c \\
k_{4}=(k) c \\
k_{5}=(i) d e \\
k_{6}=(i) f \\
k_{7}=(m) f \\
k_{8}=(j) d f \\
k_{9}=(j) g \\
k_{10}=(n) g \\
=(k+m+n) d \\
k_{12}=(l) a
\end{gathered}
$$

Com as correntes extremas, forma-se a matriz das jacobianas, tomando, $M(h, j)=N \cdot \operatorname{diag}(E \cdot j) \cdot Y^{T} \cdot \operatorname{diag}(h)$. A análise de instabilidade se dá pela matriz de linearização, M. A condição necessária e suficiente para bifurcações do tipo sela-nó, responsável pela multiestabilidade é uma raiz nula no polinômio 
característico de $\mathbf{M}$. Para tal, o termo independente do polinômio deve apresentar ao menos um coeficiente negativo.

$$
\begin{aligned}
& \text { abdefhijkl }+2 \text { abdefhijlm }+ \text { abdefhijln }+ \text { abdeghijkl } \\
& + \text { abdeghijlm }+ \text { abdfghijkl }- \text { abdfghijlm } \\
& + \text { acdefhijkl }+2 \text { acdefhijlm }+ \text { acdefhijln } \\
& + \text { acdeghijkl }+ \text { acdeghijlm }+ \text { acdfghijkl } \\
& + \text { acdfghijln }
\end{aligned}
$$

Analiticamente, os parâmetros ( $\mathrm{a} d \mathrm{~h}$ i j l) estão presentes em todos os elementos do temor independente, sendo assim, simplifica-se o polinômio característico fazendo, $a=d=h=i=j=l=1$. Apenas os termos negativos apresentam o produto $(g . n)$, então, os parâmetros $g$ ou $n$ devem ser grandes o suficiente para anular os outros termos. Fazendo:

$$
\begin{gathered}
a=1 \\
b=1 \\
c=1 \\
d=1 \\
e=0.1 \\
f=1 \\
g=1.1 \\
h=1 \\
i=1 \\
j=1 \\
k=0.1 \\
l=1 \\
m=0.1 \\
n=0.162
\end{gathered}
$$

O termo independente do polinômio característico em (111) torna-se nulo, fazendo com que a matriz $\mathbf{M}$ apresente um autovalor nulo, condição necessária e 
suficiente para multiestabilidades. Com esses parâmetros, as constantes cinéticas tornam-se:

$$
\begin{gathered}
k_{1}=1 \\
k_{2}=1 \\
k_{3}=1 \\
k_{4}=0.1 \\
k_{5}=0.1 \\
k_{6}=1 \\
k_{7}=0.1 \\
k_{8}=0.1 \\
k_{9}=1.1 \\
k_{10}=0.1782 \\
k_{11}=0.362 \\
k_{12}=1
\end{gathered}
$$

As constantes cinéticas das equações (113) geram uma bifurcação do tipo sela-nó. Para a averiguação da dinâmica multiestável, o sistema deve ser levado para as vizinhanças da bifurcação, isso é, deve existir uma perturbação no sistema que lhe cause múltiplos estados estacionários. $O$ sistema apresenta duas condições de conservação, $[B]+[C]=$ constante e $[E]+[F]+[G]=$ constante. Fazendo $k_{9}=0.1$ e $k_{12}=1.5$, respeitando as condições de conservação, o sistema apresenta multiestabilidade.

Tabela 5. Múltiplos estados para a rede diminuta da embriogêniese da mosca Drosophila melanogaster. O modelo apresenta três estados estacionários, dois estáveis e um instável, sendo esse, o segundo estado estacionário. A concentração da espécie $D$, proteína hunchback, quando no estado estacionário é representada em $\left[X_{\text {ee }}\right]$.

\begin{tabular}{cccc}
\hline \hline Espécie & $1^{\underline{\mathrm{a}}}\left[\mathrm{X}_{\mathrm{ee}}\right]$ & $2^{\mathrm{a}}\left[\mathrm{X}_{\mathrm{ee}}\right]$ & $3^{\mathrm{a}}\left[\mathrm{X}_{\mathrm{ee}}\right]$ \\
\hline $\mathrm{D}$ & 0.56 & 1.19 & 3.34
\end{tabular}


Variando a constante cinética $\mathrm{k}_{12}$ de 0.5 a 5.0 , com passos de meia unidade, um gráfico de análise de bifurcação pode ser criado:

Figura 46. Tomando $k_{1}=k_{2}=k_{3}=k_{6}=1, \quad k_{4}=k_{5}=k_{7}=k_{8}=k_{9}=0.1$, $k_{10}=0.1782$ e $k_{11}=0.362$, variando 0 valor de $k_{12}$, traça-se um gráfico entre a constante cinética e a concentração no estado estacionário da proteína hunchback.

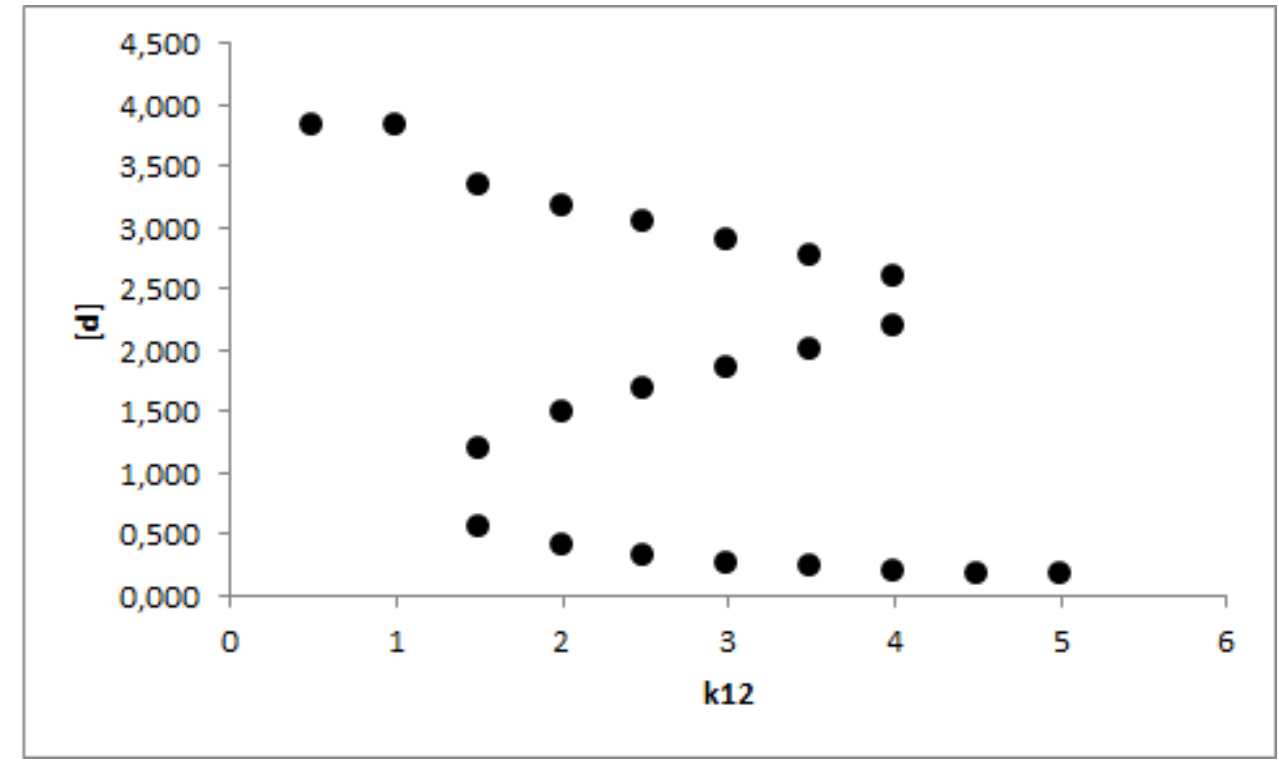

Esse gráfico é uma análise de bifurcação e demonstra uma relativa robustez do sistema, pois demarca a gama na variação de uma constante cinética, no caso, $\mathrm{k}_{12}$, em que a multiestabilidade é observada. Assim, caso aconteça uma perturbação no sistema, por exemplo, uma mudança de temperatura, ou $\mathrm{pH}$, portanto que a constante permaça na sua área de multiestabilidade, essa dinâmica ainda será observada. Outra forma de evidenciar a robustez do sistema é confrontando a variação de duas constantes cinéticas: 
Figura 47. Tomando $k_{3}=k_{6}=1, \quad k_{4}=k_{5}=k_{7}=k_{8}=k_{9}=0.1, \quad k_{10}=0.1782$, $k_{11}=0.362$ e $k_{12}=1$, a área escura demonstra para quais valores de $k_{1}$ e $k_{2}$ haverá multiestabilidade.

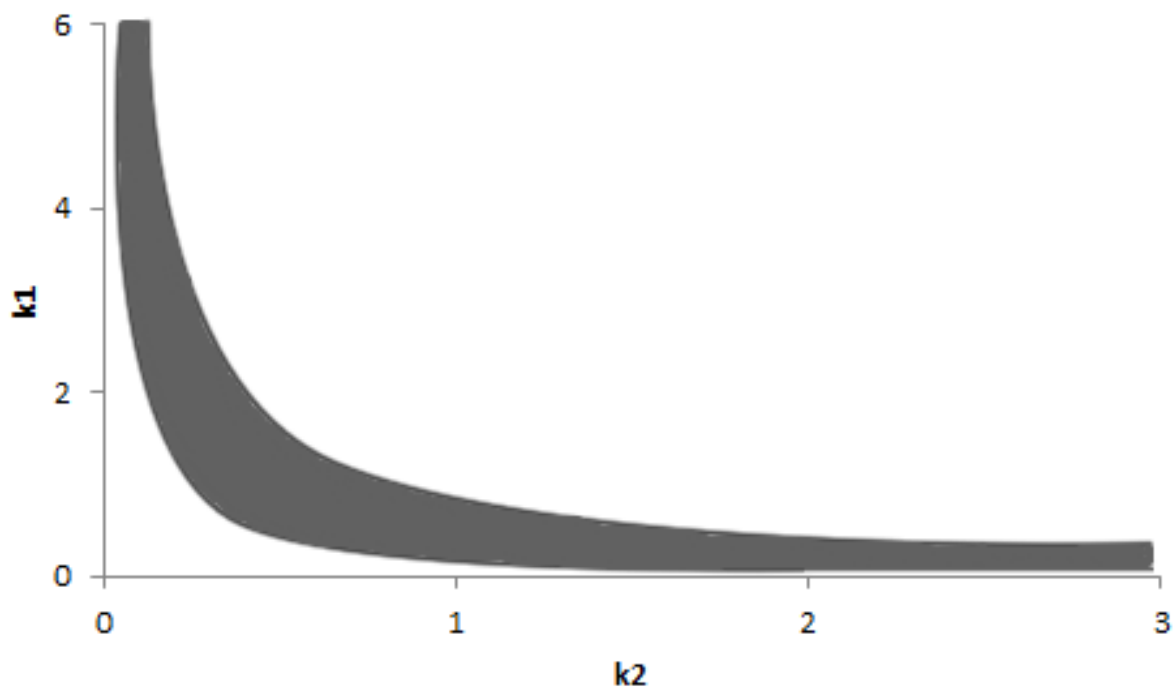

Analiticamente, a dinâmica multiestável é extinta para valores muito grandes ou pequenos de $\mathrm{k}_{2}$, e isso reflete na conclusão de Lopes et al. ${ }^{19}$, que constatou o alargamento da região multiestável, para menores valores fixos de $\mathrm{k}_{2}$, variando $\mathrm{k}_{1}$. Além do alargamento, quanto menor for $k_{2}$, também observa-se um afastamento, para maiores valores de $k_{1}$, da região de multiestabilidade. Dessa forma, tem-se o seguinte gráfico: 
Figura 48. Dependência do formato e região biestável, para a concentração da espécie $D$, proteína hunchback, com a variação da constante $\mathrm{k}_{1}$. Os pontos vermelhos, pretos e azuis, representam $k_{2}=0.5, k_{2}=1$ e $k_{2}=2$, respectivamente. Para valores de $k_{2}$ pequenos, observa-se um afastamento da origem, e um alargamento da região de multiestabilidade. Abaixo estão apenas as linhas de tendência.

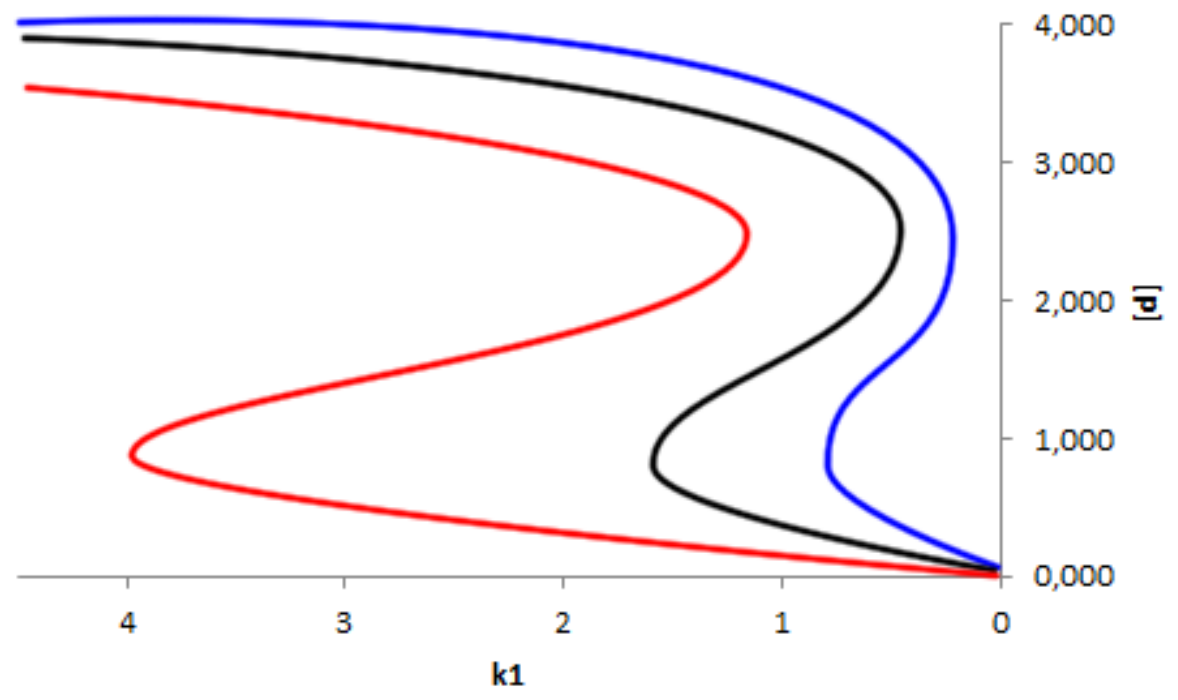

Na figura 47 evidencia-se um fenômeno análogo ao demonstrado no modelo maior, como pode ser apreciado no seguinte gráfico: 
Figura 49. Concentração no estado estacionário da proteína hunchback, pela variação da constante cinética de formação da proteína bicoid. Como na figura 47 , na cor vermelha, têm-se valores de constantes cinéticas de acoplamento da proteína bicoid ao sítio bicoid, menores, seguidas por preto e azul, com constantes cinéticas maiores, em ordem crescente.

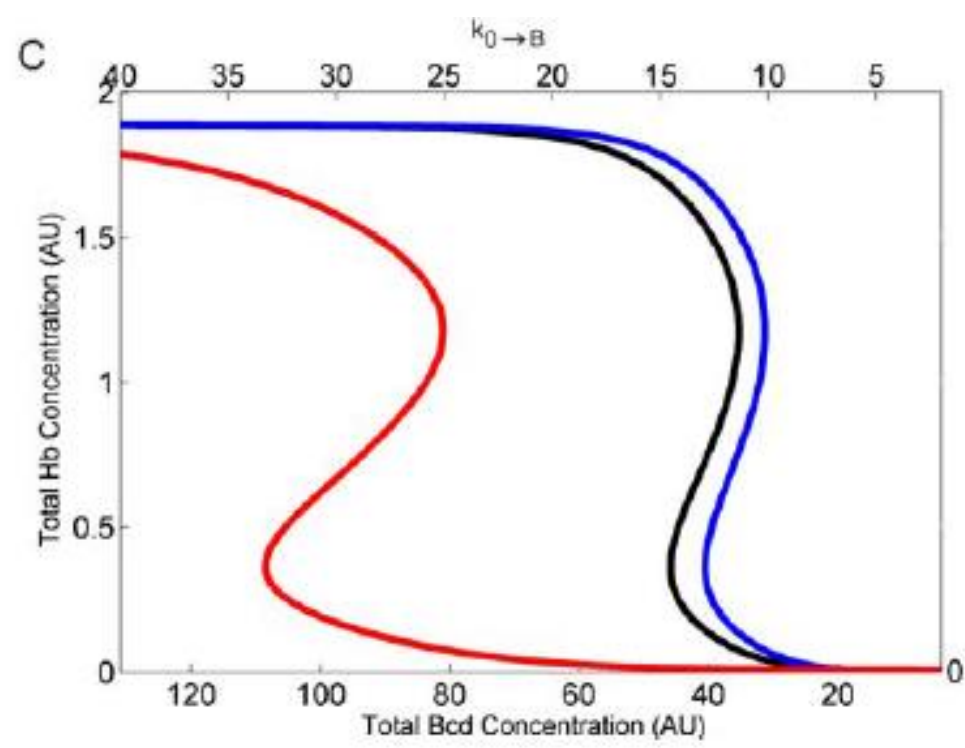

Fonte: LOPES et al., 2008. ${ }^{19}$

Como visto, existe uma similaridade característica entre os gráficos em 47 e 48 , e isso demonstra que o modelo diminuto, expresso em (107), pode conservar algumas propriedades do seu análogo maior. Portanto, mesmo que necessite de maiores evidências, os cálculos de multiestabilidade e análise de bifurcação, expostos até então, dão força a hipótese de que a quantidade de sítios bicoid, definido por $b_{n}$ nos modelos, garantem apenas uma robustez ao sistema, e não configuram uma condição suficiente para multiestabilidades. ${ }^{19}$ 


\section{CONCLUSÕES}

O método de análise da rede estequiométrica mostrou-se uma ferramenta eficaz para a análise de dinâmicas complexas, como oscilações e multiestabilidades, causadas pelas bifurcações de Hopf e sela-nó, respectivamente. Também, se pressupõe que o método SNA seja capaz de caracterizar outros tipos de bifurcações, como por exemplo, a bifurcação transcrítica, responsável pelo surgimento e extinção de espécies no sistema e a série de bifurcações que levam ao movimento caótico. Por ser uma técnica baseada em algoritmos, pode ser automatizado, tornando sua utilização mais simples e rápida.

Sua maior vantagem é a não necessidade do conhecimento explicito dos valores das constantes cinéticas para identificar o comportamento dinâmico de uma rede de reação. Ademais, a técnica também tem como vantagem, construir mapas, chamados de análise de bifurcação, que mostram em quais regiões de determinados parâmetros existem dinâmicas notáveis, informações essas, cruciais para os experimentalistas, que podem se apoiar nos resultados teóricos, para, por exemplo, determinar uma relação entre constantes cinéticas, ou mesmo uma região, no espaço das constantes, de existência de condições para a presença do fenômeno.

Além das condições necessárias e suficientes para a observação de dinâmicas complexas, e também a análise de bifurcação, a técnica por SNA pode, inclusive, expor outra propriedade biológica dos modelos, a exemplo da robustez. A própria análise de bifurcação é uma maneira de se avaliar a robustez do sistema, porém, as correntes extremas igualmente discutem a robustez do modelo. Citando o caso da menor rede cíclica contendo oscilações, como ela possui apenas um vetor extremo, basta vetá-lo para que a rede não cumpra seu objetivo.

Nota-se a importância que os modelos analisados sigam a lei de ação de massa. $\mathrm{Na}$ análise da rede dos cílios olfativos, foi necessária a adição de um expoente $\varepsilon$, de valor específico. Isso significa que ajustes foram feitos para que 0 modelo obedeça a lei de velocidade especificada. Portanto, é de suma importância que se conheça todos os aspectos do modelo, e que o mesmo seja o mais fiel possível a realidade.

A análise gráfica da rede estequiométrica mostrou-se um valioso método complementar para a SNA. Por ela, é possível fazer uma análise prévia na rede, 
com o intuito de determinar se a mesma contém a condição necessária. Por ser uma análise gráfica, com poucos e simples cálculos envolvidos, a técnica pode ser aplicada facilmente em redes grandes e com grande potencial para instabilidades, como as redes bioquímicas, cuja complexidade está no começo de suas explorações, pois pouco se conhece sobre seus participantes e suas conexões, para nem falar de valores de constantes, da exata cinética de cada caso, e outras complicações. Além disso, o método mostrou uma significativa versatilidade, ao expressar quais reações configuram as condições necessárias, tendo como exemplo, as reações autocatalíticas, que geralmente são uma condição necessária para oscilações. A variante gráfica foi competente na modelagem de uma rede diminuta, análoga ao modelo multiestável de auto-regulação para a embriogênese da mosca Drosophila melanogaster. Por meio da técnica, um fragmento crítico de ordem menor ao necessário para multiestabilidade foi encontrado e originou uma segunda rede menor, essa contém o fragmento crítico e por isso apresenta a dinâmica instável.

A rede diminuta para a embriogênese da Drosophila melanogaster mostrou a dinâmica multiestável esperada, e também, foi capaz de reproduzir outras características da rede maior. Esses resultados dão força a hipótese de que não são necessárias seis sítios bicoid para a conservação dos estados múltiplos. Também foi constatado que a condição necessária e suficiente para multiestabilidade no modelo é a presença das duas reações de auto-regulação da rede pela proteína hunchback.

Com tudo, os métodos analíticos supracitados foram eficazes na compreensão da bioquímica em sistemas que apresentam dinâmicas complexas, não apresentando incorreções ou dificuldades. As análises comprovaram os fenômenos já esperados ao demonstrar e tipificar os fenômenos de oscilações e multiestabilidade nas redes estudadas e permitiram a elucidação de características não previstas por outros métodos, como por exemplo, a capacidade de extrair o conjunto exato de reações essenciais para os aspectos mais relevantes de uma dada dinâmica. 


\section{BIBLIOGRAFIA}

1. SAVAGEAU, M. V. Biochemical Systems Analysis: A Study of Function and Design in Molecular Biology. Reading: Addison-wesley, 1976. 379 p.

2. BOWER, J. M.; BOLOURI, H. (Ed.). Computational Modeling of Genetic and Biochemical Networks. Cambridge: The MIT Press, 2001. 390 p.

3. VOIT, E. O. Biochemical Systems Theory: A Review. Isrn Biomathematics, Atlanta, v. 2013, p.1-53, 2013. Hindawi Publishing Corporation. DOI: $10.1155 / 2013 / 897658$.

4. KLIPP, E. et al. Systems Biology: A Textbook. Weinheim: Wiley-vch, 2009. 569 p.

5. DOMIJAN, M.; KIRKILIONIS, M. Bistability and oscillations in chemical reaction networks. Journal Of Mathematical Biology, v. 59, n. 4, p.467-501, 21 nov. 2008. Springer Science + Business Media. DOI: 10.1007/s00285-008-0234-7.

6. HUNT, K. L. C.; HUNT, P, M.; ROSS, J. Nonlinear Dynamics and Thermodynamics of Chemical Reactions Far From Equilibrium. Annu. Rev. Phys. Chem., v. 41, n. 1, p.409-439, out. 1990. Annual Reviews. DOI:

10.1146/annurev.pc.41.100190.002205.

7. GOLDBETER, A. Biochemical Oscillations and Cellular Rhythms: The Molecular Bases of Periodic and Chaotic Behaviour. Cambridge: Cambridge University Press, 1997. 632 p.

8. TOMCHIK, K. J.; DEVREOTES, P. N. Adenosine 3',5'-monophosphate waves in Dictyostelium discoideum: a demonstration by isotope dilution-fluorography. Science, v. 212, n. 4493, p.443-446, 24 abr. 1981. American Association for the Advancement of Science (AAAS). DOI: 10.1126/science.6259734. 
9. CHANCE, B. et al (Ed.). Biological and Biochemical Oscillators. New York: Academic Press, Inc., 1973. 534 p.

10. DUPONT, G. et al. Calcium Oscillations. Cold Spring Harbor Perspectives In Biology, v. 3, n. 3, 8 dez. 2010. Cold Spring Harbor Laboratory Press. DOI: 10.1101/cshperspect.a004226.

11. ANGELI, D.; FERRELL, J. E.; SONTAG, E. D. Detection of multistability, bifurcations, and hysteresis in a large class of biological positive-feedback systems. Proceedings Of The National Academy Of Sciences, v. 101, n. 7 , p.1822-1827, 6 fev. 2004. Proceedings of the National Academy of Sciences. DOI: 10.1073/pnas.0308265100.

12. HADAC, O. et al. Stoichiometric network analysis of dynamics of catalytic oxidation of $\mathrm{CO}$ and hydrocarbons. Chemical Engineering Transactions, Ísquia, v. 11, p.15-20. 2007.

13. CLARKE, B. L. Stoichiometric network analysis. Cell Biophysics, v. 12, n. 1 , p.237-253, jan. 1988. Springer Science + Business Media. DOI: $10.1007 /$ bf02918360.

14. MINCHEVA, M.; ROUSSEL, M. R. Graph-theoretic methods for the analysis of chemical and biochemical networks. I. Multistability and oscillations in ordinary differential equation models. Journal Of Mathematical Biology, v. 55, n. 1, p.61-86, 31 maio 2007. Springer Science + Business Media. DOI: 10.1007/s00285-007-00991.

15. HESS, B. The glycolytic oscillator. J. Exp. Biol., Edinburgh, v. 81, n. 1, p.7-14, ago. 1979

16. SEL'KOV, E. E. Self-Oscillations in Glycolysis: 1. A Simple Kinetic Model. Eur. J. Biochem., v. 1, n. 4, p.79-86, mar. 1968. 
17. BERG, J. M.; TYMOCZKO, J. L.; STRYER, L.. Biochemistry. 5. ed. New York: W H Freeman, 2002. 1515 p.

18. AGUDA, B. D.; CLARKE, B.I. Bistability in chemical reaction networks: Theory and application to the peroxidase-oxidase reaction. J. Chem. Phys. v. 87, n. 6, p.3461-3470, 1987. AIP Publishing. DOI: 10.1063/1.452991.

19. LOPES, F. J. P. et al. Spatial Bistability Generates hunchback Expression Sharpness in the Drosophila Embryo. Plos Computational Biology, v. 4, n. 9, p.114, 26 set. 2008. Public Library of Science (PLoS). DOI:

10.1371/journal.pcbi.1000184.

\section{LIEBERMEISTER, W. Construction and control analysis of biochemical} network models. 2012. 39 f. Tese (tese de habilitação para a obtenção da qualificação docente para a Biofísica Teórica) - Curso de Biofísica Teórica, Faculdade de Matemática e Ciências Naturais, Universidade Humboldt de Berlim, Berlim, 2012. Disponível em: <http://jaguar.biologie.huberlin.de/ wolfram/data/habilitation_liebermeister.pdf>. Acesso em: 10 dez. 2015.

21. WILHELM, T.; HEINRICH, R. Smallest chemical reaction system with Hopf bifurcation. Journal Of Mathematical Chemistry, v. 17, n. 1, p.1-14, 1995. Springer Science + Business Media. DOI: 10.1007/bf01165134.

22. VIEIRA, F. M. C.; BISCH, P. M. Complete set of Hopf bifurcation in an autocatalytic ring network. Journal Of Mathematical Chemistry, v. 17, n. 1, p.55-67, 1995. Springer Science + Business Media. DOI: 10.1007/bf01165137.

\section{SHIU, A. J. Algebraic methods for biochemical reaction network} theory. 2010. $105 \mathrm{f}$. Tese (Doutorado) - Curso de Matemática, University Of California, Berkeley, 2010. 
24. BERRIDGE, M. J.; LIPP, P.; BOOTMAN, M. D. The versatility and universality of calcium signalling. Nature Reviews Molecular Cell Biology, v. 1, n. 1, p.11-21, 1 out. 2000. Nature Publishing Group. DOI: 10.1038/35036035.

25. CLAPHAM, D. E. Calcium Signaling. Cell, v. 131, n. 6, p.1047-1058, dez. 2007. Elsevier BV. DOI: 10.1016/j.cell.2007.11.028.

26. LEWIT-BENTLEY, A.; RÉTY, S. EF-hand calcium-binding proteins. Current Opinion In Structural Biology, v. 10, n. 6, p.637-643, dez. 2000. Elsevier BV. DOI: 10.1016/s0959-440x(00)00142-1.

27. ALMEIDA, T. M. B. Estudo da ligação de cátions divalentes em sítios efhand utilizando a cadeia leve regulatória de miosina de músculo liso. 2000. 121 f. Tese (Doutorado) - Curso de Química, Departamento de Bioquímica, Universidade de São Paulo, São Paulo, 2000.

28. REIDL, J. et al. Model of Calcium Oscillations Due to Negative Feedback in Olfactory Cilia. Biophysical Journal, v. 90, n. 4, p.1147-1155, fev. 2006. Elsevier BV. DOI: 10.1529/biophysj.104.058545.

29. KURAHASHI, T.; MENINI, A. Mechanism of odorant adaptation in the olfactory receptor cell. Nature, v. 385, n. 6618, p.725-729, 20 fev. 1997. Nature Publishing Group. DOI: 10.1038/385725a0.

30. ZUFALL, F. The Cellular and Molecular Basis of Odor Adaptation. Chemical Senses, v. 25, n. 4, p.473-481, 1 ago. 2000. Oxford University Press (OUP). DOI: 10.1093/chemse/25.4.473.

31. ARIF, S. H. A Ca ${ }^{2+}$-binding protein with numerous roles and uses: parvalbumin in molecular biology and physiology. Bioessays, v. 31, n. 4, p.410-421, abr. 2009. Wiley-Blackwell. DOI: 10.1002/bies.200800170. 
32. LEINDERS-ZUFALL, T. et al. Imaging odor-induced calcium transients in single olfactory cilia: specificity of activation and role in transduction. J. Neurosci, New Haven, v. 15, n. 18, p.5630-5639, ago. 1998.

33. DOUGHERTY, D. P.; WRIGHT, G. A.; YEW, A. C. Computational model of the cAMP-mediated sensory response and calcium-dependent adaptation in vertebrate olfactory receptor neurons. Proceedings Of The National Academy Of Sciences, v. 102, n. 30, p.10415-10420, 18 jul. 2005. Proceedings of the National Academy of Sciences. DOI: 10.1073/pnas.0504099102.

34. TRUDEAU, M. C.; ZAGOTTA, W. N. Calcium/Calmodulin Modulation of Olfactory and Rod Cyclic Nucleotide-gated Ion Channels. Journal Of Biological Chemistry, v. 278 , n. 21 , p.18705-18708, 7 mar. 2003. American Society for Biochemistry \& Molecular Biology (ASBMB). DOI: 10.1074/jbc.r300001200.

35. MINCHEVA, M. Oscillations in Biochemical Reaction Networks Arising from Pairs of Subnetworks. Bull Math Biol, v. 73, n. 10, p.2277-2304, 22 jan. 2011. Springer Science + Business Media. DOI: 10.1007/s11538-010-9620-6.

36. CHANDRA, F. A.; BUZI, G.; DOYLE, J. C. Glycolytic Oscillations and Limits on Robust Efficiency. Science, v. 333, n. 6039, p.187-192, 7 jul. 2011. American Association for the Advancement of Science (AAAS). DOI: 10.1126/science. 1200705 .

37. NELSON, D. L.; COX, M. M. Princípios de Bioquímica de Lehninger. 3. ed. São Paulo: Sarvier, 2002. 1009 p.

38. REED, Michael C.; LIEB, Anna; NIJHOUT, H. Frederik. The biological significance of substrate inhibition: A mechanism with diverse functions. Bioessays, v. 32, n. 5, p.422-429, 22 abr. 2010. Wiley-Blackwell. DOI: 10.1002/bies.200900167.

39. TRAUT, T. Allosteric Regulatory Enzymes. New York: Springer Science+business Media, LLC, 2008. 250 p. 
40. MADSEN, M. F.; DANØ, S.; SØRENSEN, P. G. On the mechanisms of glycolytic oscillations in yeast. Febs Journal, v. 272, n. 11, p.2648-2660, 13 maio 2005. WileyBlackwell. DOI: 10.1111/j.1742-4658.2005.04639.x.

41. ROSEN, R.; SNELL, F. M. (Ed.). Progress in Theoretical Biology. v. 4. New York: Academic Press, Inc., 1976. 297 p.

42. HEINRICH, R.; SCHUSTER, S. The Regulation Of Cellular Systems. New York: Chapman \& Hall, 1996. 372 p.

43. AGUDA, B. D.; LARTER, R. Sustained oscillations and bistability in a detailed mechanism of the peroxidase-oxidase reaction. J. Am. Chem. Soc., v. 112, n. 6 , p.2167-2174, mar. 1990. American Chemical Society (ACS). DOI: 10.1021/ja00162a018.

44. YING, W. NAD $/ N A D H$ and NADP + NADPH in Cellular Functions and Cell Death: Regulation and Biological Consequences. Antioxidants \& Redox Signaling, v. 10, n. 2, p.179-206, fev. 2008. Mary Ann Liebert Inc. DOI: 10.1089/ars.2007.1672.

45. PetRIDES, P. E.; NAUSEef, W. M. (Ed.). The Peroxidase Multigene Family of Enzymes: Biochemical Basis and Clinical Applications. New York: Springer Science + Business Media, 2000. 193 p.

46. VEITCH, N. C. Horseradish peroxidase: a modern view of a classic enzyme. Phytochemistry, v. 65, n. 3, p.249-259, fev. 2004. Elsevier BV. DOI: 10.1016/j.phytochem.2003.10.022.

47. OLSEN, L. F.; HAUSER, M. J. B.; KUMMER, U. Mechanism of protection of peroxidase activity by oscillatory dynamics. Eur J Biochem, v. 270, n. 13, p.27962804, jul. 2003. Wiley-Blackwell. DOI: 10.1046/j.1432-1033.2003.03655.x. 
48. DEGN, H. Bistability caused by Substrate Inhibition of Peroxidase in an Open Reaction System. Nature, v. 217, n. 5133, p.1047-1050, 16 mar. 1968. Nature Publishing Group. DOI: 10.1038/2171047b0.

49. ARNAO, M. B. et al. A kinetic study on the suicide inactivation of peroxidase by hydrogen peroxide. Biochimica Et Biophysica Acta (bba) - Protein Structure And Molecular Enzymology, v. 1041, n. 1, p.43-47, out. 1990. Elsevier BV. DOI: 10.1016/0167-4838(90)90120-5.

50. RODRIGUEZ-LÓPEZ, J. N. et al. Mechanism of reaction of hydrogen peroxide with horseradish peroxidase: Identification of intermediates in the catalytic cycle. Journal of the American Chemical Society, v. 123, n. 48, p.11838-11847, nov. 2001. DOI: $10.1021 / \mathrm{ja} 011853+$

51. YOKOTA, K.; YAMAZAKI, I. Analysis and computer simulation of aerobic oxidation of reduced nicotinamide adenine dinucleotide catalyzed by horseradish peroxidase. Biochemistry, v. 16, n. 9, p.1913-1920, maio 1977. American Chemical Society (ACS). DOI: 10.1021/bi00628a024.

52. OLSON, D. L.; SCHEELINE, A. The peroxidase-NADH biochemical oscillator. 2. Examination of the roles of hydrogen peroxide and superoxide. The Journal of Physical Chemistry, v. 99, n. 4, p.1212-1217, jan. 1995. American Chemical Society (ACS). DOI: 10.1021/j100004a022.

53. HAUSER, M. J. B.; LUNDING, A.; OLSEN, L. F.. On the role of methylene blue in the oscillating peroxidase-oxidase reaction. Phys. Chem. Chem. Phys., v. 2, n. 8 , p.1685-1692, 2000. Royal Society of Chemistry (RSC). DOI: 10.1039/a910319h.

54. AGUDA, B. D.; FRISCH, L. L. H.; OLSEN, L. F. Experimental evidence for the coexistence of oscillatory and steady states in the peroxidase-oxidase reaction. J. Am. Chem. Soc., v. 112, n. 18, p.6652-6656, ago. 1990. American Chemical Society (ACS). DOI: 10.1021/ja00174a030. 
55. BARD, J. Morphogenesis: The Cellular and Molecular Processes of Developmental Anatomy. New York: Cambridge University Press, 1990. 303 p.

56. HOUILLON, C. Embriologia. São Paulo: Edgard Blucher Ltda., 1972.

57. GILBERT, S. F.; SINGER, S. Developmental Biology. 8. ed. Sunderland: Sinauer Associates Inc, 2006. 785 p.

58. GRIFFITHS, A. J. F. et al. An Introduction to Genetic Analysis. 8. ed. New York: W. H. Freeman, 2000. 706 p.

59. SIMPSON-BROSE, M.; TREISMAN, J.; DESPLAN, C. Synergy between the hunchback and bicoid morphogens is required for anterior patterning in Drosophila. Cell, v. 78, n. 5, p.855-865, set. 1994. Elsevier BV. DOI: 10.1016/s00928674(94)90622-x.

60. MAZALA JUNIOR, W.; SCHUCHARDT, U.; PAOLI, M. Reações Oscilantes: Revisão e Demonstração Experimental.Química Nova, v. 1, n. 4, p.9-15, out. 1978.

\section{EPSTEIN, I. R.; POJMAN, J. A. An Introduction to Nonlinear Chemical}

Dynamics: Oscillations, Waves, Patterns, and Chaos. Oxford: Oxford University Press, 1998. $392 \mathrm{p}$.

62. FARIA, R. B. Introdução aos Sistemas Químicos Oscilantes. Química Nova, v. 18, n. 3, p.281-194, maio 1995.

63. WILHELM, T. The smallest chemical reaction system with bistability. Bmc Syst Biol, v. 3, n. 1, p.90-99, 2009. Springer Science + Business Media. DOI: 10.1186/1752-0509-3-90. 
64. LAURENT, M.; KELLERSHOHN, N. Multistability: a major means of differentiation and evolution in biological systems. Trends In Biochemical Sciences, v. 24, n. 11, p.418-422, nov. 1999. Elsevier BV. DOI: 10.1016/s09680004(99)01473-5.

65. CRACIUN, G.; TANG, Y.; FEINBERG, M. Understanding bistability in complex enzyme-driven reaction networks. Proceedings Of The National Academy Of Sciences, v. 103, n. 23, p.8697-8702, 30 maio 2006. Proceedings of the National Academy of Sciences. DOI: 10.1073/pnas.0602767103.

66. SCHMITZ, G. et al. The Illustration of Multistability. J. Chem. Educ., v. 77, n. 11, p.1502-1505, nov. 2000. American Chemical Society (ACS). DOI: 10.1021/ed077p1502.

67. RESAT, H.; PETZOLD, L.; PETTIGREW, M. F. Kinetic Modeling of Biological Systems. Methods In Molecular Biology, v. 541, p.311-335, mar. 2009. Springer Science + Business Media. DOI: 10.1007/978-1-59745-243-4_14.

68. ARNAUT, L. G.; FORMOSINHO, S. J.; BURROWS, H.. Chemical Kinetics: From Molecular Structure to Chemical Reactivity. Elsevier, 2006. 562 p.

69. LEVENSPIEL, O. Chemical Reaction Engineering. 3. ed. New York: John Wiley \& Sons, 1999. $668 \mathrm{p}$.

70. CLARKE, B. L. Stability of Complex Reaction Networks. Advances In Chemical Physics, p.1-215, 1 jan. 1980. Wiley-Blackwell. DOI: 10.1002/9780470142622.ch1.

71. DOMIJAN, M. Mathematical aspects of chemical reaction networks. 2008. 152 f. Tese (Doutorado) - Curso de Filosofia, University Of Warwick, Warwick, 2008. 
72. SCHMITZ, G. et al. Stoichiometric Network Analysis and Associated

Dimensionless Kinetic Equations. Application to a Model of the Bray-Liebhafsky Reaction. J. Phys. Chem. A, v. 112, n. 51, p.13452-13457, 25 dez. 2008. American Chemical Society (ACS). DOI: 10.1021/jp8056674.

73. MAćEŁlć, S. R. et al. Current rates and reaction rates in the Stoichiometric Network Analysis (SNA). Open Chemistry, v. 13, n. 1, p.591-599, 23 jan. 2014. Walter de Gruyter GmbH. DOI: 10.1515/chem-2015-0077

74. VIEIRA, F. M. C. Estudo de modelos não-lineares para o transporte ativo em biomembranas. 1993. Tese (Doutorado) - Curso de Física, Centro Brasileiro de Pesquisas Físicas, Rio de Janeiro, 1993.

75. PERKO, L. Differential Equations and Dynamical Systems: Texts in Applied Mathematics. 3. ed. New York: Springer, 2006. 555 p.

76. DEUTSCH, A. et al. Function and Regulation of Cellular Systems. Basileia: Birkhäuser Verlag, 2004. $447 \mathrm{p}$.

77. MACENA, M. C. S. M. Teoria de bifurcação para equações diferenciais generalizadas e aplicações às equações diferenciais ordinárias. 2013. 92 f. Dissertação (Mestrado) - Curso de Ciências - Matemática, Instituto de Ciências Matemáticas e de Computação, Universidade de São Paulo, São Paulo, 2013.

78. SILVA, D. J. R. NONLINEAR DYNAMICS AND LIMITING REAGENT: A TRANSCRITICAL BIFURCATION EXAMPLE. Química Nova, v. 37, n. 4, p.748-752, 2014. GN1 Genesis Network. DOI: 10.5935/0100-4042.20140119.

79. VIANA, R. L. Introdução à Dinâmica Não-Linear e Caos em Economia. Curitiba, 2012. Disponível em: <http://fisica.ufpr.br/viana/caos/livro.pdf>. 
80. VÉRRI, J. A. Estabilidade Global e Bifurcação de Hopf em um Modelo de HIV baseado em Sistemas do Tipo Lotka-Volterra. 2013. 103 f. Dissertação

(Mestrado) - Curso de Matemática Aplicafaculdade de Ciências e Tecnologiada e Computacional, Universidade Estadual Paulista, São Paulo, 2013.

81. MINCHEVA, M.; CRACIUN, G.. Multigraph Conditions for Multistability, Oscillations and Pattern Formation in Biochemical Reaction Networks. Proc. leee, v. 96, n. 8, p.1281-1291, ago. 2008. Institute of Electrical \& Electronics Engineers (IEEE). DOI: 10.1109/jproc.2008.925474.

82. SOUZA, G. R. Critério de Hurwitz e Estabilidade de Equilíbrios. 2005. 60 f. Dissertação (Mestrado) - Curso de Matemática, Departamento de Matemática, Universidade Federal de Minas Gerais, Belo Horizonte, 2005. 